\title{
A NEW LOOK INTO THE LINKAGES BETWEEN METAL SPECIATION AND BIOAVAILABILITY AND TOXICITY IN NATURAL WATERS
}

\author{
by \\ Rong Wang \\ B.Eng. (Zhengzhou University, China)
}

A thesis submitted to the Faculty of Graduate Studies and Research in partial fulfillment of the requirements for the degree of

Doctor of Philosophy

Department of Chemistry

Carleton University

Ottawa, Ontario

January, 2008

copyright (C 2008

Rong Wang 


$\begin{array}{ll}\begin{array}{l}\text { Library and } \\ \text { Archives Canada }\end{array} & \begin{array}{l}\text { Bibliothèque et } \\ \text { Archives Canada }\end{array} \\ \begin{array}{l}\text { Published Heritage } \\ \text { Branch }\end{array} & \begin{array}{l}\text { Direction du } \\ \text { Patrimoine de l'édition }\end{array} \\ \begin{array}{l}\text { 395 Wellington Street } \\ \text { Ottawa ON K1A 0N4 }\end{array} & \begin{array}{l}\text { 395, rue Wellington } \\ \text { Ottawa ON K1A ON4 }\end{array} \\ \text { Canada } & \begin{array}{l}\text { Canada } \\ \end{array}\end{array}$

Yourfile Votre référence

ISBN: 978-0-494-36798-8

Our file Notre référence

ISBN: 978-0-494-36798-8

NOTICE:

The author has granted a nonexclusive license allowing Library and Archives Canada to reproduce, publish, archive, preserve, conserve, communicate to the public by telecommunication or on the Internet, loan, distribute and sell theses worldwide, for commercial or noncommercial purposes, in microform, paper, electronic and/or any other formats.

The author retains copyright ownership and moral rights in this thesis. Neither the thesis nor substantial extracts from it may be printed or otherwise reproduced without the author's permission.
AVIS:

L'auteur a accordé une licence non exclusive permettant à la Bibliothèque et Archives Canada de reproduire, publier, archiver, sauvegarder, conserver, transmettre au public par télécommunication ou par l'Internet, prêter, distribuer et vendre des thèses partout dans le monde, à des fins commerciales ou autres, sur support microforme, papier, électronique et/ou autres formats.

L'auteur conserve la propriété du droit d'auteur et des droits moraux qui protège cette thèse. $\mathrm{Ni}$ la thèse ni des extraits substantiels de celle-ci ne doivent être imprimés ou autrement reproduits sans son autorisation.
In compliance with the Canadian

Privacy Act some supporting forms may have been removed from this thesis.

While these forms may be included in the document page count, their removal does not represent any loss of content from the thesis.
Conformément à la loi canadienne sur la protection de la vie privée, quelques formulaires secondaires ont été enlevés de cette thèse.

Bien que ces formulaires aient inclus dans la pagination, il n'y aura aucun contenu manquant.

\section{Canadä}


The undersigned hereby recommend to the Faculty of Graduate Studies and Research acceptance of the thesis,

"A new look into the linkages between metal speciation and bioavailability and toxicity in natural waters"

submitted by

Rong Wang

B.Eng. (Zhengzhou University, China)

in partial fulfillment of the requirements

for the degree of Doctor of Philosophy

Chair, Department of Chemistry

Thesis Supervisor

2008, Carleton University 


\section{Abstract}

Several traditional and newly-developed techniques were employed to better understand copper speciation and bioavailability and toxicity, and their inter-relationships in natural waters.

Speciation of copper in freshwater samples and mine aqueous effluents was studied using Anodic Stripping Voltammetry (ASV) technique alone, and by titration of copper, coupled with ASV, and also by Competing Ligand Exchange (CLE) method, coupled with Adsorptive Cathodic Stripping Voltammetry (AdCSV). It was found that the ASV techniques significantly underestimated the complexation capacity of natural organic ligands, and were capable of measuring only weak copper natural organic complex. CLEAdCSV could detect stronger copper natural organic complex. More than $95 \%$ of the total dissolved copper in all the lake freshwater samples studied by CLE-AdCSV was found to be complexed with natural organic ligands.

The newly developed CLE-ASV with EDTA as a competing ligand was used to study copper speciation in freshwater samples collected from Rideau Canal, Ottawa. The method was capable of determining naturally-occurring, very strong organic ligands for binding copper. The results indicate presence of a very strong copper-binding organic ligand with conditional stability constant above $10^{19}$, with a concentration of above $100 \mathrm{nM}$. 
Diffusive Gradients in Thin Films (DGT) technique was deployed in situ to determine the copper speciation in Rideau Canal, Ottawa. DGT was found to be a highly portable in situ technique with high sensitivity, compared to the voltammetry techniques.

The copper toxicity in the freshwater sample from a contaminated lake was determined using growth inhibition test with freshwater alga Selenastrum capricornutum. It was found that copper was more toxic to the alga in de-ionized water than in the freshwater containing natural organic ligands, which confirmed that a single metal toxicity test would be insufficient to account for the copper toxicity of a real freshwater sample.

Finally, Competing Ligand Exchange Method (CLEM), coupled with Inductively Coupled Plasma-Mass Spectrometry (ICP-MS), was applied to investigate the copper uptake kinetics by freshwater alga Selenastrum capricornutum. The intent was to explore the linkages between the copper speciation and bioavailability and toxicity. The newlydeveloped Reactor, coupled with ICP-MS proved to be successful in the preliminary studies, showing its great potential for investigating the copper uptake kinetics by algae and the copper speciation kinetics in the bulk solution at the same time. 


\section{Acknowledgements}

My experience in Canada would not have been nearly as rewarding if it were not for my supervisor, Professor. C.L. Chakrabarti (a.k.a. Chak). He gave me an opportunity to study what I have wanted - Chemistry and do what I have loved - Chemistry at Carleton University. I am very grateful for his continued support, guidance and encouragement.

I should also like to thank Dr. B. R. Hollebone and Dr. D. Miller, who taught me "Principle of Toxicology" and "Chemical Toxicology" courses, respectively. I enjoyed and benefited substantially from their eloquence and knowledge.

Dr. John Murimboh and Dr. Mohamed Salam helped me a great deal during my first year as a graduate student. For that, they deserve special thanks. I also appreciate the help of all the other members of Chak's research group: Dr. Ismail Al-Fasrous; Dr. Jeff Guthrie; Cathy Murimboh; Dr. Nouri Hassan; Lin Si; Jamaluddin; Jiujiang Zhao; Parthasarathi Chakraborty; Min Yang; Tahir Yapici and Yamini Gopalapillai. With them, my stay at Carleton has been a pleasant and fruitful experience.

Finally, I have to thank my family, and especially my parents, and my thanks are for their unconditional love. 


\section{Table of Contents}

Abstract iii

Acknowledgement $\quad \mathrm{V}$

Table of Contents vi

\section{Chapter 1 Introduction}

1.1 Introduction 2

1.2 Statement of problem 4

1.3 Current state of the knowledge 4

1.3.1 Free Ion Activity Model (FIAM) 5

1.3.2 Current techniques 5

1.3.3 Windermere Humic Aqueous Model (WHAM) 6

1.3.4 Biotic Ligand Model (BLM) 7

1.4 Weakness in the current state of knowledge 9

$\begin{array}{lll}1.5 & \text { Hypothesis and objective } & 10\end{array}$

$\begin{array}{lll}1.6 & \text { Outline of the thesis } & 10\end{array}$

$\begin{array}{lll}1.7 & \text { References } & 12\end{array}$

Chapter 2 Investigation of copper speciation using Anodic Stripping Voltammetry (ASV)

$\begin{array}{lll}2.1 & \text { Introduction } & 24\end{array}$

2.2 Theory 26

2.2.1 ASV and Differential Pulse ASV (DPASV) 26

$\begin{array}{lll}2.2 .2 & \text { ASV and copper titration } & 30\end{array}$

$\begin{array}{lll}2.3 & \text { Experimental } & 31\end{array}$

2.3.1 Sampling location and sampling protocol 31

2.3.2 Reagents 34

2.3.3 Apparatus 34

$\begin{array}{lll}\text { 2.3.4 Electrochemical parameters } & 35\end{array}$ 
$2.4 \quad$ Results and discussions 35

$2.5 \quad$ References 48

Chapter 3 Investigation of copper speciation using Competing Ligand Exchange (CLE) method-Adsorptive Cathodic Stripping Voltammetry (AdSCV) with catechol

3.1 Introduction 52

3.2 Theory 53

3.2.1 AdCSV and Square Wave AdCSV (SWCSV) 53

3.2.2 Competing Ligand Exchange (CLE) method 57

3.3 Experimental 58

3.3.1 Sampling location and sampling protocol $\quad 58$

3.3.2 Reagents $\quad 59$

$\begin{array}{lll}\text { 3.3.3 Apparatus } & 60\end{array}$

$\begin{array}{lll}\text { 3.3.4 Electrochemical parameters } & 60\end{array}$

3.3.5 Selection of the optimal concentration the competing ligand 61

3.3.6 Copper titration of the collected freshwater samples 61

$\begin{array}{lll}3.4 & \text { Results and discussions } & 61\end{array}$

3.4.1 Selection of the optimal concentration the competing ligand 62

3.4.2 Copper titration for the collected freshwater samples 63

$\begin{array}{lll}3.5 & \text { A baffling question } & 65\end{array}$

$\begin{array}{lll}3.6 & \text { References } & 78\end{array}$

Chapter 4 Investigation of copper speciation using Competing Ligand Exchange (CLE) method-Anodic Stripping Voltammetry (ASV) with EDTA

$\begin{array}{lll}4.1 & \text { Introduction } & 82\end{array}$

$\begin{array}{lll}4.2 & \text { Theory } & 83\end{array}$

4.2.1 ASV and DPASV 83

4.2.2 Competing Ligand Exchange (CLE) method 83

4.3 Experimental 83

4.3.1 Sampling location and sampling protocol 83 
4.3.2 Reagents 84

$\begin{array}{lll}\text { 4.3.3 Apparatus } & 87\end{array}$

4.3.4 Electrochemical parameters 87

4.3.5 Equilibration time for EDTA spiking before DPASV determination

4.3.6 Copper titration for the collected freshwater samples 88

$\begin{array}{lll}4.4 & \text { Results and discussions } & 88\end{array}$

4.4.1 Scan of deposition potential in model solutions 88

4.4.2 Copper titration of EDTA model solution and EDTA titration of copper model solutions $\quad 90$

4.4.3 Deposition potential scan of the freshwater samples 91

4.4.4 Titration of copper in the freshwater sample with EDTA as competing $\begin{array}{ll}\text { ligand } & 92\end{array}$

$\begin{array}{lll}4.5 & \text { References } & 106\end{array}$

Chapter 5 In situ Determination of copper speciation using Diffusive Gradients in Thin Films (DGT)

$\begin{array}{lll}5.1 & \text { Introduction } & 113\end{array}$

$\begin{array}{lll}5.2 \text { Theory } & 116\end{array}$

$\begin{array}{lll}5.3 & \text { Experimental } & 118\end{array}$

5.3.1 Gel preparation and mounting 118

5.3.1.1 Reagents and materials 118

$\begin{array}{lll}\text { 5.3.1.2 Pre-gel solution } & 118\end{array}$

$\begin{array}{lll}\text { 5.3.1.3 Diffusive gel preparation } & 119\end{array}$

$\begin{array}{lll}\text { 5.3.1.4 Resin gel preparation } & 119\end{array}$

$\begin{array}{lll}\text { 5.3.1.5 DGT assembling } & 119\end{array}$

$\begin{array}{ll}\text { 5.3.2 Sampling location and sampling protocol } & 119\end{array}$

5.3.3 Binding gel and water samples treatment in the laboratory 120

$\begin{array}{lll}5.4 & \text { Results and discussions } & 120\end{array}$

$\begin{array}{lll}5.5 & \text { References } & 128\end{array}$ 
Chapter 6 Investigation of copper toxicity using freshwater alga Selenastrum capricornutum

$\begin{array}{lll}6.1 & \text { Introduction } & 130\end{array}$

$\begin{array}{lll}6.2 & \text { Theory } & 131\end{array}$

6.3 Experimental 131

6.3.1 Sampling location and sampling protocol 131

$\begin{array}{lll}6.3 .2 & \text { Reagents } & 131\end{array}$

$\begin{array}{lll}6.3 .3 & \text { Algal culturing } & 132\end{array}$

6.3.4 Growth inhibition test using S. capricornutum 134

6.4 Results and discussions 137

$\begin{array}{lll}6.5 & \text { References } & 141\end{array}$

Chapter 7 Investigation of copper uptake kinetics by freshwater alga Selenastrum capricornutum using Competing Ligand Exchange (CLE) with Inductively Coupled Plasma-Mass Spectrometry (ICP-MS)

$\begin{array}{lll}7.1 & \text { Introduction } & 143\end{array}$

$\begin{array}{lll}7.2 & \text { Theory } & 145\end{array}$

$\begin{array}{lll}7.3 & \text { Experimental } & 149\end{array}$

$\begin{array}{lll}\text { 7.3.1 Preliminary experiment } & 149\end{array}$

$\begin{array}{lll}7.4 & \text { Discussions } & 151\end{array}$

$\begin{array}{lll}7.5 & \text { References } & 160\end{array}$

$\begin{array}{lll}\text { Chapter } 8 & \text { Conclusions } & 163\end{array}$ 


\section{List of Figures}

Figure 1.1 Schematic Diagram of the Biotic Ligand Model (BLM) 8

Figure 2.1 Schematic diagram showing deposition and stripping steps of ASV.

Figure 2.2 Schematic diagram of Differential Pulse Waveform

Figure 2.3 DPASV of a spiked freshwater sample with trace metal concentrations: $10 \mu \mathrm{M}$ for $\mathrm{Cu}(\mathrm{II}), \mathrm{Pb}(\mathrm{II}), \mathrm{Cd}(\mathrm{II})$ and $\mathrm{Zn}(\mathrm{II})$, at $\mathrm{pH} 7$.

Figure 2.4 Map of the sampling lakes in the Rouyn-Noranda area

Figure 2.5 Copper titration curves by DPASV of different aqueous samples. $\triangle$ the freshwater sample from Lake Opasatica; 0 the freshwater sample from Lake Dufault; $\square$ the aqueous effluent sample from Sudbury; + the aqueous effluent sample from CCWWTP. The error bar represents two standard deviations of three replicates of the DPASV measurement.

Figure 2.6 van den Berg-Ruzic plot of Sudbury effluent sample copper titration data.

Figure 2.7 Depositional Potential Scan for (Copper Cliff Waste Water Treatment Plant) CCWWTP aqueous effluent sample. The error bar indicates two standard deviations of three replicates of the DPASV measurement.

Figure 2.8 Comparison between experimental results and WHAM VI prediction

Figure 3.1 Schematic diagram showing deposition and stripping steps of CSV.

Figure 3.2 Schematic diagram of Square Wave Waveform

Figure 3.3 SWCSV of copper-catechol complexes in a freshwater sample containing spiked catechol, at $\mathrm{pH} 7$.

Figure 3.4 Catechol titration curve of copper in a freshwater sample from Lake Dufault. The error bar represents two standard deviations of three replicates of the SWCSV measurement. 
Figure 3.5 Catechol titration curve of copper in a freshwater sample from Lake Osisko. The error bar represents two standard deviations of three replicates of the SWCSV measurement.

Figure 3.6 Catechol titration curve of copper in a freshwater sample from Lake Opasatica. The error bar represents two standard deviations of three replicates of the SWCSV measurement.

Figure 3.7 Copper titration curves in three lake freshwater samples collected in June 2003. $\triangle$ the freshwater sample from Lake Opasatica; + the freshwater sample from Lake Dufault; $\square$ the aqueous freshwater sample from Lake Osisko.

Figure 3.8 Data analysis for one freshwater sample from Lake Opasatica. calculated data from titration; the solid line is from data plotted by FITEQL.

Figure 3.9 Comparison between experimental results and WHAM VI prediction. $\triangle$ the freshwater sample from Lake Dufault collected in June; $\boldsymbol{\Delta}$ the freshwater sample from Lake Dufault collected in August; $\square$ the freshwater sample from Lake Opasatica collected in June; - the freshwater sample from Lake Opasatica collected in August; $\circ$ the freshwater sample from Lake Osisko collected in June; $\bullet$ the freshwater sample from Lake Osisko collected in August.

Figure 3.10 Calculated distribution of ML2 complex ion as a function of the catechol concentration of copper model solution with $1 \mathrm{E}-7 \mathrm{M} \mathrm{Cu}(\mathrm{II})$ at different $\mathrm{pH}$.

at $\mathrm{pH} 7.7 ; \Delta$ at $\mathrm{pH} 7.1 ; \square$ at $\mathrm{pH} 6.5$.

Figure 3.11 Catechol titration curves by SWCSV of copper model solution with 1E$7 \mathrm{M} \mathrm{Cu}$ (II) at different $\mathrm{pH}$. at $\mathrm{pH} 7.7 ; \boldsymbol{\Lambda}$ at $\mathrm{pH} 7.1 ; \square$ at $\mathrm{pH} 6.5 .76$

Figure 3.12 Deposition potential scan of copper model solution containing 1E-7M $\mathrm{Cu}$ (II) and 1E-5M catechol, by SWCSV, at pH 7.7.

Figure 4.1 Map of sampling site on Rideau Canal

Figure 4.2 Pseudopolarograms for $\mathrm{Cu}$ with and without EDTA. $\mathrm{pH}$ 7.1; Deposition time 20 s. $\square 1 \mu \mathrm{M} \mathrm{Cu}$ with $0.5 \mu \mathrm{M}$ EDTA; $\circ 1 \mu \mathrm{M} \mathrm{Cu}$ without EDTA 
Figure 4.3 Pseudopolarograms for $\mathrm{Cu}$ in the SRFA solution with and without EDTA. pH 7.1; Deposition time $30 \mathrm{~s}$. $\square 1 \mu \mathrm{M} \mathrm{Cu}$ with $10 \mathrm{mg} / \mathrm{L}$ SRFA with 0.5 $\mu \mathrm{M}$ EDTA; $\circ 1 \mu \mathrm{M} \mathrm{Cu}$ with $10 \mathrm{mg} / \mathrm{L}$ SRFA without EDTA. 96

Figure 4.4 Pseudopolarograms for $\mathrm{Cu}$ in the $\mathrm{HA}$ solution with and without EDTA. pH 7.1; Deposition time 30 s. $\square 1 \mu \mathrm{M} \mathrm{Cu}$ with $10 \mathrm{mg} / \mathrm{L}$ HA with $0.5 \mu \mathrm{M}$ EDTA; $\circ 1 \mu \mathrm{M} \mathrm{Cu}$ with $10 \mathrm{mg} / \mathrm{L} \mathrm{HA}$ without EDTA.

Figure 4.5 Curves for titration of $\mathrm{Cu}$ with $0.3 \mu \mathrm{M}$ EDTA, $\mathrm{pH} 7.1$; deposition time 30 s. $\square$ deposition potential at $-1.2 \mathrm{~V}$; o deposition potential at $-0.3 \mathrm{~V} .98$

Figure 4.6 Curves for titration of EDTA with $0.1 \mu \mathrm{M} \mathrm{Cu}, \mathrm{pH} 7.1$; deposition time $100 \mathrm{~s}$; deposition potential $-1.2 \mathrm{~V}$

Figure 4.7 Pseudopolarograms of $\mathrm{Cu}$ in the Rideau Canal freshwater sample collected in June, 2007. $\circ$ the sample alone, with deposition time 300 seconds; $\square$ the sample spiked with $1 \mu \mathrm{M} \mathrm{Cu}$, with deposition time 30 seconds. 100

Figure 4.8 Titration curves showing peak current $\left(i_{p}\right)$ as functions of $[\mathrm{Cu}]_{\mathrm{T}}$ for the Rideau Canal freshwater sample collected in June, 2007. Different symbols represent titrations conducted at different deposition potentials: at $-0.7 \mathrm{~V}(\square)$, and at $-1.2 \mathrm{~V}(\mathrm{O})$.

101

Figure 4.9 van den Berg-Ruzic linear transformation of the copper titration data for the Rideau Canal freshwater sample collected in June, 2007. Different symbols represent titrations conducted at different deposition potentials: at $-0.7 \mathrm{~V}(\square)$, and at $-1.2 \mathrm{~V}(\mathrm{O})$.

102

Figure 5.1 Diagram of DGT device 114

Figure 5.2 Schematic representation of the free concentration of ionic species in a hydrogel assembly in contact with aqueous solution, where the concentration is $\mathrm{C}_{\mathrm{b}}$. DBL is diffusive boundary layer. The rate of diffusion is assumed to be the same in the gel and solution.

115

Figure 5.3 DGT uptake of copper with time in Rideau Canal during the period of 15 days. The error bars represent two standard deviations of four replicates of the DGT determination. 
Figure 5.4 DGT uptake of lead with time in Rideau Canal during the period of 15 days. The error bars represent two standard deviations of four replicates of the DGT determination.

Figure 5.5 DGT uptake of nickel with time in Rideau Canal during the period of 15 days. The error bars represent two standard deviations of four replicates of the DGT determination.

Figure 6.1 Standard microplate configuration. A, to be used for tests where ultrapure water is used for dilution; B, for tests where lake water sample is used for dilution. Peripheral wells are filled with $220 \mu \mathrm{L}$ of ultrapure water. T1 and T10 are the highest and lowest test concentrations.

Figure 7.1 Diagram of CLEM apparatus

Figure 7.2 $\mathrm{Cu}$ and $\mathrm{Zn}$ readings of the ICP-MS from first Reactor. $\square$ copper readings;

- zinc readings.

154

Figure 7.3 $\mathrm{Cu}$ and $\mathrm{Zn}$ readings of the ICP-MS from second Reactor. $\square$ copper readings; • zinc readings.

155

Figure 7.4 $\mathrm{Cu}$ and $\mathrm{Zn}$ readings of the ICP-MS from third Reactor. $\square$ copper readings;

- zinc readings.

156

Figure 7.5 New reactor with an extra sampling tube for injecting $2 \%(\mathrm{v} / \mathrm{v}) \mathrm{HNO}_{3}$ (ultrapure).

Figure 7.6 $\mathrm{Cu}$ and $\mathrm{Zn}$ readings of ICP-MS with $6 \times 10^{6} \mathrm{cell} / \mathrm{ml}$ algae added to $5 \times 10^{-}$ ${ }^{4} \mathrm{M} \mathrm{NaCl}$ and $4 \times 10^{-9} \mathrm{M} \mathrm{Cu}\left(\mathrm{NO}_{3}\right)_{2}$ solution. $\square$ copper readings; $\bullet$ zinc readings. 158

Figure 7.7 $\mathrm{Cu}$ and $\mathrm{Zn}$ ICP-MS curves with $6 \times 10^{6}$ cell/ $/ \mathrm{ml}$ algae added to macronutrient medium and $4 \times 10^{-8} \mathrm{M} \mathrm{Cu}\left(\mathrm{NO}_{3}\right)_{2}$ solution. $\square$ copper readings; $\bullet$ zinc readings. 


\section{List of Tables}

Table 2.1 Chemical composition of the collected water samples

Table 2.2 DPASV-labile species of $\mathrm{Cu}(\mathrm{II})$ and $\mathrm{Zn}$ (II) in the freshwater samples collected from the two lakes in 2002

Table 2.3 Labile $\mathrm{Cu}(\mathrm{II})$ species of the freshwater samples from the two lakes determined by DPASV, and also by DPASV-copper titration method

Table 2.4 $\mathrm{Cu}(\mathrm{II})$ speciation parameters of the freshwater samples from the two lakes and of two aqueous effluent samples, determined by DPASV-copper titration method

Table 3.1 Chemical composition of freshwater samples from three lakes collected in 2003

Table 3.2 Copper speciation parameters determined by CLE-AdCSV in freshwater samples from three lakes collected from in 2003

Table 4.1 General chemical information for the Rideau Canal freshwater sample collected on September 26, 2007.

Table 4.2. Results of copper speciation determined with van den Berg-Ruzic plot at different detection windows for the Rideau Canal freshwater samples collected in September, 2006. $[\mathrm{L}]_{\mathrm{T}}$ represents the total concentration of the copper-binding natural organic ligand. $\mathrm{K}$ represents the conditional stability constant of the copper complex formed with the natural organic ligand.

104

Table 4.3. The average conditional stability constants and the average total concentrations using different detection window at the $95.5 \%$ confidence level determined in the Rideau Canal freshwater samples, collected in September 2006 and June 2007. [L $]_{\mathrm{T}}$ represents the total concentration of the copper-binding natural organic ligand. $\mathrm{K}$ represents the conditional stability constant of the copper complex formed with the natural organic ligand. 
Table 5.1 General chemical information on the Rideau Canal freshwater sample 126

Table 5.2 DGT-labile species of copper, lead and nickel determined in Rideau Canal

Table 6.1 Final concentrations of nutrients in the liquid growth medium of the stock algal culture.

133

Table 6.2 Final concentrations of nutrients in the microtest medium.

136

Table 6.3 Growth inhibition test using Selenastrum capricorntum in the freshwater sample from Lake Dufault.

139

Table 6.4 Concentrations of some trace metals in freshwater sample from Lake

Dufault. 
Dedicated to mama, baba, yang, and xiaomaodou 
-Chapter 1-

Introduction 


\subsection{Introduction}

"Water is one of the earth's most precious and threatened resources. Health is one of each person's most precious resources. We need to protect and enhance them both [1]." This foreword of the World Health Organization (WHO) World Water Day report (2001) reenforced the importance of the study of natural waters, Chemical speciation of the potentially toxic metals has been attracting the attention of environmental scientists for some time because of the importance role that metal speciation plays in metal bioavailability and geochemical behavior [2-4]. In natural water systems, potentially toxic metals may not be totally available to biota because of their complexation with Natural Organic Matter (NOM). Numerous studies have shown the ability of NOM to strongly complex a variety of metals and to dominate metal speciation under various natural conditions [5-13], thereby reducing the metal's bioavailability and toxicity [1418]. NOM constitutes a whole spectrum of ligands available for complexing metals. They are highly dispersed, and consist of heterogeneous molecules with a substantial polyfunctional and polyelectrolytic characters [19-21]. The major functional groups in NOM include carboxylic, phenolic, amino and thiol groups, which attach to a carbon backbone [22]. The physical (e.g., shape) and chemical properties (e.g., surface charge) of NOM tend to change with the changing chemical conditions in solution (e.g., pH, ionic strength) $[23,24]$. In order to accurately assess the fate and transport of potentially toxic metals and to develop effective controlling technologies it is absolutely essential to understand the complexation of metals with NOM and the physical/chemical/biological reaction of metals with organisms. However, because of the heterogeneity of NOM, it is impossible to characterize the spectrum of metal-binding natural organic ligands in a 
simple manner. As a result, in order to acquire predictive capability for metal complexation in natural waters, environmental scientists have tried to categorize NOM into several arbitrary categories of natural organic ligands with discrete metal-binding capacities.

NOM has been studied according to the origin of its components. From the environment perspective, the most chemically significant fraction of NOM is humic substances, which are formed by the decomposition of plant, animal and microbial material [22]. Traditionally, humic substances have been considered to comprise three main fractions, distinguished by their solubility and adsorption properties: humic acids are soluble in base but insoluble in acid, whereas fulvic acids are soluble in both base and acid; a third fraction, humin, is not readily soluble. Humin may consist of humic acid in strong association with mineral matter, highly condensed insoluble humic matter, gugal melanins, and paraffinic substances [19]. Broadly speaking, humic acids and humin occur mostly in soils and sediments as part of the solid phase, while fulvic acids are more soluble and account for a major part of the dissolved organic matter in natural waters. Once formed, humic substances resist degradation [22].

For humic substances in waters, full scale isolation of each component is impractical. The most useful determination is Dissolved Organic Carbon (DOC). Although not a proper measure of humic substances, DOC concentrations provide a useful indication of humic substances since much of the DOC is usually humic substances. Concentrations of DOC in freshwater streams, rivers and lakes vary from less than $0.5 \mathrm{mg} \mathrm{L}^{-1}$ to as high as 100 
$\mathrm{mg} \mathrm{L}^{-1}$, depending on the nature of the sampling location, including the climate, the latitude of the water body, and pollutant inputs. The average value of the major river of the world is ca $5 \mathrm{mg} \mathrm{L}^{-1}[25]$.

A few studies have reported that some phytoplankton release organic molecules that alter the bioavailability of metals in ambient seawater [26, 27]. There have also been a number of studies which have reported that a series of strong ligands exist in freshwaters, which may be freshly produced by organisms [28-31].

Suspended particulate matter is always present in surface waters, in which colloids are materials with dimensions in the range $1 \mathrm{~nm}^{-1} 1 \mu \mathrm{m}$ with very large surface areas. In research on natural waters, for simplicity, suspended solids are commonly separated by filtering water samples through filters, usually with pore size of $0.45 \mu \mathrm{m}$.

\subsection{Statement of the problem}

Environmental conservation and pollution control are becoming one of the most important issues on earth as a result of more than one century of heavy industrialization and commercial exploitation of natural resources. To protect and manage the water resources, it is absolutely essential to obtain the capability to accurately assess the water quality, which requires both accurate analytical techniques and accurate data analysis.

\subsection{Current state of the knowledge}




\subsubsection{Free Ion Activity Model (FIAM)}

It has been long established that total metal concentration is not a good predictor of metal toxicity and that the use of results from laboratory water often leads to an overestimation of metal toxicity in natural water systems. There are some metal species which are not toxic. This realization has led to the need to evaluate the importance of metal speciation for metal bioavailability and toxicity studies. Based on the experimental toxicity data obtained using well-defined exposure media, the Free Ion Activity Model (FIAM) was developed to predict metal toxicity [32-34]. Although the free metal ion is not the only toxic metal species, it is a good predictor of metal toxicity in the aquatic environment [35-37]. Campbell [36] critically reviewed the validation of FIAM: out of the 59 cases examined, 52 confirmed the FIAM.

\subsubsection{Current techniques}

Up to date, numerous methods have been developed to determine the metal speciation in aquatic systems directly or indirectly. Ion Selective Electrodes (ISE) potentiometry can measure the free metal ion activity directly [38-40]. However, because of the low analytical sensitivity of ISE, its application to natural waters with very low concentrations of trace metals is limited. For quantitative determination of labile metal species (which scientists related to bioavailable species), there are both voltammetric methods [41, 42] and non-voltammetric techniques, such as Diffusive Gradients in Thin Films (DGT) [43, 44], and Ion Exchange Technique (IET) [45, 46]. In order to determine both the free metal ion concentration and the complexation capacity of NOM, more complicated approaches are required. Most importantly, NOM contains a spectrum of 
metal-binding organic ligands. It is impossible to characterize them individually. To simplify speciation study, environmental scientists tried to categorize these metalbinding substances into several arbitrary discrete organic ligands categories with different metal-binding capabilities. Thus, the complexation behavior of NOM can be expressed by using the representative complexation parameters (several ligand concentrations and the corresponding conditional stability constants of metal complexes of the ligands).

Competing Ligand Exchange (CLE) method, coupled with Adsorptive Cathodic Stripping Voltammetry (AdCSV), has became a popular technique to determine both the free metal ion concentration and the representative complexation parameters because of its high sensitivity and flexible detection window of the technique[47-51]. The concentration of the metal complexes formed with the competing ligand is measured by AdCSV. By titrating the water sample with the metal, the free metal ion concentration and the representative complexation parameters can be obtained by chemical equilibrium calculation. However, there are some drawbacks of this technique, such as heavy workload involved, accuracy of analytical sensitivity [49, 52-54], and the limitation of the detection window [55-57]. It should also be pointed out that the complexation parameters obtained by CLE do not necessarily reflect the whole complexation behavior of the NOM in the water sample; but they represent the calculated results which fit well with the titration data within the titration range.

\subsubsection{Windermere Humic Aqueous Model (WHAM)}


The Windermere Humic Aqueous Model (WHAM) [58] is one of the several geochemical model/computer programs for metal speciation [59-63]. The WHAM V and VI $[59,64]$ are superior to most of the models because the WHAM models try to include NOM into the model, which is still a challenge. The WHAM models predict the metal speciation in waters, sediments, and soils in which natural organic matter is a significant component. By incorporating electrostatic interactions of humic substances containing multiple binding sites with varying strengths and competitions between various cations for various sites, the WHAM represents some of the most significant advances over the last decade [65]. It takes into account the interactions of metals with: (i) inorganic ligands (e.g. $\mathrm{OH}^{-}, \mathrm{HCO}_{3}{ }^{-}, \mathrm{CO}_{3}{ }^{2-}, \mathrm{SO}_{4}{ }^{2-}, \mathrm{Cl}^{-}$), using conventional equilibrium formulations and equilibrium constants from the literature [66], and also, (ii) humic substances using Humic Ion Binding Model V [61].

\subsubsection{Biotic Ligand Model (BLM)}

The BLM is an equilibrium-based model: computer program designed to assess the acute ecological effects of metals to organisms in the aquatic systems [67]. It is based on a conceptual model similar to the gill site interaction model proposed by Pagenkopf [68], and incorporates a version of Chemical Equilibria in Soils and Solutions (CHESS) [69] that has recently been modified to include the chemical and electrostatic interactions described in the Windermere Humic Aqueous Model (WHAM) [58], with the copperand silver-gill complexation constants reported by R. Playle and coworkers [70-77]. 


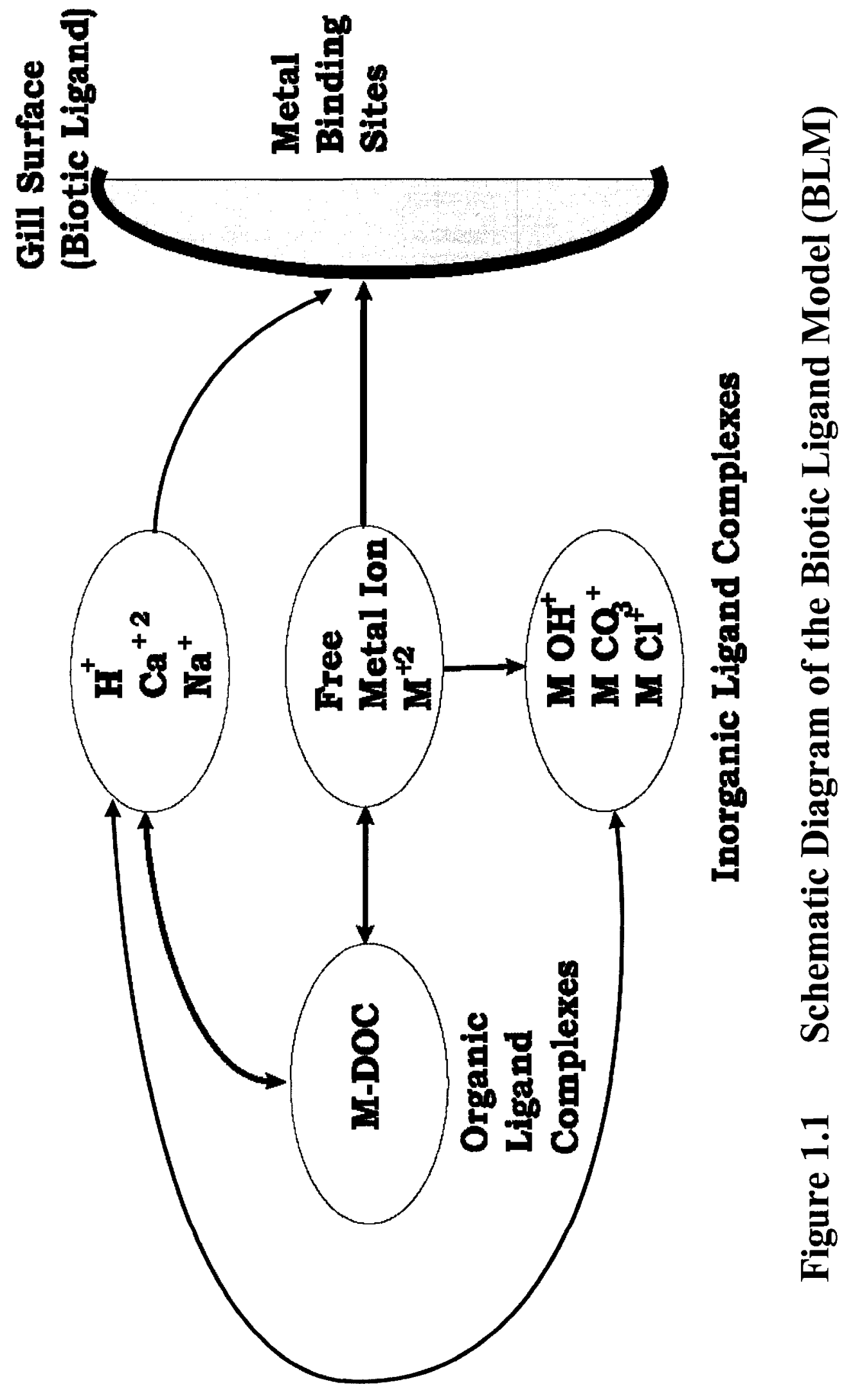


The BLM assumes that only the free metal ion is bioavailable for uptake by organisms. The binding sites on the organism membrane, in this case the fish gill, are regarded as the biotic ligands, as illustrated in Figure 1.1. The biotic ligands compete with inorganic and organic ligands to bind free metal ions. The biotic ligand is understood in the case in Fig 1.1 to be $\mathrm{Na}, \mathrm{K}$-ATPase, an enzyme that is needed for the active uptake of sodium from the water. The fish dies from ionic imbalance caused by a critical drop in sodium. Generally speaking, the biotic ligand represents a biological sensitive receptor, which could induce acute metal toxicity if it accumulates enough toxic metal. Inorganic and organic ligands can also bind the toxic metal, and hence, reduce accumulation at the biotic ligand and reduce the metal toxicity. Several studies have reported excellent agreement between the BLM predicted metal toxicity/LC50 (Lethal Concentration 50, the concentration of a chemical which kills $50 \%$ of a sample population) and the measured metal toxicity/LC50 [78, 79].

\subsection{Weakness in the current state of knowledge}

Our current knowledge of the complexation of the metals with NOM and the physical/chemical/biological reaction of the metals with organisms is confounded by the extreme complexity of the natural water systems. The current computer-based metal speciation models are mainly based on the metal speciation data at higher metal levels. The majority of the uncontaminated natural waters has very low levels of trace metals, which makes the prediction biased. Moreover, in both the metal speciation model and the metal toxicity model, it is assumed that chemical equilibrium is established in the bulk solution and at the biological surface, which is sometimes overly optimistic and 
simplistic because of slow complexation reactions between organic ligands and the metals in natural waters.

\subsection{Hypothesis and objective}

The overall objective of this thesis was to test the following hypotheses: (1) that the extended detection window would provide better knowledge of copper - Natural Organic Matter (NOM) interactions, and would thereby lead to a greater understanding of the heterogeneity of NOM and more reliable prediction of copper speciation in natural waters; (2) that the study of kinetics of copper - organism interactions would provide greater knowledge of the relationship between metal speciation, bioavailability and toxicity, enhancing our ability to predict copper toxicity in natural waters.

\subsection{Outline of the thesis}

Most of this study is on copper because of its ubiquity and extensive database. After the introduction in Chapter 1, Chapter 2 investigates copper speciation using a traditional metal speciation technique - Anodic Stripping Voltammetry (ASV). It applies ASV to some freshwater samples and mine aqueous effluents and demonstrates the applications and limitations of ASV. Chapter 3 describes the application of the Competing Ligand Exchange (CLE) method-Adsorptive Cathodic Stripping Voltammetry (AdCSV) to freshwater samples, and addresses its limitations and an unsolved problem of this method. Chapter 4 proposes a novel CLE-ASV method with EDTA as a competing ligand, showing its advantage of a very high detection window, which provides CLE-ASV the capability of detecting very strong copper-binding organic ligands of NOM. Chapter 5 
deals with determination of copper speciation using a non-voltammetric method Diffusion Gradients in Thin Films (DGT) technique. From Chapter 6, the thesis starts to deal with metal-organism interactions. Chapter 6 reports the results of a standard toxicity test - growth inhibition test with freshwater alga Selenastrum capricornutum, applied to a freshwater sample. The results show that metal mixtures have mixed effect on organisms, and that a single metal toxicity test is inadequate to account for the toxicity of freshwaters which contain usually metal mixtures plus heterogeneous NOM. Chapter 7 discusses the application of a technique which had been exclusively used for the determination of metal-NOM complexation kinetics, to the study of the kinetics of metal uptake by algae. The above technique shows a great potential to quickly detect labile species in freshwater samples. The major findings and conclusions of this thesis are presented in Chapter 8 . 


\section{$1.7 \quad$ References}

1. WHO World Water Day Report (2001), http://www.who.int/water_sanitation_health/takingcharge.html

2. Gächter, R.; Davis, J.S.; Mares, A., Regulation of copper availability to phytoplankton by macromolecules in lake water. Environmental Science and Technology (1978), 1416-1421

3. Swallow, K.C.; Westall, J.C.; McKnight, D.M.; Morel, N.M.L.; Morel, M.M., Potentiometric determination of copper complexation by phytoplankton exudates Limnology and Oceanography (1978), 538-542

4. Sunda, W.G.; Ferguson, R.L., Wong, C.S.; Boyle, E.; Bruland, K.W.; Burton, J.D.; Goldberg, E.O., Editors, Trace Metals in Seawater, Proceedings of the NATO Advanced Research. Institute Symposium, Plenum Press, London, 1983

5. Sunda, William G.; Hanson, Peter J. Chemical speciation of copper in river water. Effect of total copper, $\mathrm{pH}$, carbonate, and dissolved organic matter. ACS Symposium Series (1979), 93 (Chem. Model. Aqueous System: Speciation, Sorption, Solubility, Kinetics), 147-80.

6. Coale, Kenneth H.; Bruland, Kenneth W. Copper Complexation in the Northeast Pacific. Limnology and Oceanography (1988), 33(5), 1084-1101.

7. Moffett, J. W.; Zika, R. G.; Brand, L. E. Distribution and potential sources and sinks of copper chelators in the Sargasso Sea. Deep-Sea Research, Part A: Oceanographic Research Papers (1990), 37(1A), 27-36. 
8. Sunda, William G.; Huntsman, Susan A. The use of chemiluminescence and ligand competition with EDTA to measure copper concentration and speciation in seawater. Marine Chemistry (1991), 36(1-4), 137-63.

9. Xue, HanBin; Sunda, William G. Comparison of [Cu2+] Measurements in Lake Water Determined by Ligand Exchange and Cathodic Stripping Voltammetry and by Ion-Selective Electrode. Environmental Science and Technology (1997), 31(7), 1902-1909.

10. Bruland, Kenneth W.; Donat, John R.; Hutchins, David A. Interactive influences of bioactive trace metals on biological production in oceanic waters. Limnology and Oceanography (1991), 36(8), 1555-77.

11. Donat, John R.; Bruland, Kenneth W. A comparison of two voltammetric techniques for determining zinc speciation in northeast Pacific Ocean waters. Marine Chemistry (1990), 28(4), 301-23.

12. Xue, Hanbin; Oestreich, Andrea; Kistler, David; and Sigg, Laura. Free cupric ion concentrations and $\mathrm{Cu}$ complexation in selected Swiss lakes and rivers. Aquatic Sciences (1996), 58, 69-87

13. Lewis, B. L.; Luther III, G. W.; Lane, H.; Church, T. M. Determination of metalorganic complexation in natural waters by SWASV with pseudopolarograms. Electroanalysis (1995), 7, 166-177

14. Tubbing, Diny M. J.; Admiraal, Wim; Cleven, Rob F. M. J.; Iqbal, Mohammed; van de Meent, Dik; Verweij, Wilko. The contribution of complexed copper to the 
metabolic inhibition of algae and bacteria in synthetic media and river water. Water Research (1994), 28(1), 37-44.

15. Erickson, Russell J.; Benoit, Duane A.; Mattson, Vincent R.; Nelson, Henry P., Jr.; Leonard, Edward N. The effects of water chemistry on the toxicity of copper to fathead minnows. Environmental Toxicology and Chemistry (1996), 15(2), 18193.

16. Playle, Richard C.; Dixon, D. George; Burnison, Kent. Copper and cadmium binding to fish gills: Modification by dissolved organic carbon and synthetic ligands. Canadian Journal of Fisheries and Aquatic Sciences (1993), 50(12), $2667-77$.

17. Hollis, Lydia; Burnison, Kent; Playle, Richard C. Does the age of metaldissolved organic carbon complexes influence binding of metals to fish gills? Aquatic Toxicology (1996), 35(3, 4), 253-264.

18. Todd R. Sandrin and Raina M. Maier Impact of Metals on the Biodegradation of Organic Pollutants. Environmental Health Perspectives (2003), 111(8), 10931101

19. F.J. Stevenson, Humus Chemistry: Genesis, Composition, Reactions, Wiley, New York, USA, 1994.

20. J. Buffle, Complexation Reactions in Aquatic Systems: An Analytical Approach, Ellis Horwood Limited, Chichester, UK, (1988) pp. 5, 21, 195-198.

21. J.A. Rice, in Humic Substances in Soil Sediment and Water, G.R. Aiken, D.M. McKnight, R.L. Wershaw and P. McCarthy (Eds.) Wiley Interscience, New York, USA, (1985), Chapter 21. 
22. Tippings, E, Cation Binding by Humic substances, Cambridge University Press; 2002

23. Johannes, M.C. De Wit, W.H. Van Riemsdijk, N.M. Nederlof, D.G. Kinniburgh and L.K. Koopal, Analytica Chimica Acta (1990), 232, 189.

24. E. Tipping and D. Cooke, Geochimica et Cosmochimica Acta 1982, 46, 75.

25. Thurman, E. M., 1985, Organic Geochemistry of Natural Waters. Martinus Nijhoff/Dr W. Junk Publishers: Boston, 497 pp.

26. Fisher, N. S.; Fabris, J. G. Complexation of $\mathrm{Cu}, \mathrm{Zn}$ and $\mathrm{Cd}$ by metabolites excreted from marine diatoms Marine Chemistry (1982), 11, 245-255

27. Moffett, J. W.; Brand, L. E. Production of strong, extracellular Cu chelators by marine cyanobacteria in response to $\mathrm{Cu}$ stress. Limnology and Oceanography (1996), 41(3), 388-395

28. Xue, HanBin; Sigg, Laura. Free cupric ion concentration and copper(II) speciation in a eutrophic lake. Limnology and Oceanography (1993), 38(6), $1200-1213$.

29. Xue, H.; Kistler, D.; Sigg, L. Competition of copper and zinc for strong ligands in a eutrophic lake. Limnology and Oceanography (1995) 40, 1142-1152.

30. Achterberg, Eric P.; van den Berg, Constant M. G.; Boussemart, Marc; Davison, William. Speciation and cycling of trace metals in Esthwaite water: a productive English lake with seasonal deep-water anoxia Geochimica et Cosmochimica Acta (1997), 61(24), 
31. Xue, Hanbin; Sigg, Laura. Comparison of the complexation of $\mathrm{Cu}$ and $\mathrm{Cd}$ by humic or fulvic acids and by ligands observed in lake waters. Aquatic Geochemistry (1999), 5(4), 313-335.

32. Morel F.M.M. Pronciples of Aquatic Chemistry (1983) pp. 301-308. Wiley InterScience, New York, NY

33. Morel F.M.M. and Hering J.G. Principles and Applications of Aquatic Chemistry (1993) pp. 405-414. Wiley InterScience, New York, NY

34. Sunda, W.G. Trace metal interactions with marine phytoplankton. Biological Oceanography. (1988/89), 6, 411-442

35. Errecalde, O.; Seidl, M.; Campbell, P. G. C. Influence of a low molecular weight metabolite (citrate) on the toxicity of cadmium and zinc to the unicellular green alga Selenastrum Capricornutum: An exception to the free-ion model. Water Research (1998), 32(2), 419-429.

36. P.G.C. Campbell, in Metal Speciation and Bioavailability in Aquatic Systems, A. Tessier and D.R. Turner (Eds.), IUPAC Series on Analytical and Physical Chemistry of Environmental Systems, John Wiley, Chichester, UK, (1995) pp. $45-102$.

37. Sunda, W. G.; Huntsman, S. A. Processes regulating cellular metal accumulation and physiological effects: Phytoplankton as model systems. Science of the Total Environment (1998), 219, 165-181. 
38. Sunda, William G.; Hanson, Peter J. Chemical speciation of copper in river water. Effect of total copper, $\mathrm{pH}$, carbonate, and dissolved organic matter. ACS Symposium Series (1979), 147-80.

39. Marina; Tartari, Gianni; Zirino, Alberto. Measurement and prediction of copper ion activity in Lake Orta, Italy. Environmental Science and Technology (1991), 25(4), 678-83.

40. Xue, HanBin; Sunda, William G. Comparison of [Cu2+] Measurements in Lake Water Determined by Ligand Exchange and Cathodic Stripping Voltammetry and by Ion-Selective Electrode. Environmental Science and Technology (1997), 31(7), 1902-1909.

41. Henze, Guenter. Application of polarographic and voltammetric techniques in environmental analysis. NATO ASI Series, Series G: Ecological Sciences (1990), 391-408.

42. Tercier-Waeber, M.-L.; Buffle, J. Submersible Online Oxygen Removal System Coupled to an in Situ Voltammetric Probe for Trace Element Monitoring in Freshwater. Environmental Science and Technology (2000), 34(18), 4018-4024.

43. Davison, W.; Zhang, H. In situ speciation measurements of trace components in natural waters using thin-film gels. Nature (1994), 367(6463), 546-8.

44. Zhang, Hao; Davison, William. Performance Characteristics of Diffusion Gradients in Thin Films for the in Situ Measurement of Trace Metals in Aqueous Solution. Analytical Chemistry (1995), 67(19), 3391-400. 
45. Marchand, Michel. Lab. Radioecol. Mar., Commis. Energ. At., Cherboug, Fr. Physicochemical forms of cobalt, manganese, zinc, chromium, and iron in a sea water with and without organic material. Journal du Conseil, Conseil International pour l'Exploration de la Mer (1974), 35(2), 130-42.

46. Batley, G. E.; Florence, T. M. Determination of the chemical forms of dissolved cadmium, lead and copper in seawater. Marine Chemistry (1976), 4(4), 347-63.

47. Van den Berg, C.M.G. Determination of the complexing capacity and conditional stability constants of complexes of copper(II) with natural organic ligands in seawater by cathodic stripping voltammetry of copper-catechol complex ions. Marine Chemistry (1984), 15, 1-18

48. Van den Berg, Constant M. G. Determination of copper, cadmium and lead in seawater by cathodic stripping voltammetry of complexes with 8hydroxyquinoline. Journal of electroanalytical chemistry (1986), 215, 111-121

49. Lucia, M.; Campos, A.M.; van den Berg, Constant M.G. Determination of copper complexation in sea water by cathodic stripping voltammetry and ligand competition with salicylaldoxime. Analytica Chimica Acta (1994), 284, 481-496

50. Donat, John R.; Van den Berg, Constant M. G. A new cathodic stripping voltammetric method for determining organic copper complexation in seawater. Marine Chemistry (1992), 38(1-2), 69-90.

51. Moffett, James W. Temporal and spatial variability of copper complexation by strong chelators in the Sargasso Sea. Deep Sea Research (1995), 42, 1273-1295 
52. Turoczy, N. J.; Sherwood, J. E. Modification of the van den Berg/Ruzic method for the investigation of complexation parameters of natural waters. Analytica Chimica Acta (1997), 354, 15-21.

53. Kogut, M. B.; Voelker, B. M. Strong Copper-Binding Behavior of Terrestrial Humic Substances in Seawater. Environmental Science and Technology (2001), $35,1149-1156$

54. Voelker, B. M.; Kogut, M. B. Interpretation of metal speciation data in coastal waters: the effects of humic substances on copper binding as a test case. Marine Chemistry (2001), 74, 303-318

55. Xue, HanBin; Sigg, Laura. A review of competitive ligand-exchangevoltammetric methods for speciation of trace metals in freshwater. ACS Symposium Series (2002), 811(Environmental Electrochemistry), 336-370.

56. Van den Berg, C. M. G.; Nimmo, M. and Daly, P. Effects of the detection window on the determination of organic copper speciation in estuarine waters. Analytica Chimica Acta (1990), 232, 149-159

57. Miller, L. A.; Bruland, K. W. Competitive equilibration techniques for determining transition metal speciation in natural waters: Evaluation using model data Analytica Chimica Acta (1997), 343, 161-181

58. E. Tipping, Computational. Geosciences (1994), 20, 973.

59. J.C. Westall, J.L. Zachary, F.M.M. Morel, A computer program for the Calculation of Chemical Equilibrium Composition of Aqueous Systems. Tech. Note 181976 (MIT: Cambridge, MA) 
60. S.V. Mattigod, G.Sposito, in E.A. Jenna (Eds), Chemical Modeling in Aqueous Systems, ACS Symposium (1979), 837, 856

61. E. Tipping and D. Cooke, Geochimica et Cosmochimica. Acta, (1982), 46, 75.

62. J.A. Allison, E.M. Perdue, in N. Senesi, T.M. Miano (Eds), Humic Substances in the Global Environmental and Implication on Human Health. Elsevier Science, Amsterdam, (1994), pp 927-942

63. M.F. Benedetti, W.H. van Riemsdijk, L.K. Koopal, D.G. Kinneburgh, D.C. Goody, and C.J. Milne, Geochimica et Cosmochimica. Acta, 60, (1996), 448

64. E. Tipping, Aquatic Geochemistry, (1998), 4, 3.

65. Batley, Graeme E.; Apte, Simon C.; Stauber, Jennifer L. Speciation and bioavailability of trace metals in water: Progress since 1982. Australian Journal of Chemistry (2004), 57(10), 903-919.

66. A.E. Martell and R. M. Smith, Critical stability constants. New York, Plenum Press, c1974-c1989

67. Di Toro, D.M., H. Allen, H. Bergman, J. Meyer, P. Paquin, R. Santore, A Biotic Ligand Model of the Acute Toxicity of Metals: I. Technical Basis. Environmental Toxicology and Chemistry, (2001), 20(10), 2383-2396.

68. Pagenkopf G.K., Gill surface interaction model for trace metal toxicity to fish: role of complexation, $\mathrm{pH}$ and water hardness, Environmental Toxicology and Chemistry, (1983), 17, 342-347

69. Santore, R.C. and C.T. Driscoll, 1995, "The CHESS Model for Calculating Chemical Equilibria in Soils and Solutions", pp 357-375 In R. Loeppert, A.P. 
Schwab, and S. Goldberg (Ed.) Chemical Equilibrium and Reaction Models, American Society of Agronomy, Madison, WI.

70. Playle R, Gensemer R, and Dixon D. Copper accumulation on gills of fathead minnows-Influence of water hardness, complexation, and $\mathrm{pH}$ of the gill microenvironment. Environmental Toxicology and Chemistry, (1992), 11, 381-391.

71. Playle R, Dixon D, and Burnison K. Copper and cadmium binding to fish gills: Modification by dissolved organic carbon and synthetic ligands. Canadian Journal Fisheries and Aquatic Sciences. (1993), 50, 2667-2677.

72. Janes N, and Playle R. Modeling silver binding to gills of rainbow trout (Oncorhynchus mykiss). Environmental Toxicology and Chemistry, (1995), 14, $1847-1858$.

73. Hollis L, Burnison K, and Playle R. Does the age of metal-dissolved organic carbon complexes influence binding of metals to fish gills? Aquatic Toxicology (1996), 35, 253-264.

74. Hollis L, Muench L, and Playle R.1997. Influence of dissolved organic matter on copper binding, and calcium on cadmium binding, by gills of rainbow trout. Journal Fish Biology (1997), 50, 703-720.

75. Playle R. Modelling metal interactions at fish gills. Scienceof the Total Environment (1998), 219, 147-163.

76. Richards J, and Playle R.1998. Cobalt binding to gills of rainbow trout (Oncorhynchus mykiss): An equilibrium model. Comparative Biochemistry and Physiology Part C. (1998), 119, 185-197. 
77. Wood C, Playle R, and Hogstrand C. Physiology and modeling of mechanisms of silver uptake and toxicity in fish. . Environmental Toxicology and Chemistry (1999), 18, 71-83.

78. Erickson RJ, Benoit DA, Mattson VR, Nelson HP Jr., and Leonard EN. The effects of water chemistry on the toxicity of copper to fathead minnows. . Environmental Toxicology and Chemistry (1996), 15, 181-193.

79. Diamond, Jerome M., Gerardi, C., Leppo, E., and Miorelli, T. Using a watereffect ratio approach to establish effects of an effluent-influenced stream on copper toxicity to the fathad minnow Environmental Toxicology and Chemistry (1997), 16, 1480-1487. 
-Chapter 2-

Investigation of copper speciation using Anodic Stripping Voltammetry (ASV) 
Copper is an essential element for biota, but at higher concentrations it becomes toxic. Copper is released to water mainly by natural weathering of soil and discharges from industries and sewage treatment plants [1]. When copper becomes bioavailable, bioaccumulation in organisms from the natural environment may occur. Among different organisms, accumulation factors vary greatly, but tend to be higher at lower exposure concentrations. Accumulation may lead to unusually high body burdens of copper in certain animals (such as bivalves) and terrestrial plants (such as those growing on contaminated soils), although many organisms are capable of regulating their body copper concentration [1].

According to FIAM, the bioavailability of metal can be assessed using free metal ion activity (concentration). Ion Selective Electrodes (ISE) can measure free metal ion concentration directly [2-4]. But with their low sensitivity, the application of ISE to natural waters is limited because of very low levels of trace metal concentration in natural waters. Some other techniques provide direct measurement of operationally-defined labile metal species; for examples, there are voltammetric methods $[5,6]$ and nonvoltammetric methods, such as Diffusive Gradients in Thin Films (DGT) [7, 8], and Ion Exchange Technique (IET) $[9,10]$.

The ability to distinguish between labile and nonlabile species is a significant advantage of ASV in the study of metal speciation and metal toxicity. Scientists have been trying to adjust the sample solution and the ASV experimental conditions so that the concentration 
of the measured ASV-labile species in the total metal concentration would be as close as that of the bioavailable (or toxic) metal species [11-14]. Several studies in different water media have shown a good correlation between the ASV-labile species and metal toxicity using various organisms $[11,12,14-16]$. These studies have provided evidence that ASV could be used to assess the bioavailability/toxicity of copper in water systems.

ASV-labile species is an operationally-defined species, and hence has limited applications. Another methodology which couples ASV and metal titration can provide not only free metal ion concentrations, but also complexation capacity of NOM. The method was first introduced in 1973 [17], and applied to copper in 1977 [18]. The free metal ion plus the inorganic metal complex can be regarded as labile metal species, which has a more distinct definition, and hence, offers better applicability. The study by Mylon et al. has shown good correlation between the copper labile species determined by the above method and the copper uptake by algae [19].

In this chapter, the results of copper speciation in some freshwater samples and aqueous effluent samples are presented. The copper ASV-labile species by Differential Pulse ASV (DPASV) alone are compared with the copper labile species by the DPASV-copper titration method. The copper ASV-labile species are determined by the comparison of the DPASV measurement of the sample solution to the DPASV measurement of the reference solution containing the same dissolved metal concentration in ultrapure water, assuming that all the metal species are ASV-labile when the organic ligands are absent. The copper speciation parameters, determined by DPASV-copper titration method in 
freshwater samples and in aqueous mining and municipal effluent samples, are also compared.

\subsection{Theory}

\subsubsection{ASV and Differential Pulse ASV (DPASV)}

The high sensitivity of ASV allows for the determination of metal speciation in natural waters without the necessity of external pre-concentration. ASV involves two steps: deposition step, which is an internal pre-concentration, during which a negative potential is applied at the mercury drop (i.e. the working electrode) and the metal ion is reduced to the metal which dissolves in the mercury drop forming an amalgam, followed by the stripping step, during which a positive-going potential scan causes re-oxidation of the metal in the amalgam (see Figure 2.1). Thus, the amalgamated metals are stripped out of the mercury electrode and give rise to anodic peak currents, whose heights are proportional to the ASV-labile (i.e. ASV-measurable) metal species.

Differential Pulse has almost replaced linear scan in ASV with enhanced sensitivity. DPASV uses a series of discrete potential steps rather than a linear potential ramp to obtain the experimental polarogram. In this manner, the total waveform applied to the working electrode can be considered as a series of regular voltage pulses superimposed on a linearly changing voltage (see Figure 2.2 ). The analytical current in this case is the difference between the current at the end of the step and the current before the step. This differential current is then plotted vs. the average potential to obtain the differential pulse polarogram. As a result, the differential pulse polarogram is peak shaped (see Figure 2.3). 


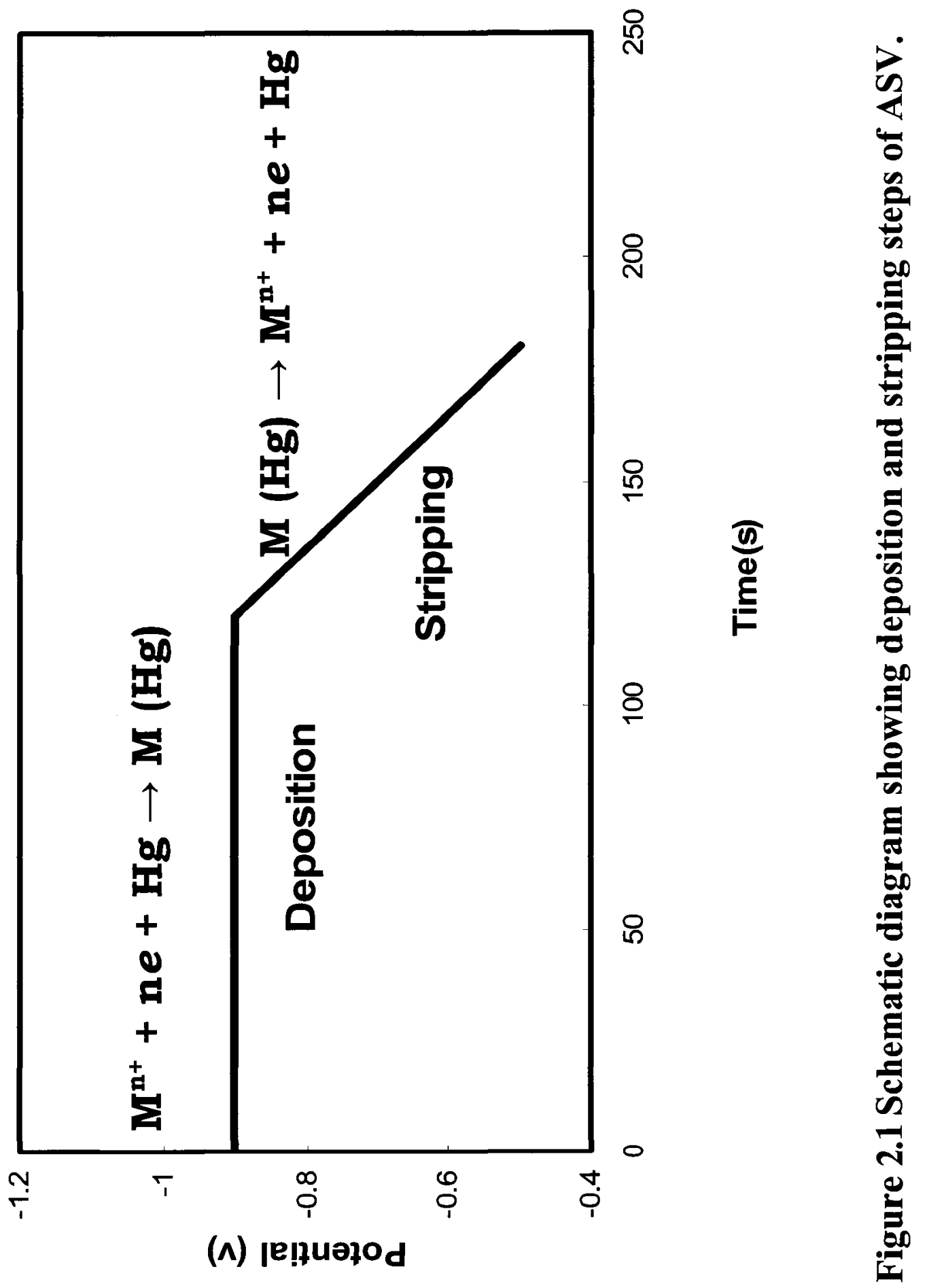




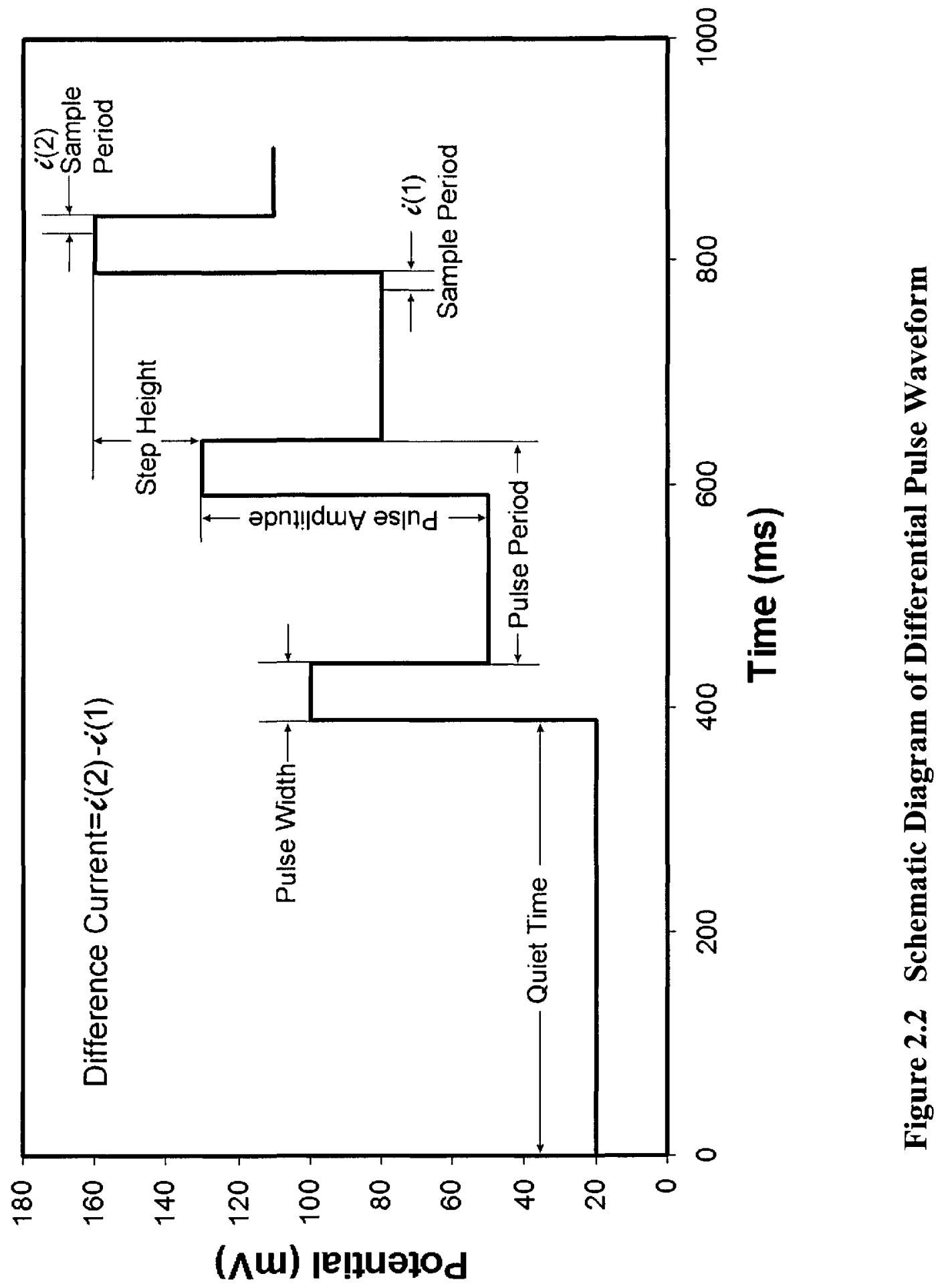



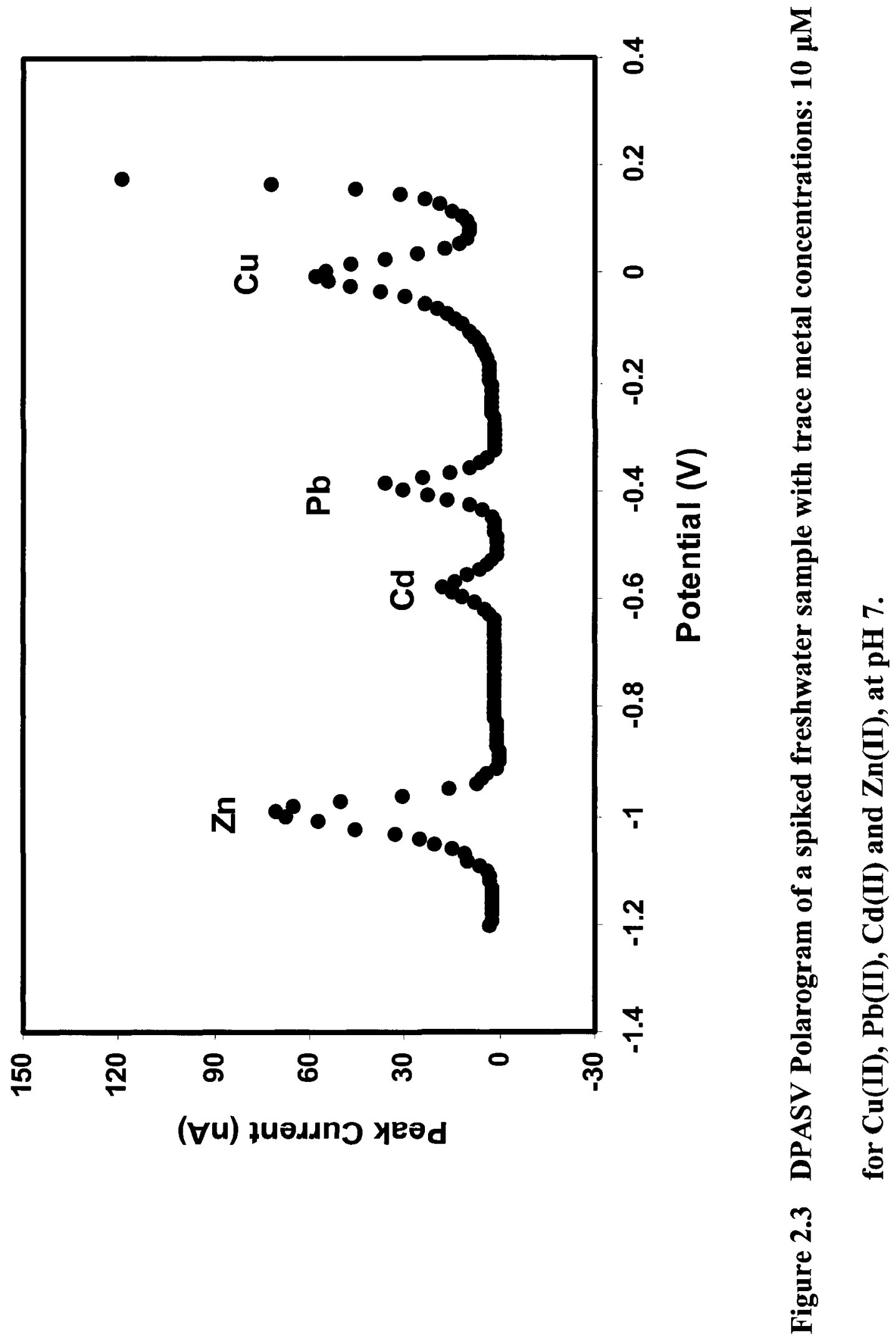


\subsubsection{ASV and copper titration}

Copper species in water systems distribute as follows:

$[C u]_{T}=\left[C u^{2+}\right]+\left[C u L_{I N}\right]+\left[C u L_{i}\right]$

where $[\mathrm{Cu}]_{\mathrm{T}}$ is the total copper concentration; $\left[\mathrm{Cu}^{2+}\right]$ is the free copper ion concentration; $\left[\mathrm{CuL}_{\mathrm{IN}}\right]$ is the concentration of copper complexed by $\mathrm{L}_{\mathrm{IN}}$, the major inorganic ligands such as $\mathrm{OH}^{-}, \mathrm{Cl}^{-}$and $\mathrm{CO}_{3}{ }^{2} ;\left[\mathrm{CuL}_{\mathrm{i}}\right]$ is the concentration of copper complexed by natural organic ligand, $\mathrm{L}_{\mathrm{i}}$. In the copper titration experiment, after equilibration, the spiked copper redistributes among different copper species.

Assuming that ASV only measure free copper ion and copper inorganic complexes, and all the copper organic complexes are ASV-inert, Equation (1) can be rearranged as follow:

$\left[C u L_{i}\right]=[C u]_{T}-\left[C u^{2+}\right]-\left[C u L_{I N}\right]=[C u]_{T}-i_{p} / S$

where $i_{p}$ is the ASV peak current; $\mathrm{S}$ is the analytical sensitivity of the ASV-labile species, and can be calculated as the slope of the linear portion of the copper titration curve, because when the spiked copper is large enough to saturate the organic ligands, peak current becomes proportional to the total copper concentration. However, there always weak copper organic complexes which can dissociate in the time scale of the measurement, i.e. there are always ASV-labile copper organic complexes, and hence, ASV-copper titration always has the potential to underestimate the complexation capacity of natural organic ligands.

$\left[\mathrm{Cu}^{2+}\right]$ can be calculated as follows:

$\left[C u^{2+}\right]=i_{p} / S /\left(1+\alpha_{C u I N}\right)$ 
where $\alpha_{\mathrm{CuIN}}$ is the side reaction coefficient of the copper inorganic complexes, and can be calculated as follows:

$\alpha_{\mathrm{CuIN}}=K_{\mathrm{CuCO}_{3}}\left[\mathrm{CO}_{3}{ }^{2+}\right]+K_{\mathrm{Cu}(\mathrm{OH}) 2}\left[\mathrm{OH}^{-}\right]^{2}+K_{\mathrm{Cu}(\mathrm{Cl}) 2}\left[\mathrm{Cl}^{-}\right]^{2}+K_{\mathrm{CuSO} 4}\left[\mathrm{SO}_{4}{ }^{2-}\right]$

where $\mathrm{K}_{\mathrm{CuCO} 3}, \mathrm{~K}_{\mathrm{Cu}(\mathrm{OH}) 2}, \mathrm{~K}_{\mathrm{Cu}(\mathrm{Cl}) 2}$, and $\mathrm{K}_{\mathrm{CuSO} 4}$ are the stability constants of $\mathrm{CuCO}_{3}$, $\mathrm{Cu}(\mathrm{OH})_{2}, \mathrm{Cu}(\mathrm{Cl})_{2}$ and $\mathrm{CuSO}_{4}$, respectively. Other inorganic ligands such as $\mathrm{NO}_{3}{ }^{-}$are ignored because of their very weak copper complexes. Then the conditional stability constant of the copper complex by strong natural organic ligand $\mathrm{K}_{\mathrm{CuLi}}$ and the concentration $\left[\mathrm{L}_{\mathrm{i}}\right]$ can be extracted from the slope and the intercept of the curve with $\left[\mathrm{CuL}_{\mathrm{i}}\right]$ and $\left[\mathrm{Cu}^{2+}\right]$ data set using any of the several data fitting techniques, such as van den Berg-Ruzic plot,

$\frac{\left[\mathrm{Cu}^{2+}\right]}{\left[\mathrm{CuL} L_{i}\right]}=\frac{\left[\mathrm{Cu}^{2+}\right]}{L}+\frac{1}{K_{C u L i} \times L}$

or Scatchard plot or FITEQL program. $\left[\mathrm{Cu}^{2+}\right]$ in the original sample can then be backcalculated using the obtained $\mathrm{K}_{\mathrm{CuLi}},\left[\mathrm{L}_{\mathrm{i}}\right]$ and the $[\mathrm{Cu}]_{\mathrm{T}}$.

\subsection{Experimental}

\subsubsection{Sampling location and sampling protocol}

Freshwater samples were collected by Lisa Kraemer (Université du Quebec) from two lakes, Lake Dufault and Lake Opasatica in August 2002 and August 2003, in RouynNoranda area, Northwestern Quebec, Canada $\left(48^{\circ} 00^{\prime} \mathrm{N}, 79^{\circ} 00^{\prime} \mathrm{W}\right)$, which had been impacted by current and historical metal mining and smelting operations (see Figure 2.4). Because of the downwind location, Lake Dufault had been directly contaminated by atmospheric deposition from the mining operation. Lake Opasatica had been much less 
contaminated because of its upwind location, and was hence used as a control site. The city of Rouyn-Noranda was formed from the amalgamation of 2 municipalities in 1986, both of which were established after the discovery of copper and gold deposits at the Noranda mine in the mid-1920s.

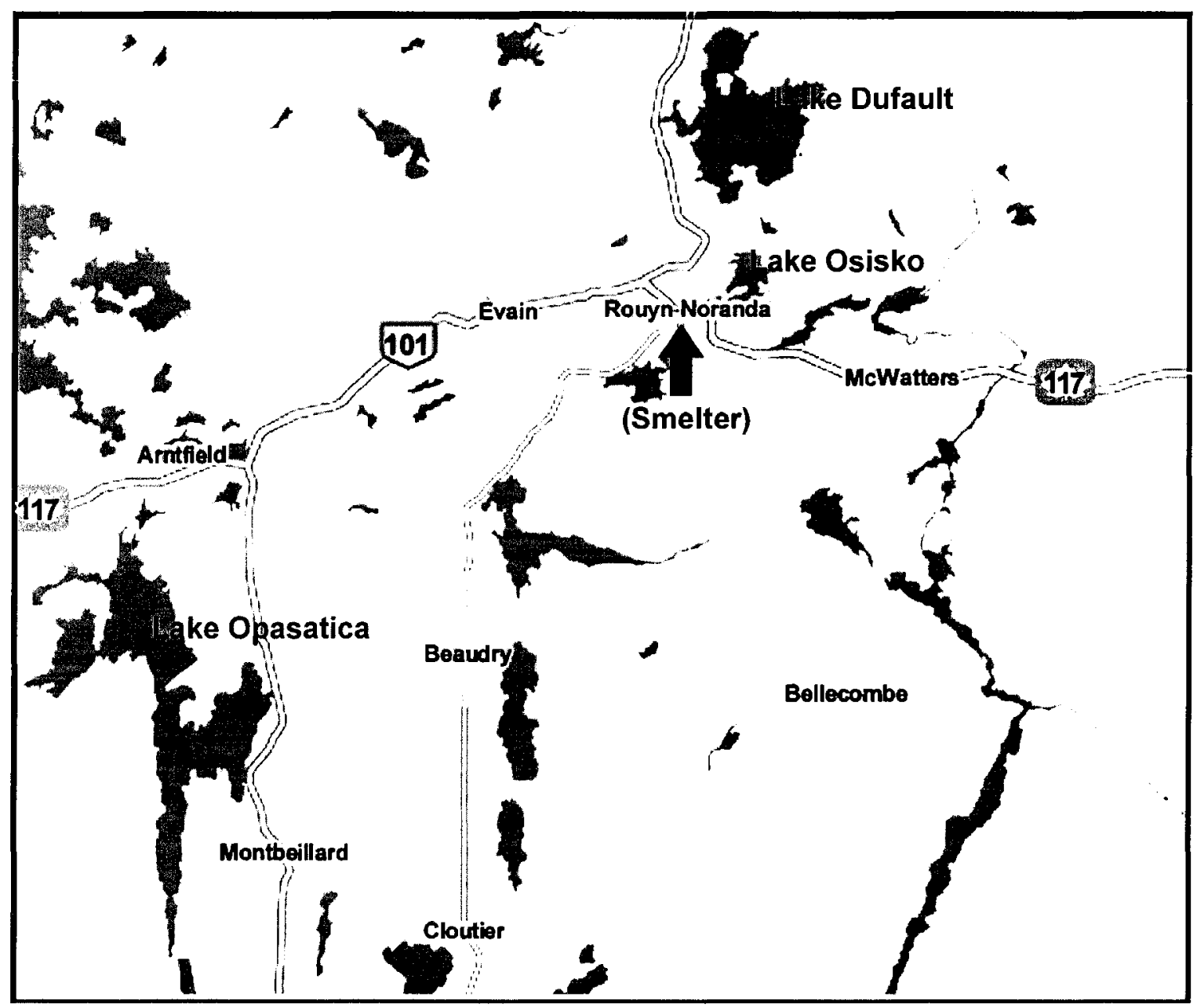

Figure 2.4 Map of the sampling lakes in Rouyn-Noranda area, modified from Google Map. 
The aqueous effluent samples were collected by Christine Brereton (Inco Ltd.) in October 2005 from two different discharge sites, Copper Cliff Waste Water Treatment Plant (CCWWTP) and Sudbury Municipal Waste Water Treatment Plant (Sudbury) in Copper Cliff Mine in Sudbury, Ontario, Canada $\left(46^{\circ} 37^{\prime} \mathrm{N}, 80^{\circ} 48^{\prime} \mathrm{W}\right)$. Toronto-based Inco, now owned by a Brazilian company CVRD, the world's second-biggest nickel producer, got its start in Sudbury in 1902 and today runs a vast mining, smelting, milling and refining complex in the region that employs some 4,500 people. (The Globe and Mail, 28/05/2005)

Acid-cleaned Teflon bottles were used to collect water samples. The bottle cleaning procedure includes: filling bottle with $10 \% \mathrm{HNO}_{3}$ for 24-hour, followed by rinsing bottle with distill water, and then filling bottle with distill water for at least 48 hour. The bottled water samples were immediately stored in an ice box or refrigerator and sent to the laboratory by Purolator courier Ltd. The water samples were then filtered through $0.45 \mu \mathrm{m}$ Versapor membrane capsule filters (Pall Corporation) and analyzed in the following days in the laboratory. A subsample $(100 \mathrm{~mL})$ of the filtered samples was acidified with ultrapure nitric acid to $\mathrm{pH}$ 1.5. The total dissolved trace metal concentrations were determined using the acidified sample by a Perkin-Elmer Elan 6000 ICP-MS. The $\mathrm{pH}$ was measured by an Accumet $20 \mathrm{pH} /$ conductivity meter (Fisher Scientific). The Dissolved Organic Carbon (DOC) concentration of the sample was measured using a Shimadzu Total Organic Carbon Analyzer (TOC-VCPH). The major cations were determined using a Perkin-Elmer 603 Flame Atomic Absorption Spectrophotometer. The major anions were determined using Ion Chromatography with a Dionex anion exchange column. 


\subsubsection{Reagents}

ICP-MS \& ICP-AES standard solutions $(1000 \mu \mathrm{g} / \mathrm{ml})$ of $\mathrm{Cu}(\mathrm{II})$ and $\mathrm{Zn}(\mathrm{II})$ were purchased from SCP Science, Montreal, Canada. Ultrapure water having resistivity of $18.2 \mathrm{M} \Omega . \mathrm{cm}$ was obtained directly from a Milli-Q-Plus water purification system (Millipore Corporation). A $2 \mathrm{M}$ stock solution of potassium nitrate, a $2 \mathrm{M}$ stock solution of $\mathrm{N}-2$ hydroxyethylpiperazine-N'-2-ethanesulphonic acid (HEPES) and a 2 M stock solution of sodium hydroxide were prepared by dissolving an appropriate quantity of potassium nitrate (Aldrich) or HEPES (Sigma) or sodium hydroxide (Aldrich) in ultrapure water. The potassium nitrate, the HEPES and the sodium hydroxide solution were then purified separately by mercury-cathode electrolysis at $-1.5 \mathrm{~V}$ vs. Saturated Calomel Electrode (SCE) for at least $48 \mathrm{~h}$ prior to their use. To prevent the impurity metal from returning to the solution, the purified solution was removed while the electrolysis was going on. All the final test solutions contained $0.01 \mathrm{M}$ potassium nitrate, $6 \mathrm{mM}$ HEPES and appropriate amount of sodium hydroxide for adjusting $\mathrm{pH}$.

\subsubsection{Apparatus}

Voltammetric measurements were made with a computer-controlled Autolab PGSTAT 30 potentiostat/galvanostat (Eco. Chemie BV, The Netherlands) in conjunction with a Metrohm 663 VA stand (Metrohm, Switzerland). The working electrode was a Hanging Mercury Drop Electrode (HMDE, Metrohm, Switzerland). The reference electrode was $\mathrm{Ag} / \mathrm{AgCl}$ electrode in a glass tube filled with $3 \mathrm{M} \mathrm{KCl}$ and fitted with a porous Vycor tip

(Bioanalytical Systems, Inc., USA). The counter electrode was made of a platinum rod (Metrohm, Switzerland). Analysis of peaks was done using the General Purpose 
Electrochemical Software v4.9 (Eco Chemie BV, The Netherlands). The data were transferred to a Pentium computer and saved for processing. All the AdCSV analyses were performed in the same Teflon working cell to secure reproducibility.

\subsubsection{Electrochemical parameters}

For all the DPASV measurements, the following conditions were used: purging with $\mathrm{N}_{2}$ for 5 minutes; Deposition potential -1.2 V; Deposition time 300 seconds; Equilibration time 30 seconds. For the stripping step, initial potential $-1.2 \mathrm{~V}$, end potential $0.3 \mathrm{~V}$, scan rate $0.02 \mathrm{~V} / \mathrm{s}$, and with a differential pulse mode. All the voltages used in this study are reported with respect to the $\mathrm{Ag} / \mathrm{AgCl}$ reference electrode.

\section{$2.4 \quad$ Results and discussions}

Table 2.1 presents the general chemical information for the six samples. It is obvious that the DOC in one aqueous effluent sample, Sudbury Municipal Waste Water Treatment Plant (Sudbury), was significantly higher than in the others. The conductivity of another aqueous effluent sample, Copper Cliff Waste Water Treatment Plant (CCWWTP), was significantly higher than those of the others. Table 2.2 presents the $\mathrm{Cu}(\mathrm{II})$ and $\mathrm{Zn}$ (II) DPASV-labile fractions in the two lake freshwater samples. Table 2.3 presents Labile $\mathrm{Cu}$ (II) species determined by DPASV, and also by DPASV-copper titration method of the freshwater samples from the two lakes. Table 2.4 presents $\mathrm{Cu}(\mathrm{II})$ speciation parameters determined by DPASV-copper titration method of the freshwater samples from the two lakes and of two aqueous effluent samples. Figure 2.5 presents copper titration curves by DPASV of the two freshwater samples and the aqueous effluent 
samples. Figure 2.6 presents an example of van den Berg-Ruzic plot of Sudbury effluent sample; Figure 2.7 presents depositional potential scan for the CCWWTP aqueous effluent sample. Figure 2.8 presents the comparison of the free copper concentration determined by DPASV-copper titration and that predicted by WHAM VI model in the two freshwater samples and the aqueous effluent samples.

Table 2.2 shows that in the Lake Dufault freshwater sample, the concentration of the bound zinc species $(101.1 \mathrm{nM})$ was similar to that of the bound copper species (123.8nM) although that the total zinc concentration was significantly higher than the total copper concentration. This may be rationalized as follows: the complexation between copper and the organic ligands was much stronger than that between zinc and the organic ligands. However, this simple explanation does not hold for the Lake Opasatica sample since the analytical parameters are opposite: the concentrations of the bound zinc and copper species were similar, whereas the concentrations of zinc and copper were also similar. This is an illustration of the fact that DPASV alone can only provide limited insight into the complexation capacity of the organic ligands in natural waters.

From Figure 2.5, some general information about the complexation capacity of the natural organic ligands can be extracted. For example, in effluent samples, there were more natural organic ligands than in freshwater samples, because when total copper concentration is more than $0.4 \mu \mathrm{M}$, the peak current of freshwater samples increased significantly, i.e. the concentration of copper labile species increased significantly as the natural organic ligands are saturated, while the peak current of effluent samples was low 
before the sudden increase at more than $1 \mu \mathrm{M}$ total copper concentration. It seems that the titration can provide valuable information for the environmental control when dealing with large metal inputs. Figure 2.6 shows that one-ligand model fits the data very well.

The difference between DPASV and DPASV-copper titration is illustrated in Table 2.3. If the lake freshwater samples collected in different years can be regarded as similar on the basis of their $\mathrm{pH}, \mathrm{DOC}$, and total copper concentrations being not significantly different, their chemical speciation should not be significantly different. However, the comparison of the results of the freshwater samples of the same lakes from the different years by the two methods shows a significant difference. DPASV-copper titration method has given a much lower concentrations of labile copper species. Weak copper organic complexes, which contribute to the ASV-labile species, can certainly account for some of the difference. In Table 2.3, comparison of the percentages of labile copper out of the total copper concentrations of the freshwater samples shows similarity between the two lake samples by the two methods: $46.6 \%$ and $56.1 \%$ of the total copper are the ASVlabile copper species in Lake Dufault and Lake Opasatica, respectively, by DPASV alone; $13.7 \%$ and $13.5 \%$ of the total copper are the labile copper species in Lake Dufault and Lake Opasatica, respectively, by DPAS-titration method, although Lake Dufault has much higher total copper concentration which should yield a greater percentage of the labile copper. This anomaly can only be account for with the copper speciation parameters listed in Table 2.4. Using a one-ligand model, the organic ligand in the Lake Dufault freshwater sample not only gives the higher concentration but also the higher complexation ability (higher $\log \mathrm{K})$. 
The advantages of the DPASV-copper titration method over the DPASV alone are illustrated in Table 2.4. More information on the complexation capability of organic ligands can be extracted from the DPASV-copper titration method. Comparison of the complexation ability of the organic ligands shows that the amounts of the organic ligands in the effluent samples are significantly different from those in the freshwater samples, which is reasonable because of the difference in the source of the water samples.

Because of the very low detection window of ASV technique, $10^{1}-10^{3}$ [20], the natural organic ligand measured would be very weak, which is confirmed by Table 2-4. (Detection window will be fully discussed in Chapter 3 and 4)

For the metals that form amalgam with mercury (e.g. $\mathrm{Zn}, \mathrm{Cd}, \mathrm{Pb}$ and $\mathrm{Cu}$ ), voltammetry with a mercury electrode is a particularly useful technique for investigating metal bioavailability because the flux reactions that occur at an electrode are inherently similar to the reactions at a biological membrane. However, the operational conditions (e.g. deposition potential, rotation rate) significantly limit its application because of the operationally-defined nature of the measurement process.

The main problem for DPASV technique is its operationally-defined nature. The deposition potential and the thickness of the diffusion layer (or the rotation rate of the electrode) greatly affect the signal. From Figure 2.7 , it is very clear that when deposition potential decreases some previously non-ASV-labile become ASV-labile, which makes the ASV-labile species very difficult to define. In order to determine copper and zinc 
simultaneously, also to keep the experimental parameters consistent, $-1.2 \mathrm{~V}$ was used as the deposition potential throughout this work. But obviously, this potential underestimates the complexation capacity of the organic ligand in the sample to a certain extent. Comparison of the free copper concentration determined by DPASV-copper titration and that predicted by WHAM VI model in Figure 2.6 also shows that the experimental results (by DPASV-copper titration) are significantly lower than the predictions by WHAM VI. In order to apply ASV techniques, the operational condition has to be carefully manipulated. Nevertheless, detecting strong natural organic ligand is still an impossible mission. A good way to overcome this problem is the Competing Ligand Exchange (CLE) method, which will be discussed in later chapters. 


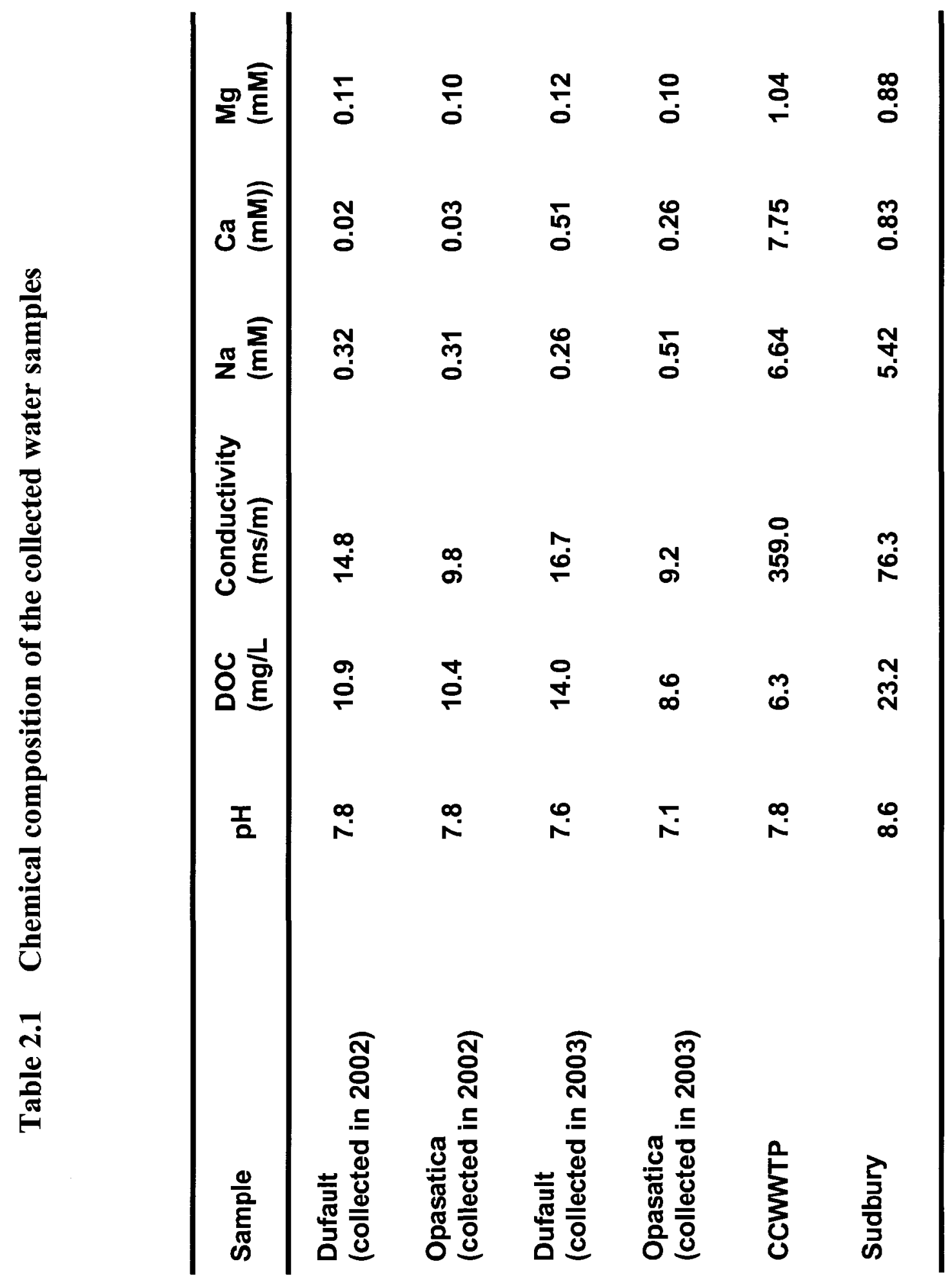




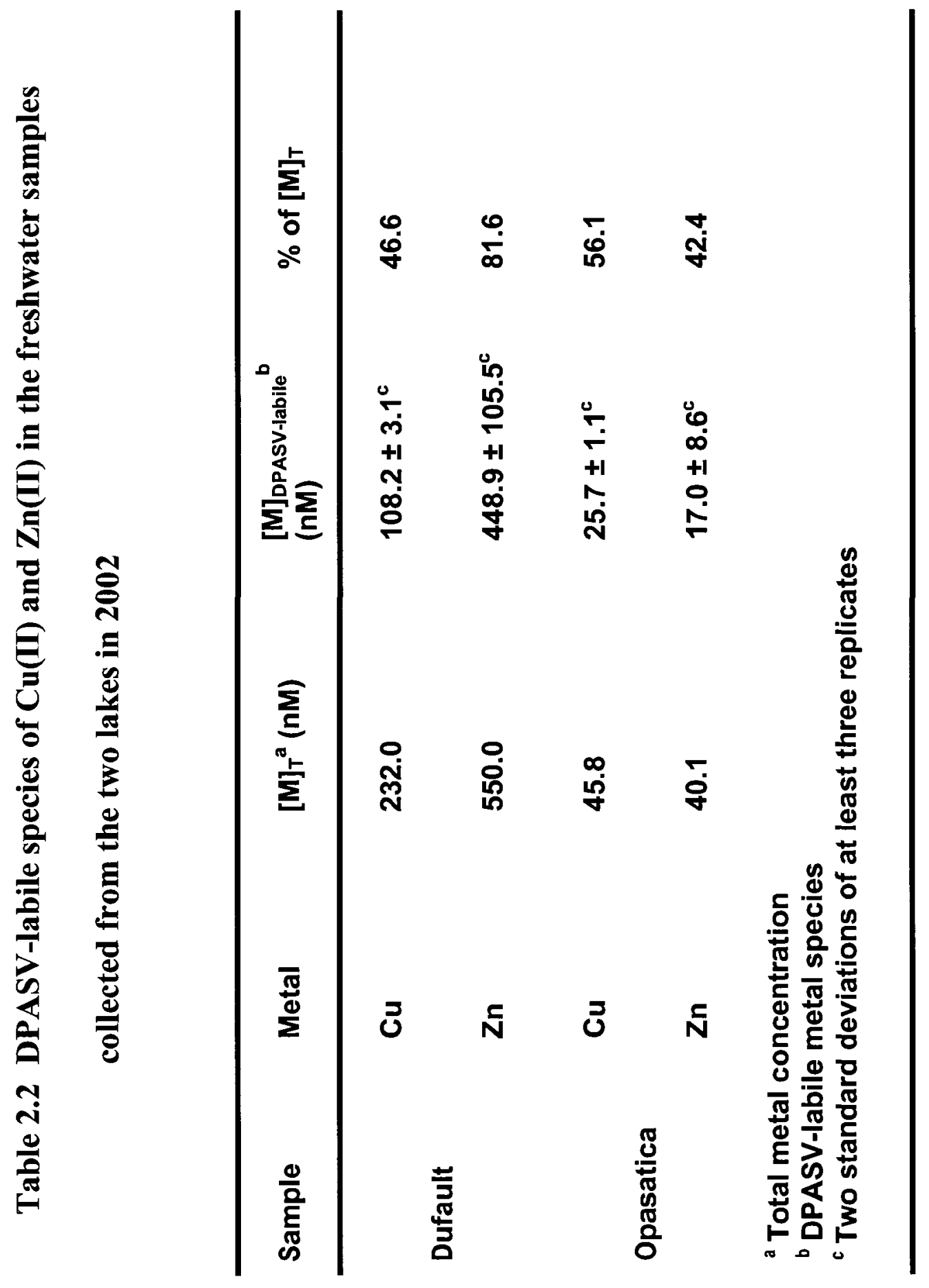




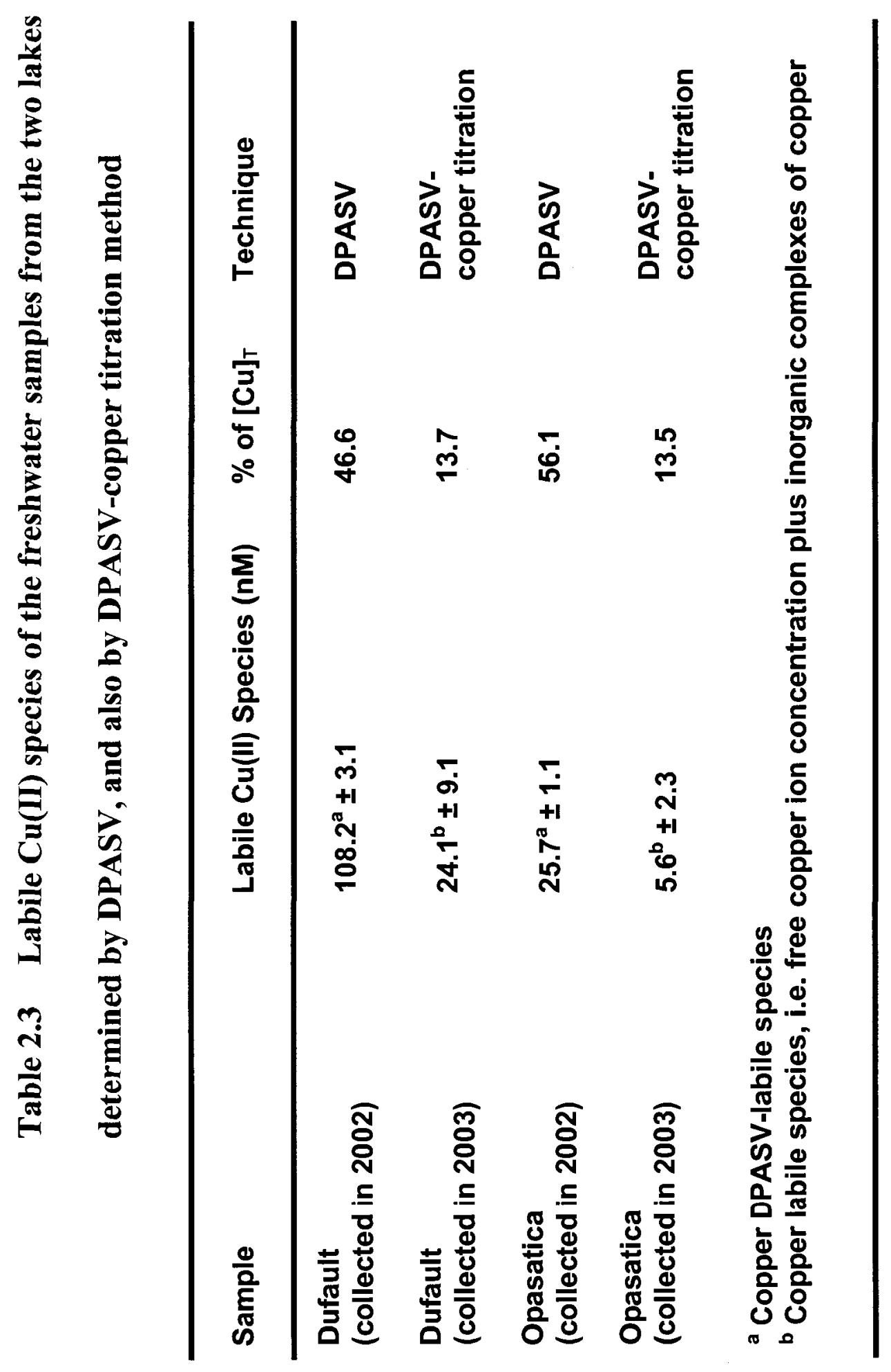




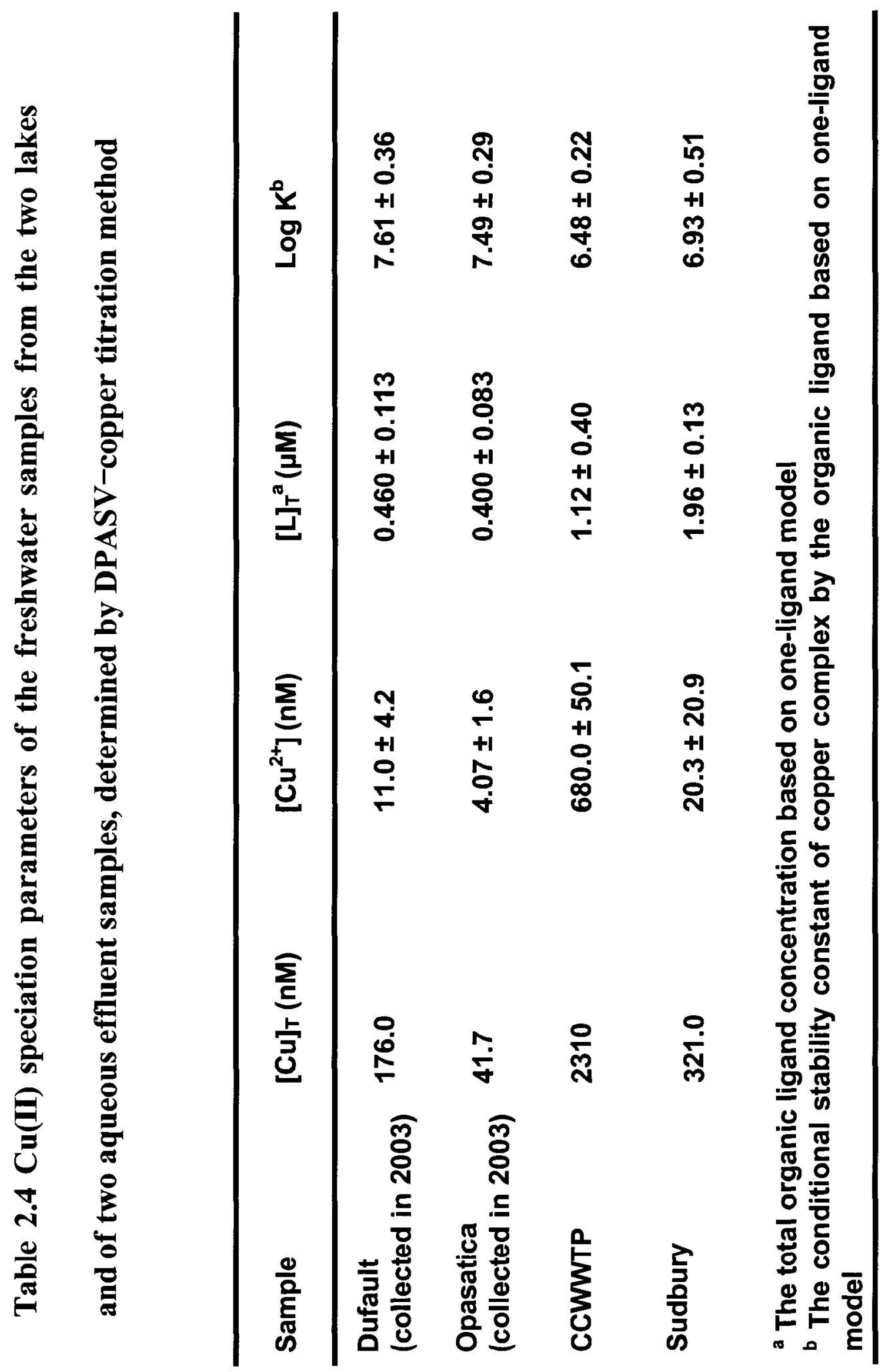




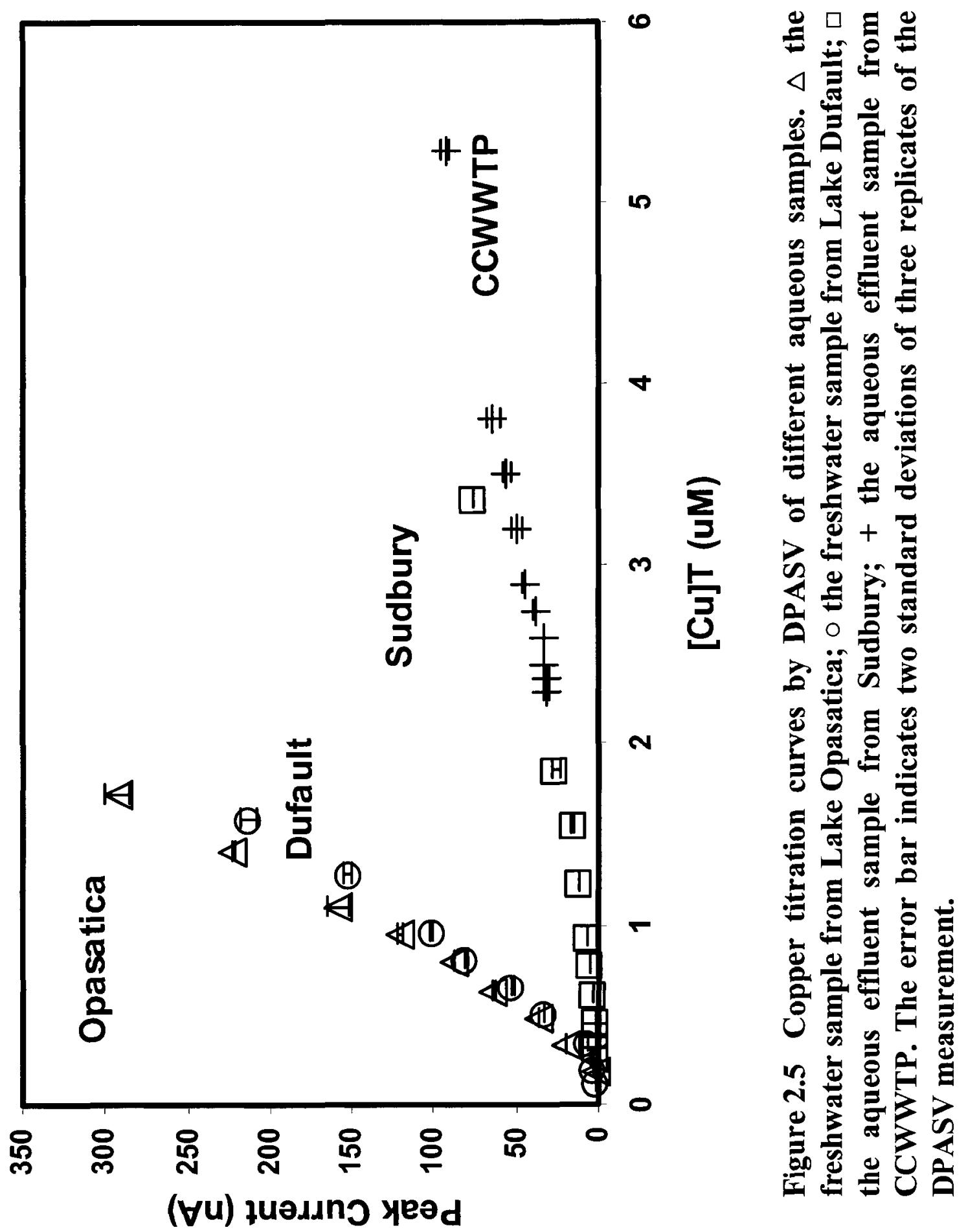




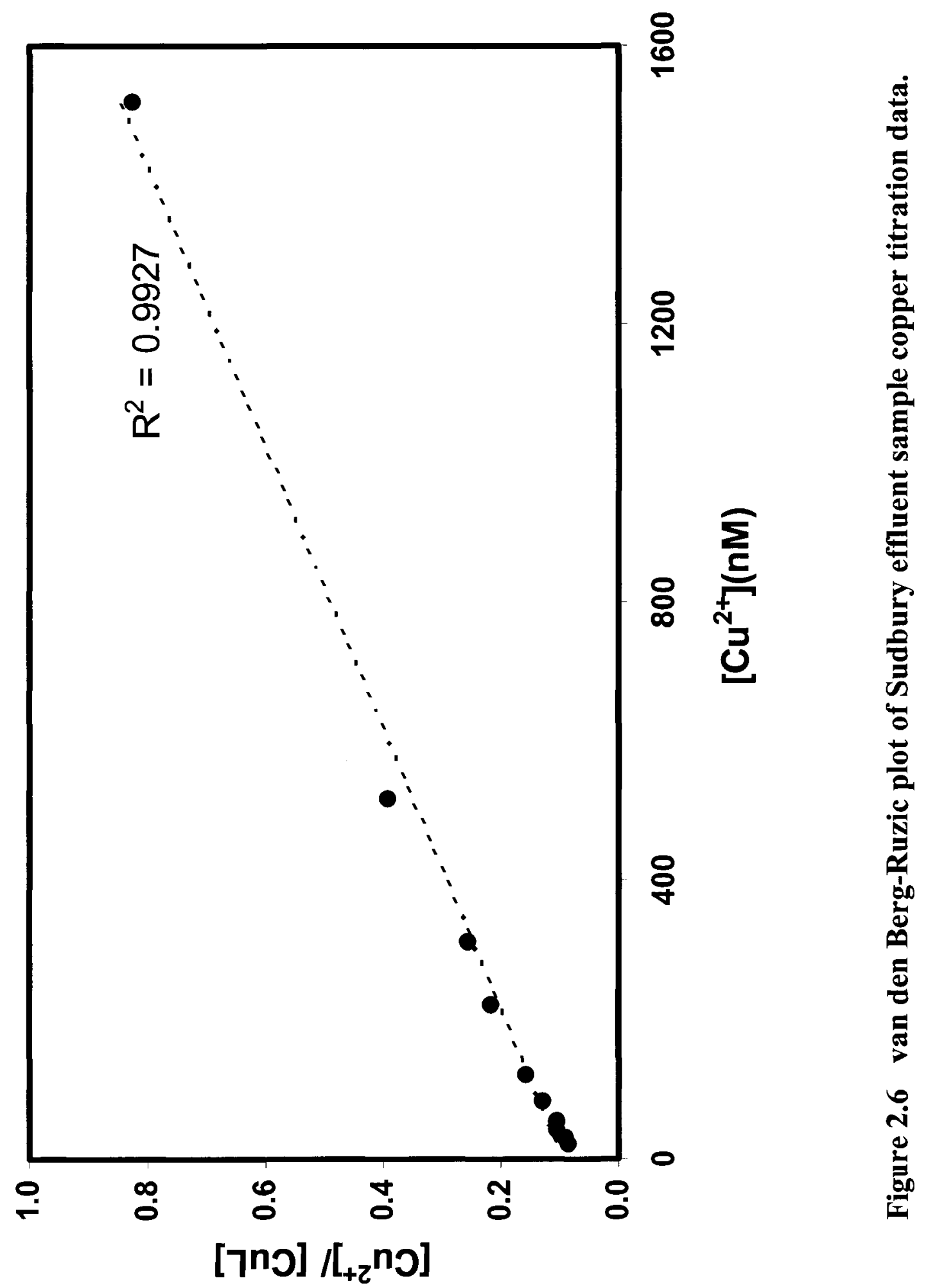




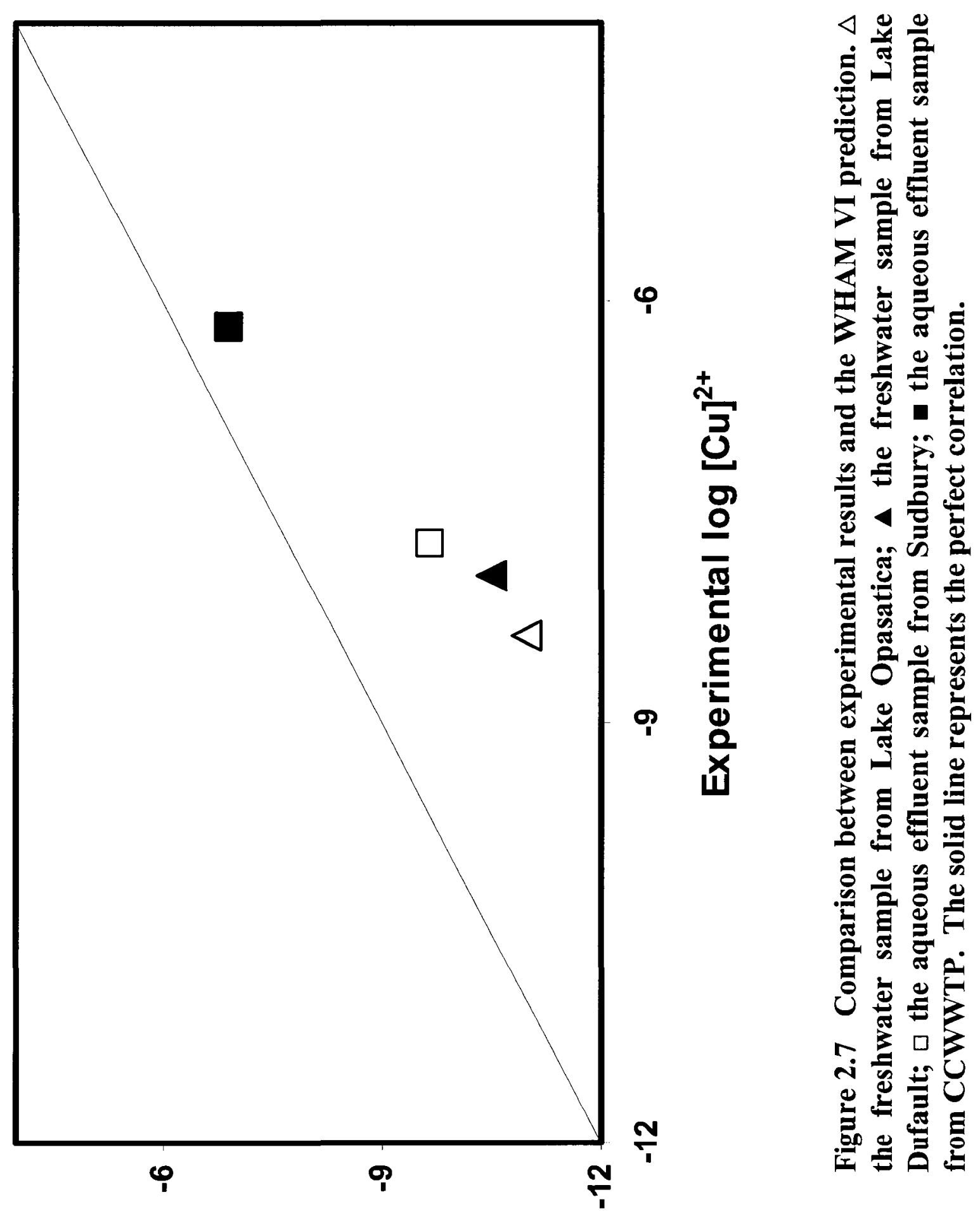

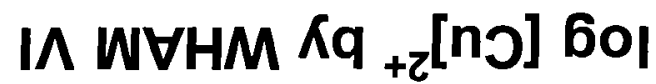




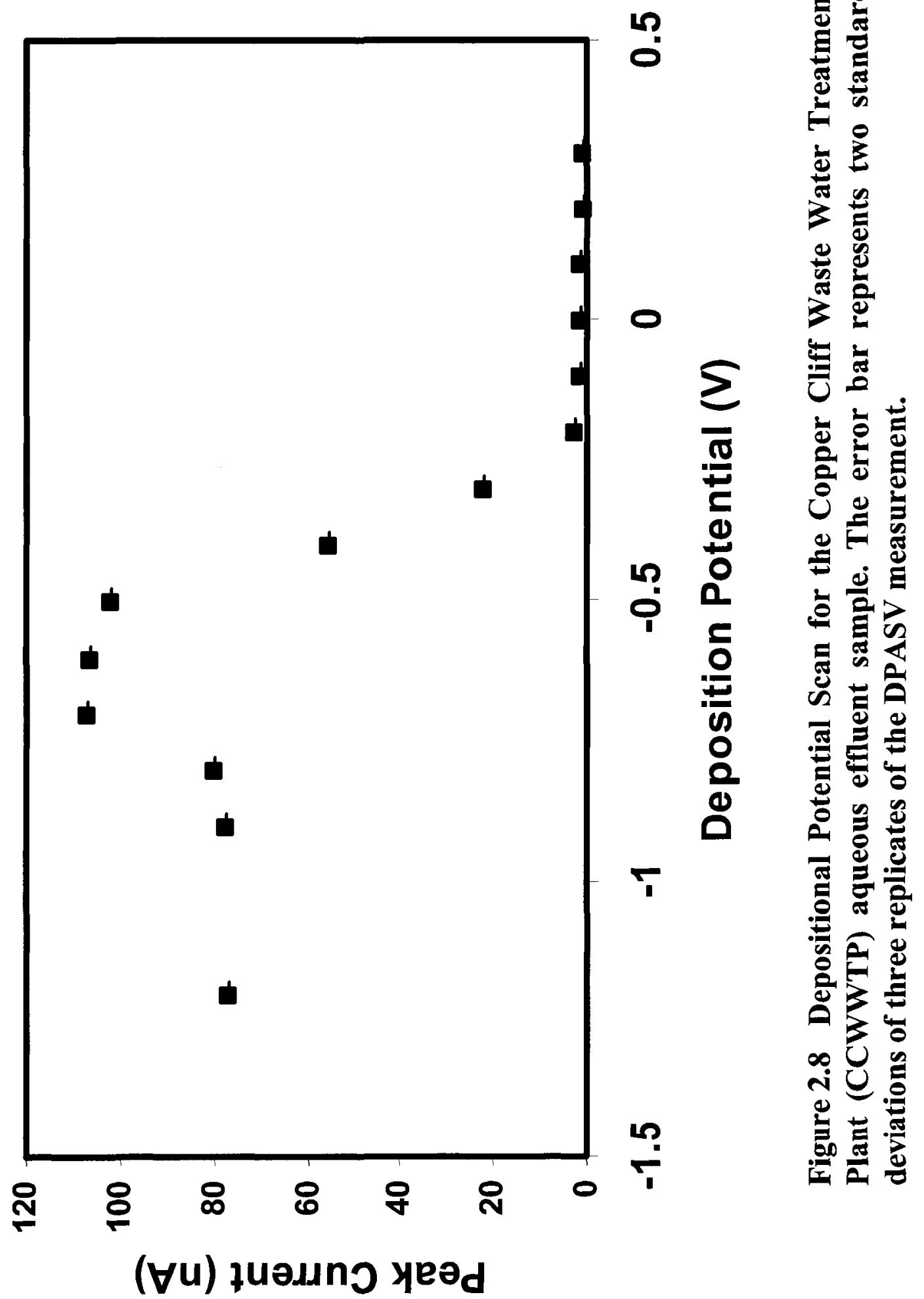




\section{$2.5 \quad$ References}

1. Dameron, C. et al. Copper. Environmental Health Criteria; 200 (1998) World Health Organization

2. Sunda, William G.; Hanson, Peter J. Chemical speciation of copper in river water. Effect of total copper, $\mathrm{pH}$, carbonate, and dissolved organic matter. $A C S$ Symposium Series (1979), 147-80.

3. Marina; Tartari, Gianni; Zirino, Alberto. Measurement and prediction of copper ion activity in Lake Orta, Italy. Environmental Science and Technology (1991), 25(4), 678-83.

4. Xue, HanBin; Sunda, William G. Comparison of $[\mathrm{Cu} 2+]$ Measurements in Lake Water Determined by Ligand Exchange and Cathodic Stripping Voltammetry and by Ion-Selective Electrode. Environmental Science and Technology (1997), 31(7), 1902-1909.

5. Henze, Guenter. Application of polarographic and voltammetric techniques in environmental analysis. NATO ASI Series, Series G: Ecological Sciences (1990), $391-408$.

6. Tercier-Waeber, M.-L.; Buffle, J. Submersible Online Oxygen Removal System Coupled to an in Situ Voltammetric Probe for Trace Element Monitoring in Freshwater. Environmental Science and Technology (2000), 34(18), 4018-4024.

7. Davison, W.; Zhang, H. In situ speciation measurements of trace components in natural waters using thin-film gels. Nature (1994), 367(6463), 546-8. 
8. Zhang, Hao; Davison, William. Performance Characteristics of Diffusion Gradients in Thin Films for the in Situ Measurement of Trace Metals in Aqueous Solution. Analytical Chemistry (1995), 67(19), 3391-400.

9. Marchand, Michel. Lab. Radioecol. Mar., Commis. Energ. At., Cherboug, Fr. Physicochemical forms of cobalt, manganese, zinc, chromium, and iron in a sea water with and without organic material. Journal du Conseil, Conseil International pour l'Exploration de la Mer (1974), 35(2), 130-42.

10. Batley, G. E.; Florence, T. M. Determination of the chemical forms of dissolved cadmium, lead and copper in seawater. Marine Chemistry (1976), 4(4), 347-63.

11. Florence, T.M.; Lumsden, B.G.; Fardy, J.J. Evaluation of some physicochemical techniques for the determination of the fraction of dissolved copper toxic to the marine diatom Nitzschia closterium. Analytica Chimica Acta (1983), 151(2), 28195.

12. Florence, T.M. Electrochemical approaches to trace element speciation in waters. A review. Analyst (1986), 111(5), 489-505.

13. Florence, T.M.; Mann, K.J. Anodic stripping voltammetry with medium exchange in trace element speciation. Analytica Chimica Acta (1987), 200(1), $305-12$.

14. Florence, T. Mark. Trace element speciation by anodic stripping voltammetry. Analyst (1992), 117(3), 551-3.

15. Morrison, G. M. P.; Florence, T. M.. Comparison of physicochemical speciation procedures with metal toxicity to Chlorella pyrenoidosa. Analytica Chimica Acta (1988), 209(1-2), 97-109. 
16. Lage, O.M.; Soares, H.M.V.M.; Vasconcelos, M.T.S.D.; Parente, A.M.; Salema, R. Toxicity effects of copper (II) on the marine dinoflagellate Amphidinium carterae: Influence of metal speciation. European Journal of Phycology (1996), $31,341-348$

17. Shuman, M.S. and Woodward Jr, G.P. Chemical constants of metal complexes from a complexometric titration followed with anodic stripping voltammetry Analytical Chemistry (1973), 45, 2032-2035

18. Shuman, M.S. and Woodward Jr., G.P. Stability constants of copper-organic chelates in aquatic samples Environmental Science and Technology (1977), 11, $809-812$

19. Mylon, S.E.; Twining, B.S.; Fisher, N.S.; and Benoit, G. Relating the Speciation of $\mathrm{Cd}, \mathrm{Cu}$, and $\mathrm{Pb}$ in Two Connecticut Rivers with Their Uptake in Algae. Environmental Science and Technology (2003), 37(7), 1261-1267

20. Town, Raewyn M., Filella, M. Crucial role of the detection window in metal ion speciation analysis in aquatic systems: the interplay of thermodynamic and kinetic factors as exemplified by nickel and cobalt Analytica Chimica Acta 466 (2002) $285-293$ 
-Chapter 3-

Investigation of copper speciation using Competing Ligand Exchange (CLE) method-Adsorptive Cathodic Stripping Voltammetry (AdCSV) with catechol 
ASV-metal titration method has a relatively long history; however, some technical problems still exist, which have made the method controversial [1]. For example, it is well known that the ASV-labile species is dependent on the reaction kinetics and the deposition potential. But there is no general rule for the operational procedure; for example, even for copper which is one of the most investigated metals in natural waters, there is no established operating protocol regarding the rotation rate or the deposition potential for the study of copper speciation using ASV. In order to get valid results, the deposition potential has to be carefully manipulated. In order to define the ASV-labile species, which means controlling (and hence, knowing) the thickness of the diffusion layer surrounding the working electrode, it is suggested that despite the poor reproducibility of a Rotating Disk Electrode (RDE), it should be used in preference to a Hanging Mercury Drop Electrode (HMDE) which gives an ill-defined diffusion layer [2, $3]$.

Competing Ligand Exchange (CLE) method coupled with Adsorptive Cathodic Stripping Voltammetry (AdCSV) has become a useful technique to determine both free metal ion concentration and the representative complexation parameters because of its high sensitivity and flexible detection windows [4-8]. The concentration of the metal complexes formed with the competing ligand is measured by AdCSV. By titrating the water sample with the metal, the free metal ion concentration and the representative complexation parameters can be obtained by chemical equilibrium calculation. However, 
there are some drawbacks inherent in the technique, such as the accuracy of analytical sensitivity $[6,9-11]$ and the limitation of the detection window [12-14].

The copper speciation in some freshwater samples, determined by CLE-AdCSV, is presented in this chapter.

\subsection{Theory}

\subsubsection{AdCSV and Square Wave AdCSV}

AdCSV has been applied for determination of metal and other chemical compounds since the 1970's. Preconcentration (deposition step) occurs when the surface-active metal complex ions adsorb onto the electrode. Then, a negative-going potential scan causes reduction of the electro-active complexes on the surface of the electrode (see Figure 3.1); hence, the concentrated metal complexes are stripped out of the electrode and they give rise to cathodic peak currents, whose heights are proportional to the concentration of surface-active, electro-active complex ions.

Square Wave (SW) offers advantages of sensitivity and speed over Differential Pulse (DP). The square wave form can be considered a special type of differential pulse wave form in which equal time is spent at the potential of the ramped baseline and the potential of the superimposed pulse (see Figure 3.2). The SW signal is the difference between the top and bottom of every SW. The differential current is plotted $v s$. the average potential to obtain the square wave polarogram. As a result, the square wave polarogram is peak shaped (see Figure 3.3). 


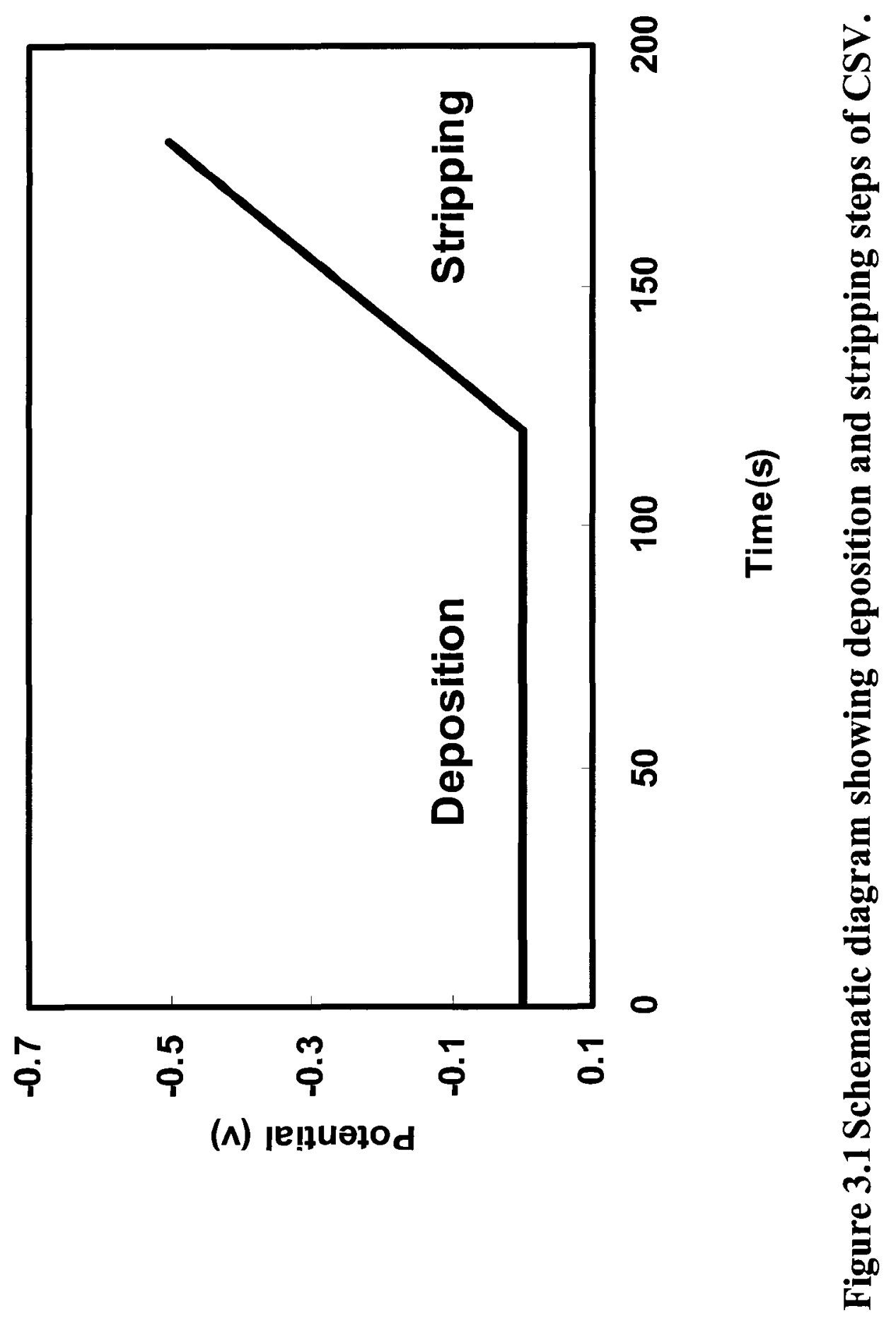




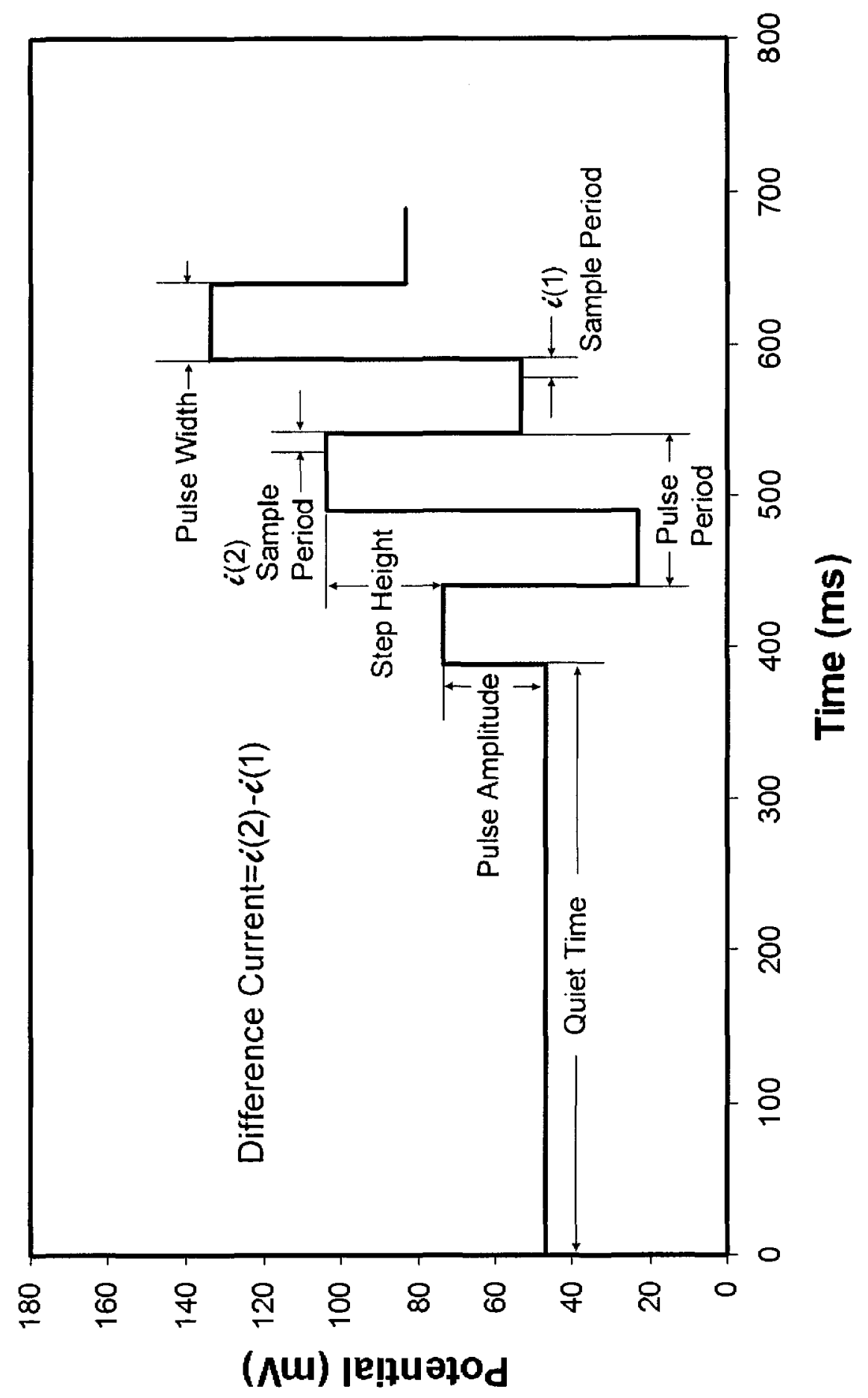

 


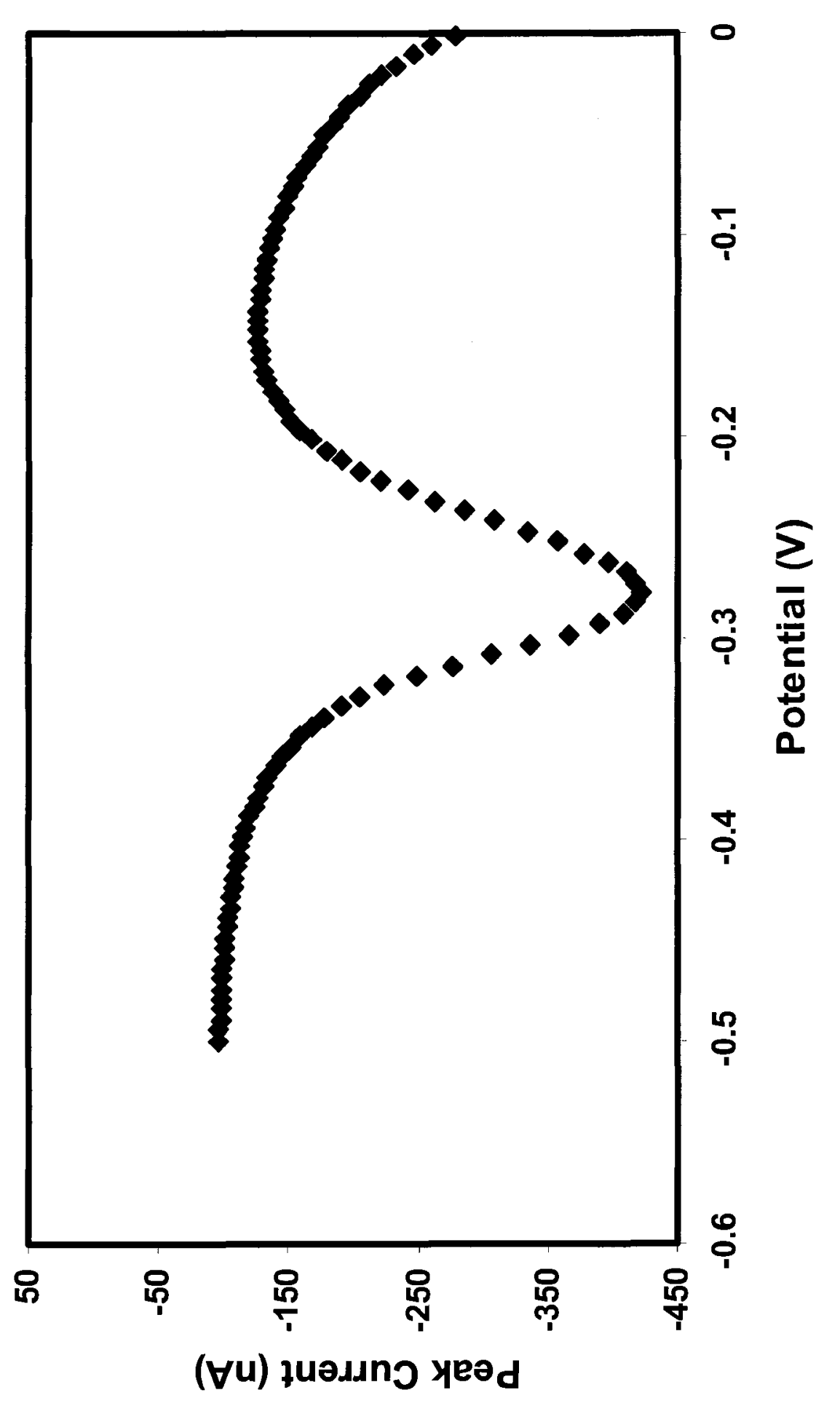

昜

㐫

๘

.झ

过



i

용 흥 흥

-

E

药

일

क के

$\sum_{\infty} \quad \stackrel{0}{3}$

m 


\subsubsection{Competing Ligand Exchange (CLE) Method}

The theory of ligand competition has been presented in great details in numerous papers $[4-8,10]$. It is based on the mass balance:

$[M]_{T}=\left[M^{2+}\right]+\left[M L_{I N}\right]+\left[M L_{A}\right]+\left[M L_{i}\right]$

where $[\mathrm{M}]_{\mathrm{r}}$ is the total metal concentration, copper in this case; $\left[\mathrm{M}^{2+}\right]$ is the free metal ion concentration; $\left[\mathrm{ML}_{\mathrm{IN}}\right]$ is the concentration of metal complexed by $\mathrm{L}_{\mathrm{IN}}$, the major inorganic ligands such as $\mathrm{OH}^{-}, \mathrm{Cl}^{-}$and $\mathrm{CO}_{3}{ }^{2-} ; \quad\left[\mathrm{L}_{\mathrm{A}}\right]$ is the concentration of added competing ligand, which is usually a well-characterized metal chelating ligand, catechol in this case; $\left[\mathrm{ML}_{\mathrm{i}}\right]$ is the concentration of metal complexed by natural organic ligand, $\mathrm{L}_{\mathrm{i}}$. $\alpha_{A}$ is the complexing coefficient of $L_{A}$, sometimes called "detection window" $[13,14]$ and defined as follows:

$\left.\alpha_{A} \equiv\left[M L_{A}\right]\right] /\left[M^{2+}\right]=K_{M L A} \cdot\left[L_{A}\right]$

$\mathrm{K}_{\mathrm{MLA}}$ is the conditional stability constant of the complex $\mathrm{ML}_{\mathrm{A}}$.

In the metal titration experiment, the concentration of the total metal, i.e. the original metal in the sample plus the metal added as spikes, is usually kept much lower than the concentration of the added competing ligand. The concentration of the competing ligand can be regarded as constant since the consumed portion of the competing ligand is much smaller than the total concentration of the competing ligand. Consequently, $\alpha_{A}$ can be regarded as constant during the metal titration.

The following mass balance,

$$
\left[M L_{i}\right]=[M]_{T}-\left[M^{2+}\right]-\left[M L_{I N}\right]-\left[M L_{A}\right]
$$


$\mathrm{M}^{2+}, \mathrm{ML}_{\mathrm{IN}}$ and $\mathrm{ML}_{\mathrm{A}}$ all usually contribute to the analytical determination. But with much higher $\alpha_{A},\left[\mathrm{M}^{2+}\right]$ and $\left[\mathrm{ML}_{\mathrm{IN}}\right]$ are negligible most of the time. $\left[\mathrm{ML}_{\mathrm{A}}\right]$ is calculated from the analytical determination as follows:

$\left[M L_{A}\right]=i_{p} / S$

And $\left[\mathrm{M}^{2+}\right]$ is calculated as follows:

$\left[M^{2+}\right]=i_{p} /\left(S \alpha_{M L A}\right)$

where $i_{p}$ is the AdCSV peak current; $\mathrm{S}$ is the analytical sensitivity of the $\mathrm{ML}_{\mathrm{A}}$, which is traditionally determined using the slope of the linear response part of the calibration curve. Then, the conditional stability constant for the metal complexation by natural organic ligand $\mathrm{K}_{\mathrm{MLi}}$, and the concentration $\left[\mathrm{L}_{\mathrm{i}}\right]$ can be extracted from the $\left[\mathrm{ML}_{\mathrm{i}}\right]$ and $\left[\mathrm{M}^{2+}\right]$ data set using any of the several data fitting techniques, such as van den Berg-Ruzic plot, Scatchard plot, or FITEQL program.

\subsection{Experimental}

\subsubsection{Sampling location and sampling protocol}

Freshwater samples were collected by Lisa Kraemer (Université du Quebec) from three lakes, Lake Dufault, Lake Osisko and Lake Opasatica, in Rouyn-Noranda area, northwestern Quebec, Canada $\left(48^{\circ} 00^{\prime} \mathrm{N}, 7^{\circ} 00^{\prime} \mathrm{W}\right)$, in June and August 2003. These sites had been impacted by current and historical metal mining operations (see Figure 2.4). Because of their downwind location, Lake Osisko and Lake Dufault had been contaminated by atmospheric deposition from the mining operation. Lake Osisko received also liquid effluents direct from the smelting operations in the past. Lake 
Opasatica was less contaminated because of its upwind location, and was usually used as a control site.

The sampling protocol has been described in Chapter 2.3.1.

The experimental procedure was originally detailed by van den Berg [4]. This experiment followed mainly a slightly modified version by Hanbin Xue and Laura Sigg [15]. The details are described as follow:

\subsubsection{Reagents}

ICP-MS \& ICP-AES standard solution $(1000 \mu \mathrm{g} / \mathrm{ml})$ of $\mathrm{Cu}(\mathrm{II})$ was purchased from SCP Science, Montreal, Canada. Ultrapure water having resistivity of $18.2 \mathrm{M} \Omega . \mathrm{cm}$ was obtained direct from a Milli-Q-Plus water purification system (Millipore Corporation). A $2 \mathrm{M}$ stock solution of potassium nitrate, a $2 \mathrm{M}$ stock solution of $\mathrm{N}-2$ Hydroxyethylpiperazine-N'-2-ethanesulphonic Acid (HEPES) and a 2 M stock solution of sodium hydroxide solution were prepared by dissolving an appropriate quantity of potassium nitrate (Aldrich) or HEPES (Sigma) or sodium hydroxide (Aldrich) in ultrapure water. The potassium nitrate, the HEPES and the sodium hydroxide solution were then purified separately by mercury-cathode electrolysis at $-1.5 \mathrm{~V} v$ s. SCE for at least $48 \mathrm{~h}$ immediately prior to their use. To prevent the impurity metal from returning to the sample solution, the purified solution was removed while the electrolysis was going on. All the final test solutions contained $0.01 \mathrm{M}$ potassium nitrate, $6 \mathrm{mM}$ MOPS and appropriate amount of sodium hydroxide for adjusting the $\mathrm{pH}$. A $0.1 \mathrm{M}$ stock solution of 
catechol was prepared everyday by dissolving an appropriate quantity of catechol (Aldrich).

\subsubsection{Apparatus}

Voltammetric measurements were made with a computer-controlled Autolab PGSTAT 30 potentiostat/galvanostat (Eco. Chemie BV, The Netherlands) in conjunction with a Metrohm 663 VA stand (Metrohm, Switzerland). The working electrode was a Hanging Mercury Drop Electrode (HMDE, Metrohm, Switzerland). The reference electrode was $\mathrm{Ag} / \mathrm{AgCl}$ electrode in a glass tube filled with $3 \mathrm{M} \mathrm{KCl}$ and fitted with a porous Vycor tip

(Bioanalytical Systems, Inc., USA). The counter electrode was made of a platinum rod (Metrohm, Switzerland). Analysis of current peaks was done using the General Purpose Electrochemical Software v4.9 (Eco Chemie BV, The Netherlands). The data were transferred to a Pentium computer and saved for processing. All the AdCSV analyses were performed in the same Teflon working cell to ensure reproducibility.

\subsubsection{Electrochemical parameters}

For all the AdCSV measurement, the following experimental conditions were used: purging with $\mathrm{N}_{2}$ for 5 minutes; after spiking catechol solution, purging with $\mathrm{N}_{2}$ for another 1 minute and equilibrating for 5 minutes; $\mathrm{Cu}$-catechol complexes were deposited at the HMDE for 30 seconds at deposition potential of $-0.05 \mathrm{~V}$ (with stirring) and then equilibrating for 15 seconds; For all the stripping steps, the experimental conditions were: initial potential $0.1 \mathrm{~V}$, end potential $-0.7 \mathrm{~V}$, scan rate $0.2 \mathrm{~V} / \mathrm{s}$, with a square wave mode. 
All the voltages used in this study are reported with respect to the $\mathrm{Ag} / \mathrm{AgCl}$ reference electrode.

\subsubsection{Selection of the optimal concentrations of the competing ligand}

The criteria and method of selecting the optimal concentrations of the competing ligand were detailed by HanBin Xue and Laura Sigg [12]. The details are discussed in Chapter 3.4.1.

Different series of Teflon cells, each containing $20 \mathrm{~mL}$ of the lake freshwater sample, were spiked with different concentrations of catechol, and the test solutions were determined by AdCSV. In order to get more readable AdCSV signals, all the Lake Opasatica freshwater samples were spiked with 250nM copper.

\subsubsection{Copper titration of the collected freshwater samples}

To obtain the copper titration curve, different series of Teflon cells, each containing 20 $\mathrm{mL}$ lake freshwater sample, were spiked with different concentrations of copper, with the highest spiking being $1.57 \mu \mathrm{M}(100 \mathrm{ng} / \mathrm{mL})$. Different series then were spiked with appropriate amounts of the electrolyte and the $\mathrm{pH}$ buffers for adjusting $\mathrm{pH}$ in order to mimic that of the original Lake freshwater samples. After equilibration for 24 hours, the $\mathrm{pH}$ was rechecked in order to make adjustments in case of any small $\mathrm{pH}$ shift following by the AdCSV determination.

\subsection{Results and discussions}




\subsubsection{Selection of the optimal concentrations of the competing ligand}

Figure 3.4-3.6 present the catechol titration curves for the three lake samples, collected in June, 2003. The optimal catechol concentrations were chosen from the steeply rising portion of the titration curves, as described below: for Lake Dufault sample, the concentration was from $1 \times 10^{-5} \mathrm{M}$ to $4 \times 10^{-5} \mathrm{M}$; for Lake Osisko sample, the catechol concentration was from $1 \times 10^{-4} \mathrm{M}$ to $4 \times 10^{-4} \mathrm{M}$; for Lake Opasatica sample, the catechol concentration was the same as that for Lake Osisko sample, from $1 \times 10^{-4} \mathrm{M}$ to 4 $\times 10^{-4} \mathrm{M}$, although the AdCSV signal was much lower. At the optimal concentration, catechol competes with the natural organic ligands and forms complex which could be accurately measured, by binding about $20-80 \%$ of the total copper. If the concentration of catechol is too low, the formed complexes may not be accurately measured. If the concentration of catechol is too high, the added catechol may outcompete all the natural organic ligands for copper so that the titration curve is almost linear, which leads to erroneous results.

From Figure 3.4-3.6, some information about the complexation capacity of natural organic ligands can be extracted. The comparison of the three graphs shows much stronger complexation by natural organic ligands in the Lake Dufault freshwater sample than in the Lake Opasatica freshwater sample and in the Lake Osisko freshwater sample, since with the same concentration of catechol, the peak current of Lake Dufault sample was the lowest, i.e. the least copper was released from natural organic complexes, although there was a high total concentration of copper in the Lake Dufault sample. Since the catechol titration is basically a ligand complexation experiment, the steeply-rising 
curve for Lake Dufault sample indicates presence of a narrow range of natural organic ligands, while the slowly-rising curves of Lake Osisko and Lake Opasatica samples indicate presence of a large distribution of natural organic ligands.

\subsubsection{Copper titration for the collected freshwater samples}

Figure 3.7 presents the copper titration curves for the three lake freshwater samples, collected in June, 2003, which provides valuable information on the labile copper species turnout if the bulk solution receives large metal input. Figure 3.7 shows that when the total copper concentration is high $(>300 \mathrm{nM})$, the concentration of copper-catechol complex in Lake Osisko sample is the highest, while in Lake Opasatica sample the second-highest, and in Lake Dufault the lowest. Figure 3.8 presents an example of data analysis by FITEQL, which shows that the calculated concentrations of copper free ion and total copper natural organic complex using one-ligand model by FITEQL can fit the experimental data very well.. Table 3.1 presents general chemical information on the six lake freshwater samples. Table 3.2 presents the copper speciation parameters determined by CLE-AdCSV.

The concentrations of free copper ion were found to be significantly higher in Lake Dufault freshwater sample than in Lake Opasatica freshwater sample, $1.94 \mathrm{nM}$ vs. 0.86 $\mathrm{nM}$ in June, 2003, while $0.47 \mathrm{nM}$ vs. $0.39 \mathrm{nM}$ in August, 2003. These results were consistent with the geographical locations of the two lakes: Lake Dufault was nearer to and directly downwind from the smelter, whereas Lake Opasatica was further away and 
upwind from the smelter. The copper speciation in Lake Osisko was more complicated because of the effluents it had received and the possible treatment.

By comparing the experimental results with the WHAM VI prediction in Figure 3.9, it is clear that WHAM VI predicts much lower free copper concentrations. But the differences are usually within one order of magnitude. The discrepancy may be due to the deficiencies of WHAM model, or of CLE-AdCSV. But the limit of the detection window for CLE-AdCSV methodology certainly hinders an accurate determination, which will be tackled in the next Chapter.

The problem arising from the ASV techniques is that strong metal complexes are not easy to detect by ASV because of the generally very low peak currents (and poor successive peak resolution) in the corresponding range of metal additions, and that the experimental titration curve is influenced more by weaker complexes. Because of the higher sensitivity of AdCSV and the competition between the strong copper-binding catechol and the natural organic ligand for binding copper, CLE-AdCSV has a potential to detect strong copper-binding natural organic ligand. From the comparison between Table 3.2 and Table 2.4, it found that CLE-AdCSV does indeed detect stronger natural organic ligand.

In this study, the detection window when using catechol is $10^{2}-10^{3}$. The importance of detection window has been discussed in many studies $[13,16-18]$. The determined complexation capacity of natural organic ligand is statistically proven to be dependent on the detection window. Therefore, to fully represent the natural organic ligands, a large range of detection window should be applied. 


\subsection{A baffling question}

The basic reaction on the surface of the Hanging Mercury Drop Electrode (HMDE) in the copper-catechol system during CSV determination has been regarded as the adsorption of $\mathrm{CuL}_{2}$ complex ion (i.e. complex containing one copper and two catechol), followed by the reduction of the copper ion, i.e. only $\mathrm{CuL}_{2}$ complex ion is CSV-labile [19]. This postulation has been based on the exponential increase of the peak current with the increase in catechol concentration until the curve reaches a plateau, similar to the distribution of $\mathrm{CuL}_{2}$ complex ion (as presented in Figure 2 of van den Berg's paper [19]). But the preliminary experiments in this work showed a little contradiction.

For catechol titration in the copper model solution with $100 \mathrm{nM}$ copper, the theoretical distribution of $\mathrm{CuL}_{2}$ complex ion at different $\mathrm{pH}$ is illustrated in Figure 3.10. If $\mathrm{CuL}_{2}$ complex ion is the single source for CSV signal, as is the general understanding, the curves for the concentrations of $\mathrm{CuL}_{2}$ complex ion at different $\mathrm{pH}$ in Figure 3.10 should also resemble the curves of the CSV signal under the same experimental conditions. But the preliminary experiment showed a different result, as illustrated in Figure 3.11. The real CSV signal seems higher than it should be at lower $\mathrm{pH}$ compared to the higher $\mathrm{pH}$, although the shape of the CSV signal is consistent with Figure 3.10. Another preliminary experiment of the deposition potential scan showed that change in the deposition potential (from $0.2 \mathrm{~V}$ to $-1.0 \mathrm{~V}$ ) did not change the CSV signal (Figure 3.12), which probably means that the adsorptive species has no charge, which is contradictive of the nature of $\mathrm{CuL}_{2}$ complex ion. 
One hypothesis for the reaction on the surface of the HMDE for the copper-catechol system during CSV determination is that the CSV-labile $\mathrm{CuL}_{2}$ complexes contain (or adsorb) two more hydrogen ions and is neutral. After the neutral complexes are formed, they compete with catechol molecules for the adsorption on the surface of the HMDE, which makes the decreasing part of the catechol titration curve possible. Unfortunately, the mathematical calculation cannot prove this hypothesis. The exact mechanism of CSV determination in copper-catechol system needs further investigation. 

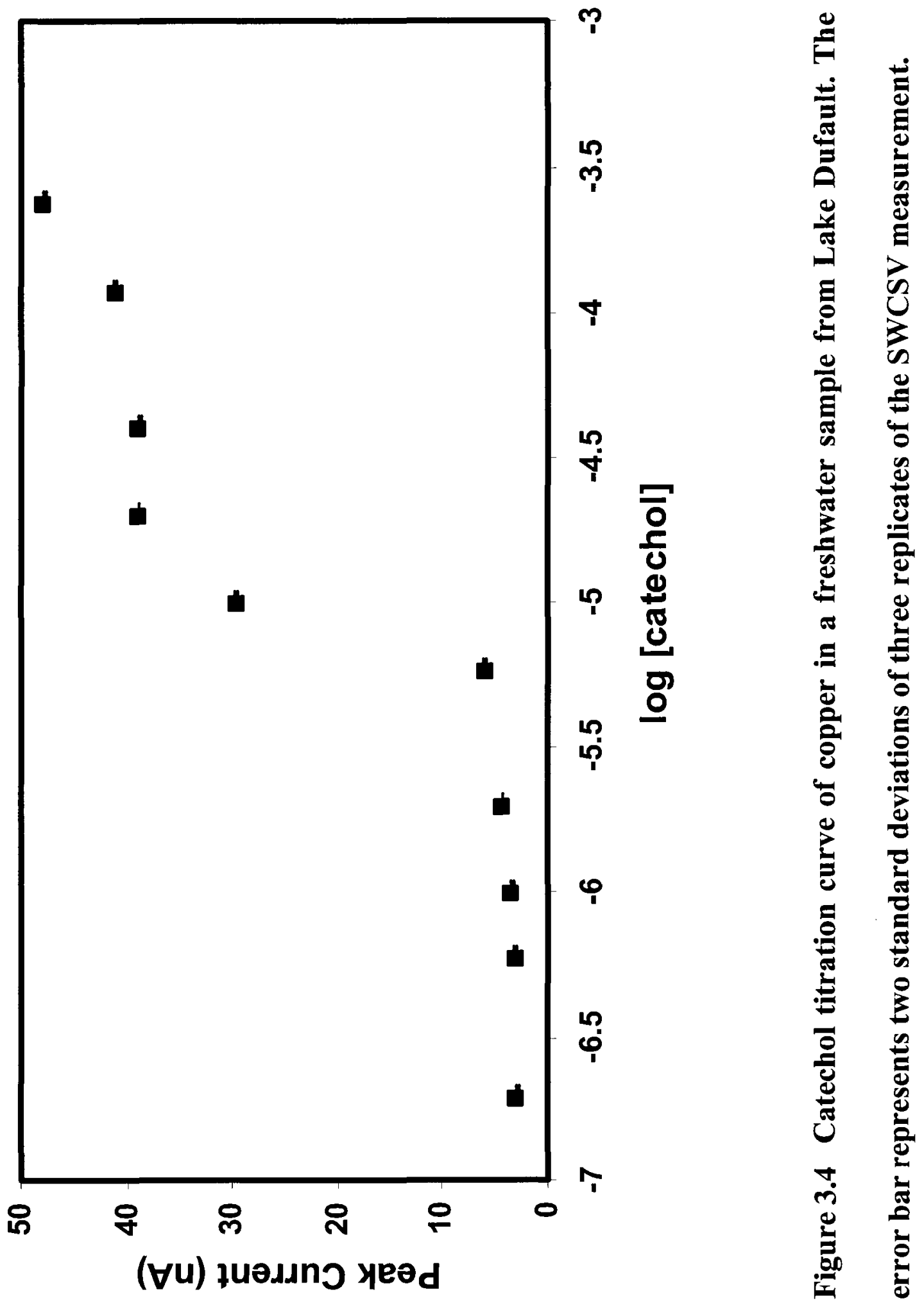

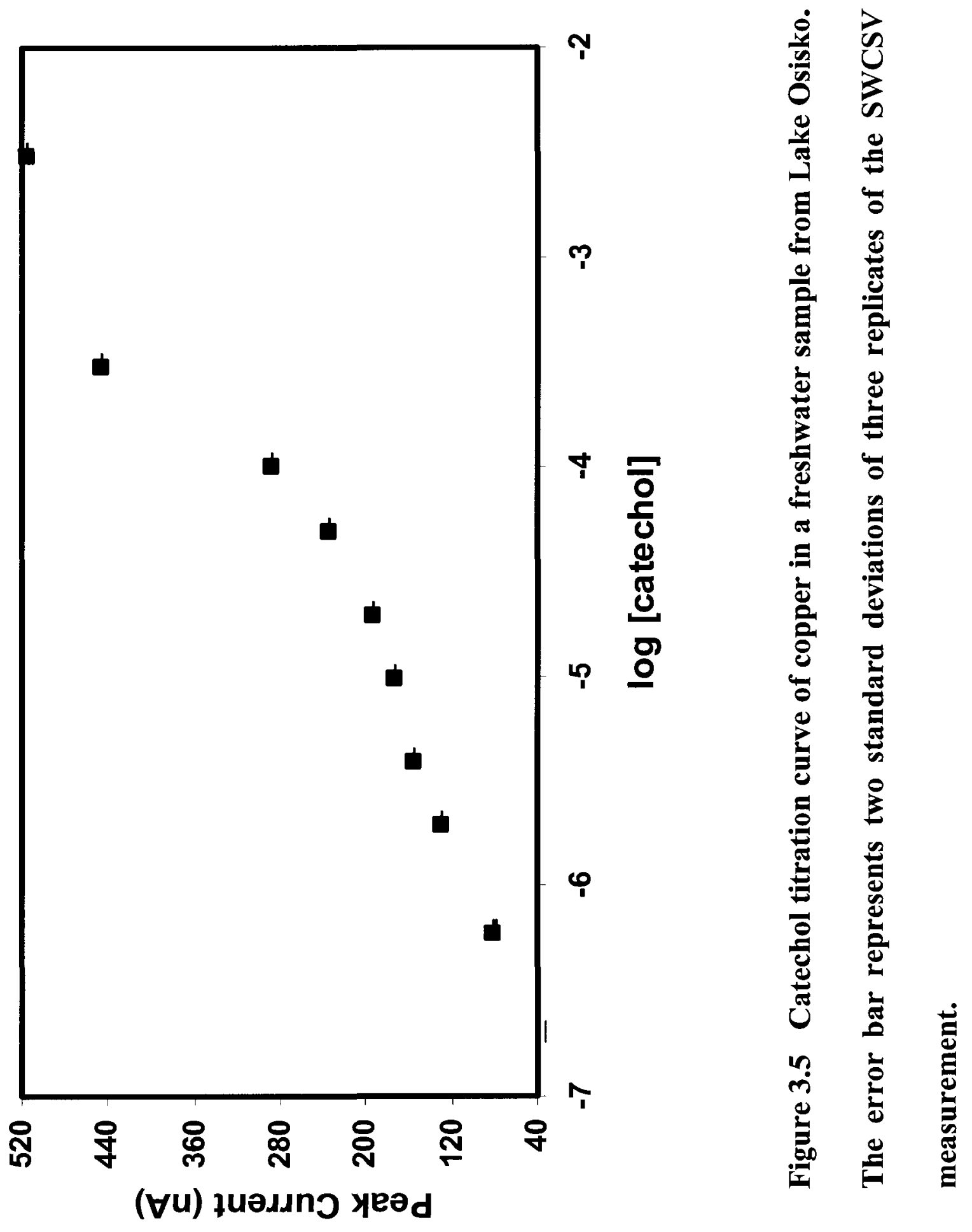

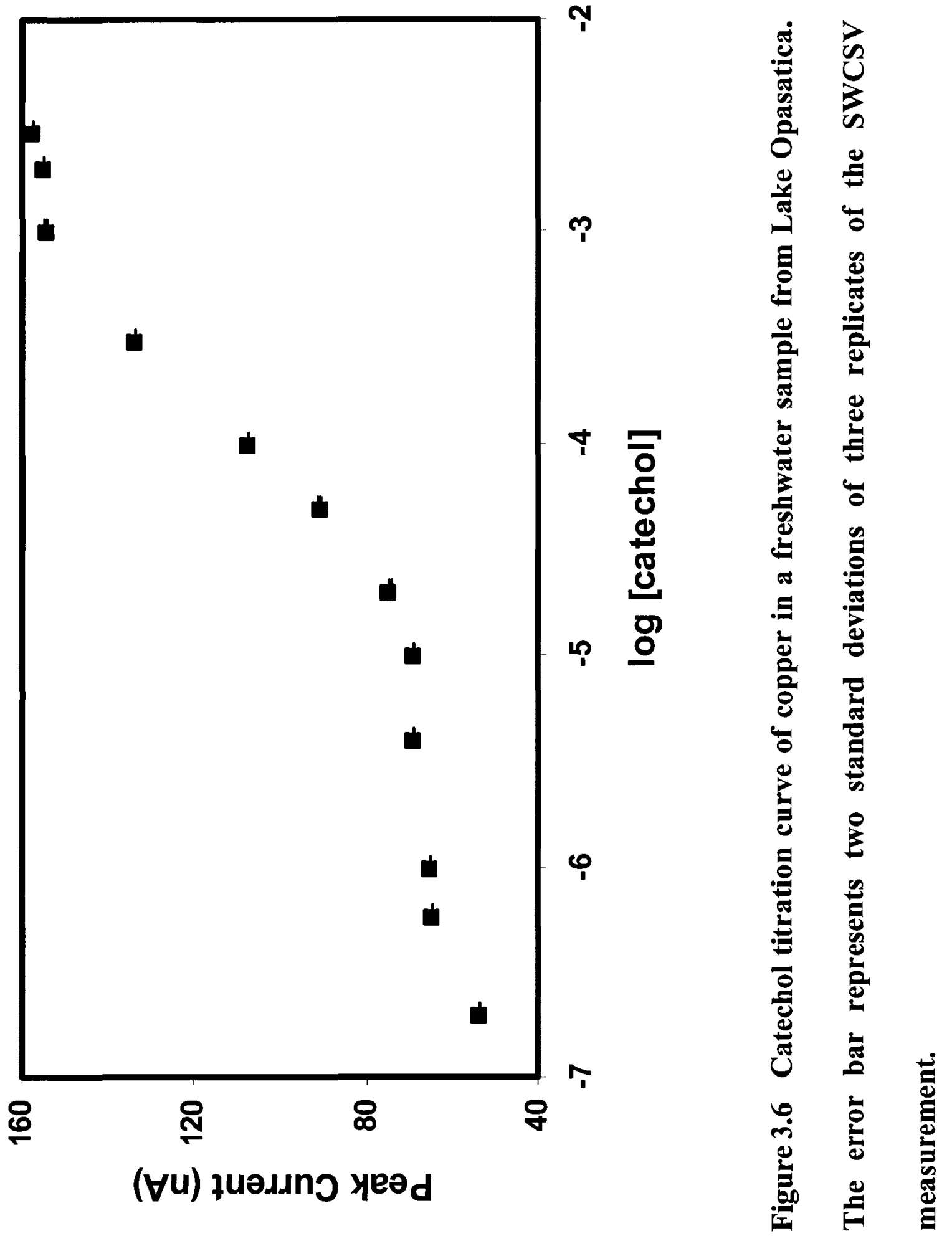

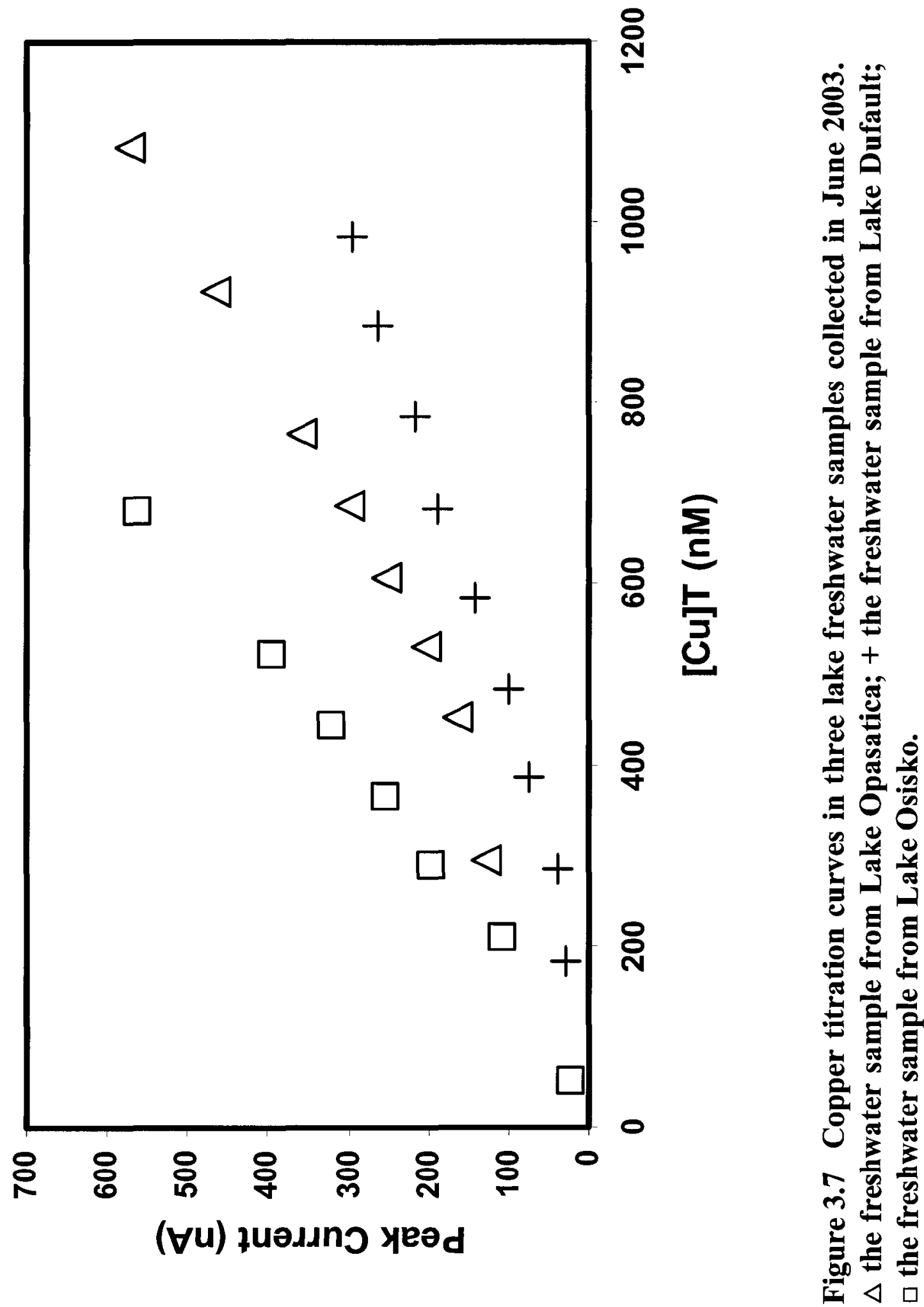

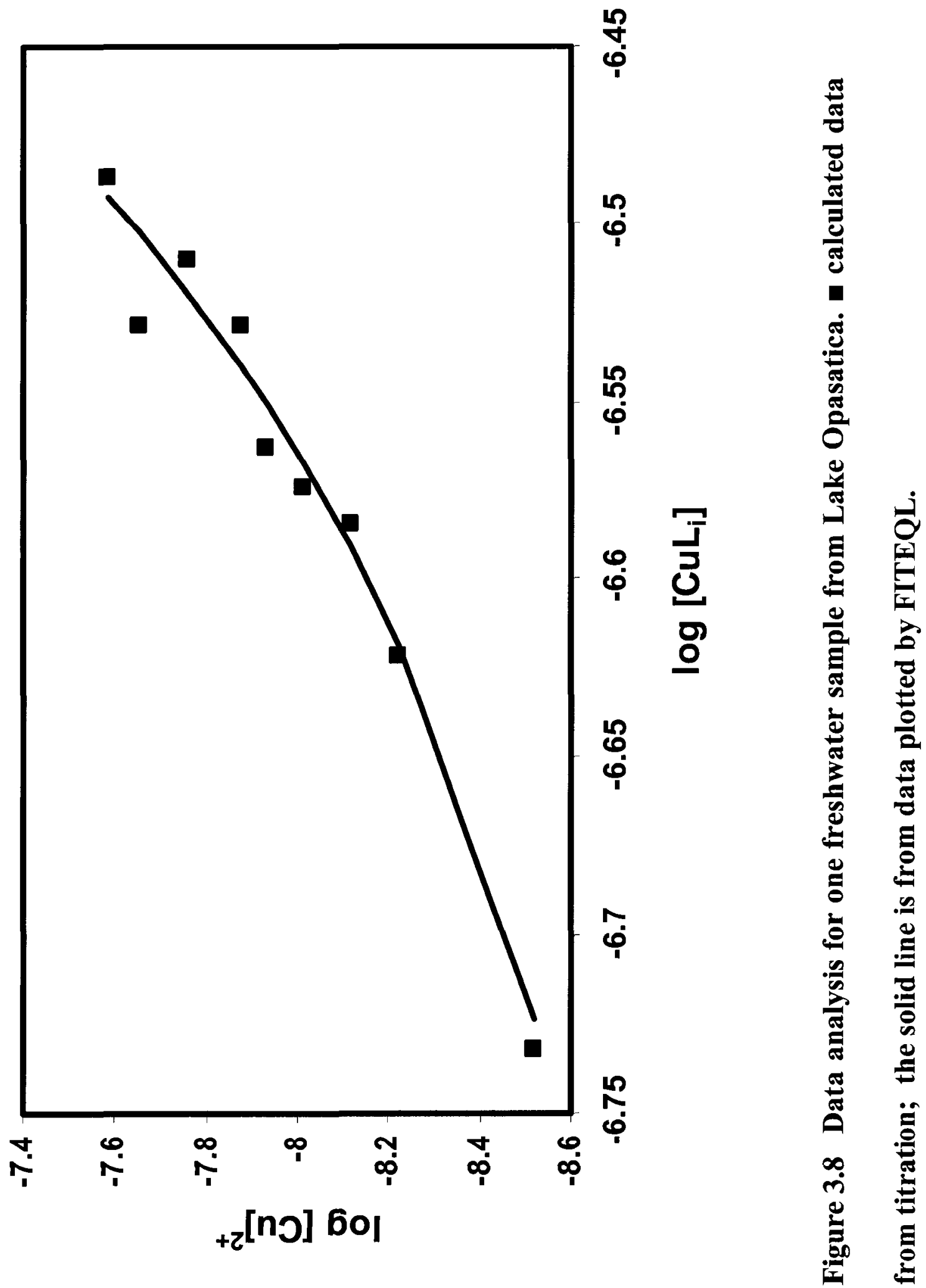


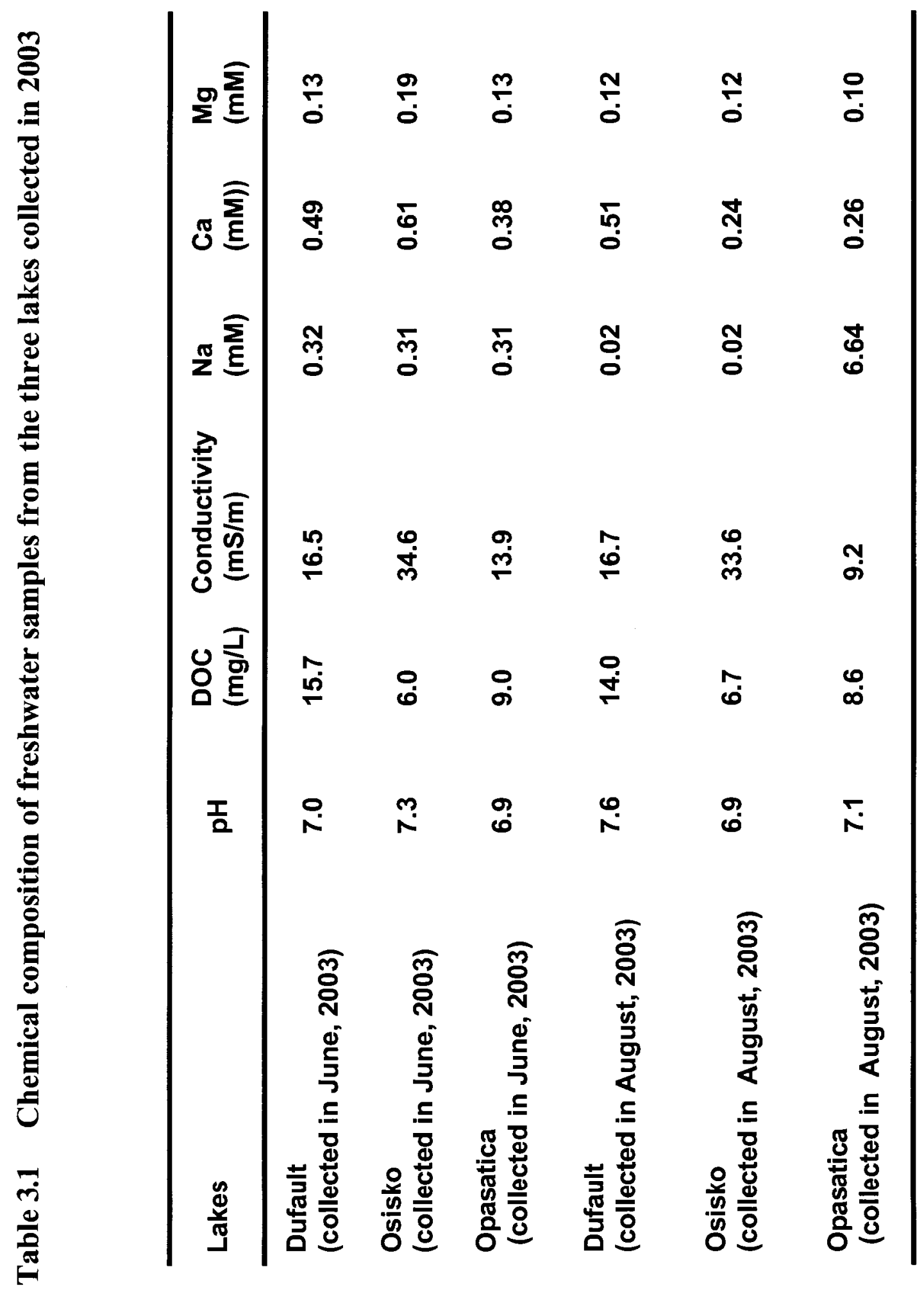




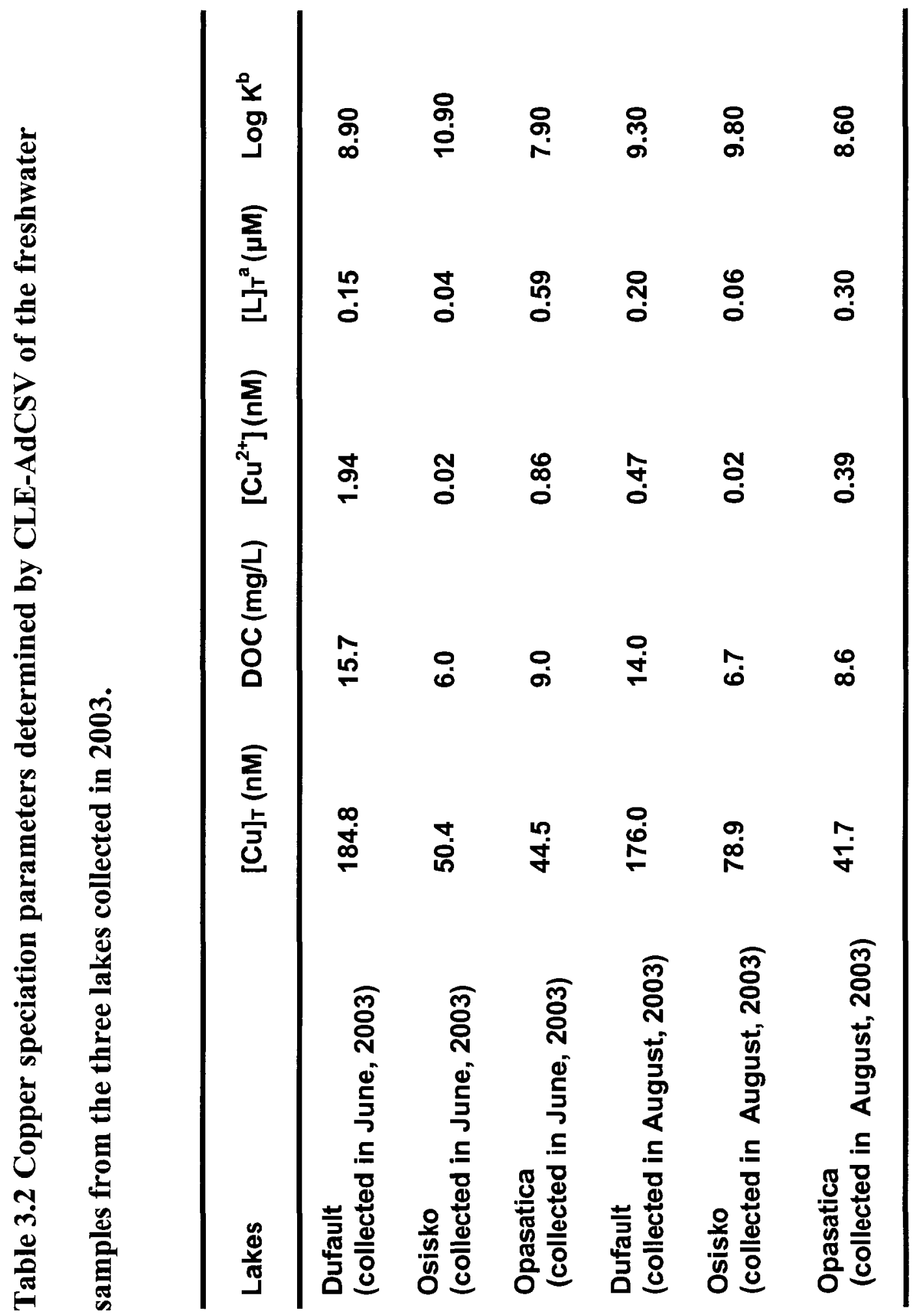



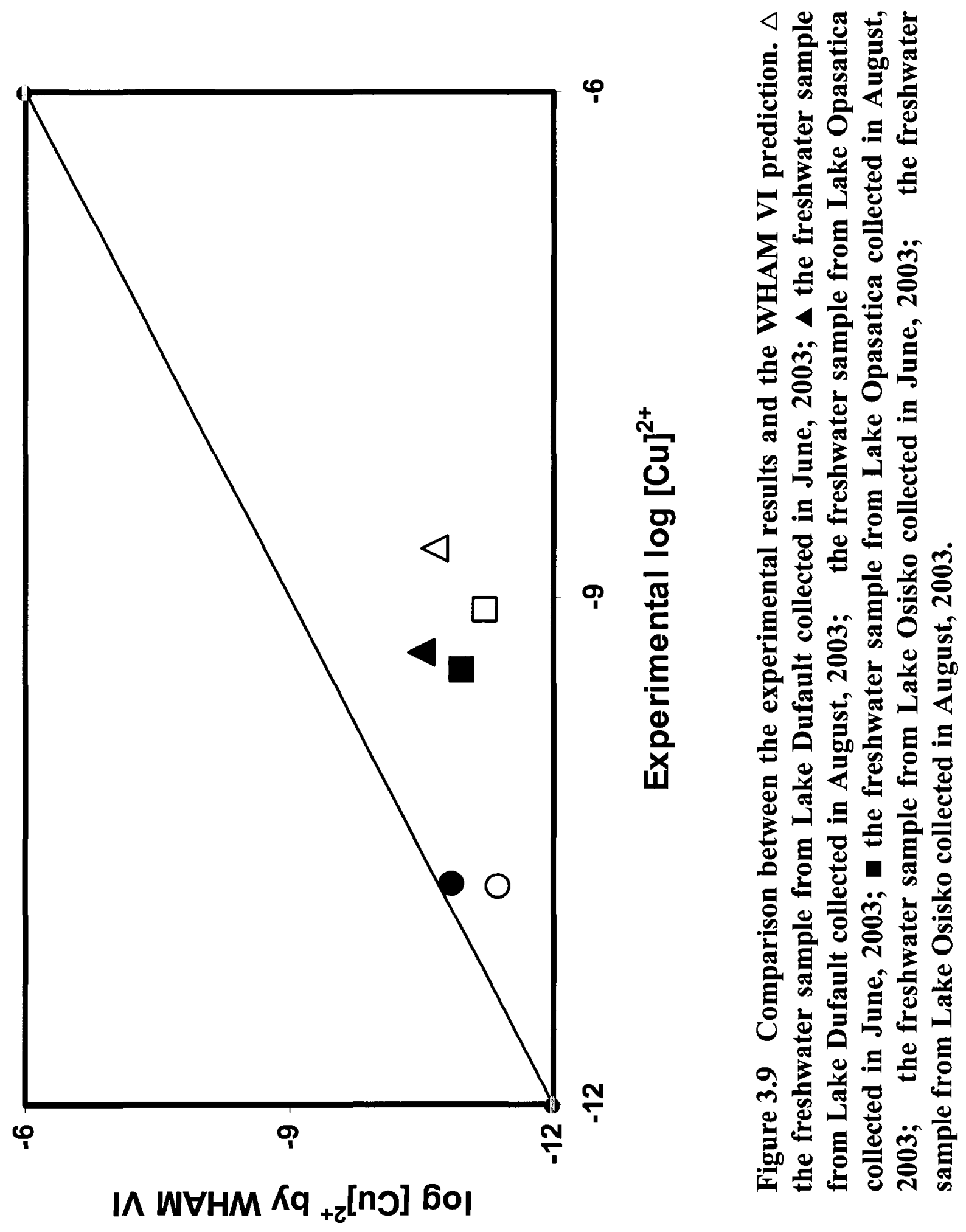

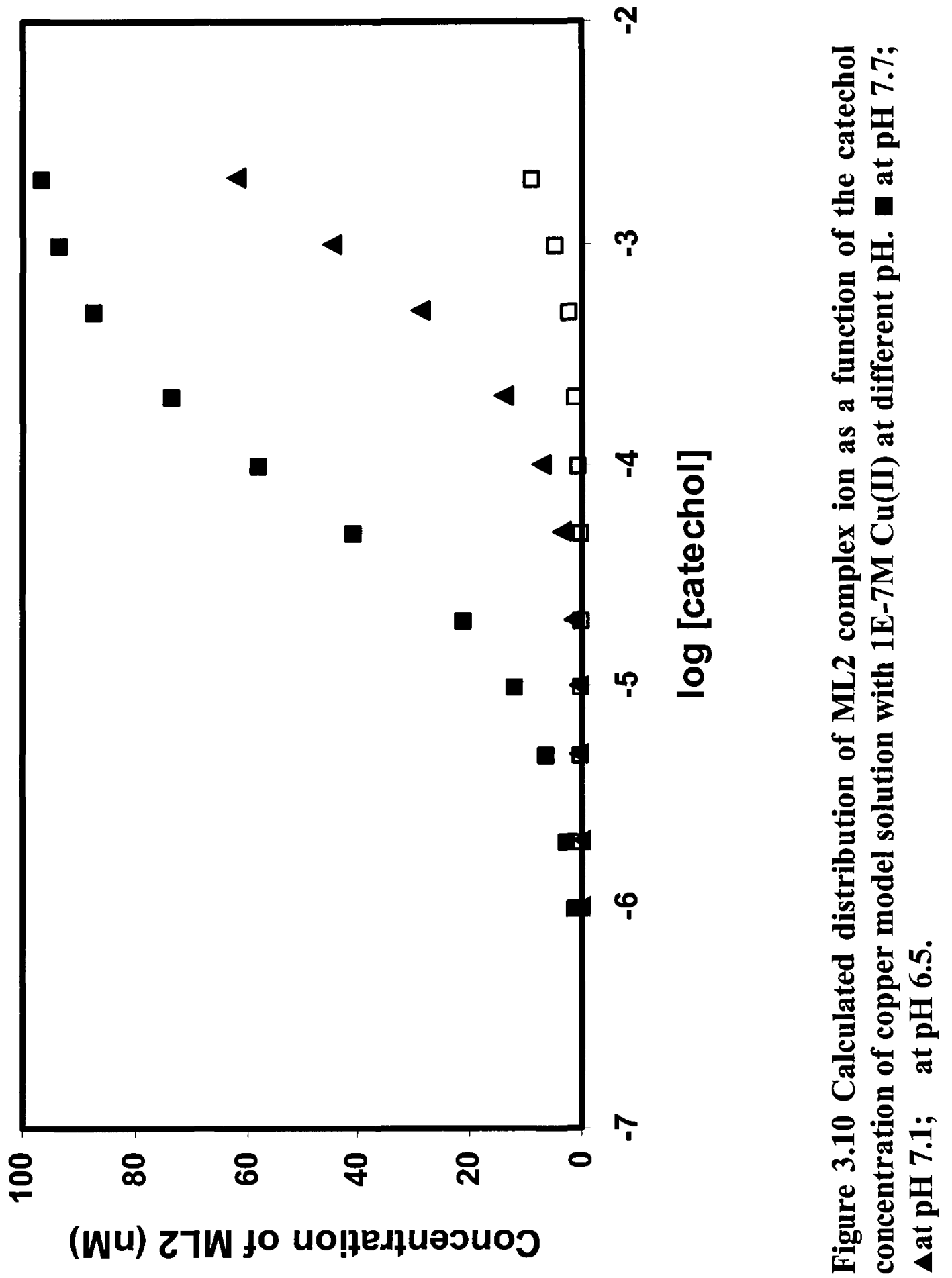

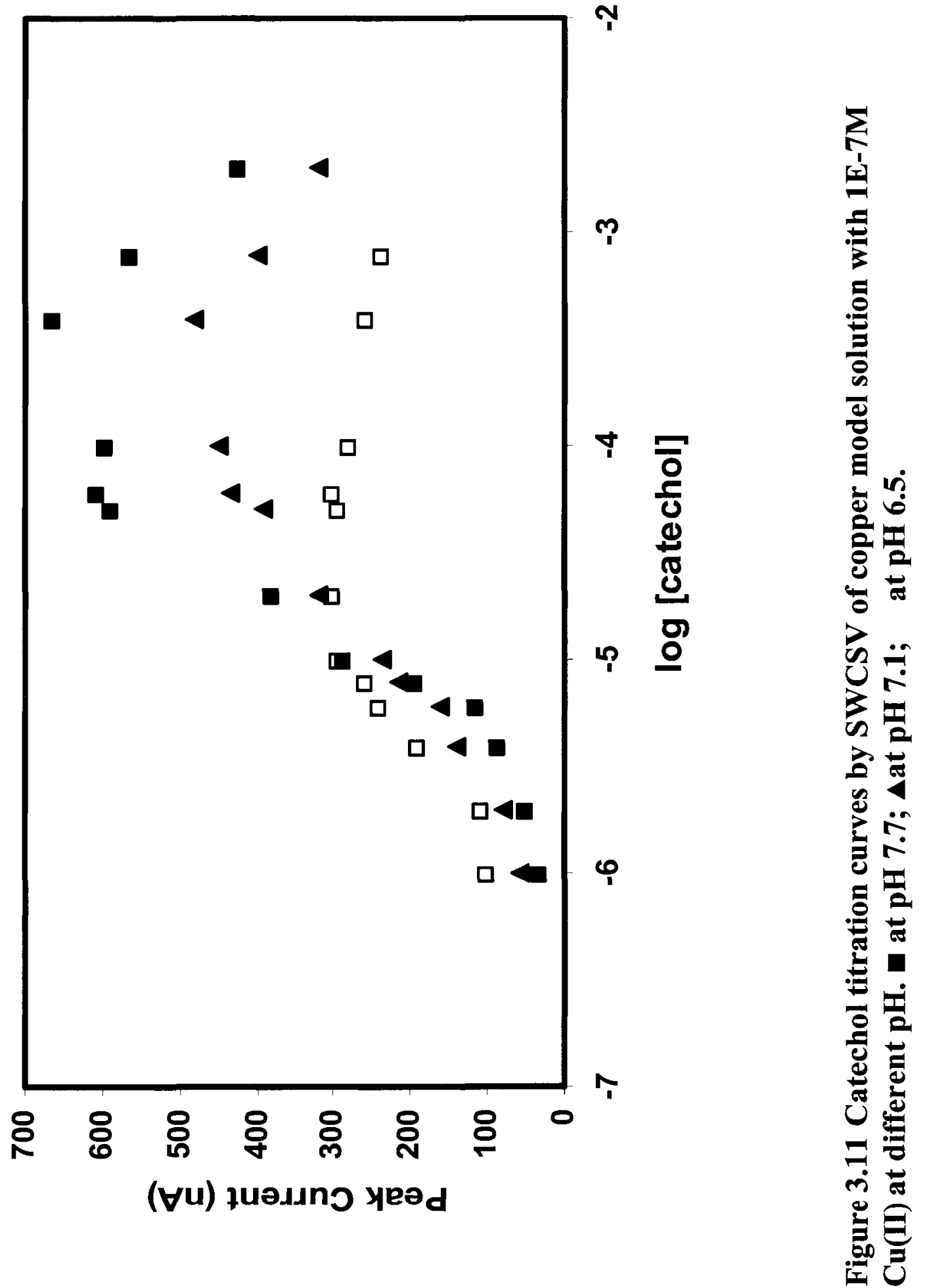


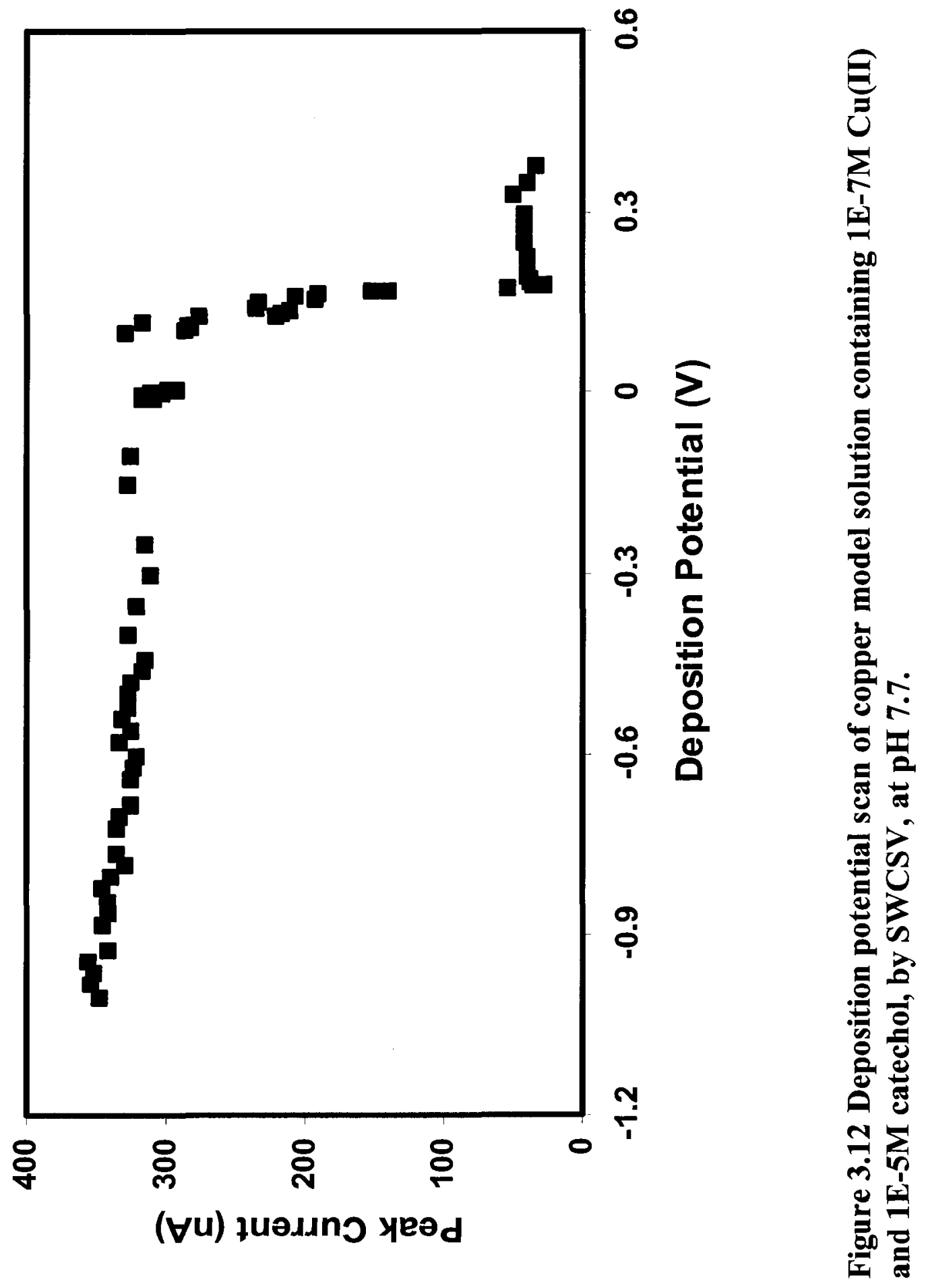




\subsection{References}

1. Tuschall, John R., Jr.; Brezonik, Patrick L. Evaluation of the copper anodic stripping voltammetry complexometric titration for complexing capacities and conditional stability constants. Analytical Chemistry (1981), 53(13), 1986-9.

2. Coale, Kenneth H.; Bruland, Kenneth W. Copper complexation in the Northeast Pacific. Limnology and Oceanography (1988), 33(5), 1084-1101

3. Donat, John R.; Lao, Kathy A.; Bruland, Kenneth W. Speciation of dissolved copper and nickel in South San Francisco Bay: a multi-method approach. Analytica Chimica Acta (1993), 284(3), 547-71.

4. Van den Berg, C.M.G. Determination of the complexing capacity and conditional stability constants of complexes of copper(II) with natural organic ligands in seawater by cathodic stripping voltammetry of copper-catechol complex ions. Marine Chemistry (1984), 15, 1-18

5. Van den Berg, Constant M. G. Determination of copper, cadmium and lead in seawater by cathodic stripping voltammetry of complexes with 8hydroxyquinoline. Journal of electroanalytical chemistry (1986), 215, 111-121

6. Lucia, M.; Campos, A.M.; van den Berg, Constant M.G. Determination of copper complexation in sea water by cathodic stripping voltammetry and ligand competition with salicylaldoxime. Analytica Chimica Acta (1994), 284, 481-496

7. Donat, John R.; Van den Berg, Constant M. G.. A new cathodic stripping voltammetric method for determining organic copper complexation in seawater. Marine Chemistry (1992), 38(1-2), 69-90. 
8. Moffett, James W. Temporal and spatial variability of copper complexation by strong chelators in the Sargasso Sea. Deep Sea Research (1995), 42, 1273-1295

9. Turoczy, N. J.; Sherwood, J. E. Modification of the van den Berg/Ruzic method for the investigation of complexation parameters of natural waters. Analytica Chimica Acta (1997), 354, 15-21.

10. Kogut, M. B.; Voelker, B. M. Strong Copper-Binding Behavior of Terrestrial Humic Substances in Seawater. Environmental Science and Technology (2001), $35,1149-1156$

11. Voelker, B. M.; Kogut, M. B. Interpretation of metal speciation data in coastal waters: the effects of humic substances on copper binding as a test case. Marine Chemistry (2001), 74, 303-318

12. Xue, HanBin; Sigg, Laura. A review of competitive ligand-exchangevoltammetric methods for speciation of trace metals in freshwater. ACS Symposium Series (2002), 811(Environmental Electrochemistry), 336-370.

13. Van den Berg, C. M. G.; Nimmo, M. and Daly, P. Effects of the detection window on the determination of organic copper speciation in estuarine waters. Analytica Chimica Acta (1990), 232, 149-159

14. Miller, L. A.; Bruland, K. W. Competitive equilibration techniques for determining transition metal speciation in natural waters: Evaluation using model data Anal. Chim. Acta (1997), 343, 161-181

15. Xue, HanBin; Sigg, Laura. Free cupric ion concentration and copper(II) speciation in a eutrophic lake. Limnology and Oceanography (1993), 38(6), 12001213. 
16. Van den Berg, C. M. G.; Donat, John R. Determination and data evaluation of copper complexation by organic ligands in sea water using cathodic stripping voltammetry at varying detection windows. Analytica Chimica Acta 257 (1992) $281-291$

17. Town, Raewyn M., Filella, M. Crucial role of the detection window in metal ion speciation analysis in aquatic systems: the interplay of thermodynamic and kinetic factors as exemplified by nickel and cobalt Analytica Chimica Acta 466 (2002) 285-293

18. Bruland, Kenneth W.; Rue, Eden L.; Donat, John R.; Skrabal, Stephen A.; Moffett, James W. Intercomparison of voltammetric techniques to determine the chemical speciation of dissolved copper in a coastal seawater sample Analytica Chimica Acta (2000), 405, 99-113

19. Van den Berg, C. M. G. Determination of copper in sea water by cathodic stripping voltammetry of complexes with catechol. Analytica Chimica Acta (1984), 164, 195-207 
-Chapter 4-

Investigation of copper speciation using Competing Ligand Exchange (CLE) method-Anodic Stripping Voltammetry (ASV) with EDTA 


\subsection{Introduction}

Anodic Stripping Voltammetry (ASV) technique has been discussed in Chapter 2. The operationally-defined nature and very low detection window have hampered its application. Pseudopolarography is another technique, which applies ASV to study metal speciation. It provides valuable information on thermodynamic stability constants, if there is no reductive decomposition of the metal-organic ligand complex or no kinetically inert metal-organic ligand complex [4].

Adsorptive Cathodic Stripping Voltammetry (AdCSV), coupled with CLE method is an alternative technique to the ASV technique and offers a lot of advantages over the latter [5-9]. CLE-AdCSV has been extensively used for copper speciation study. However, because of limited choice of the competing ligands, the currently available competing ligands for AdCSV are catechol, 8-hydroxyquinoline, salicylaldoxime, benzoylacetone, and tropolone. CLE-AdCSV has a limited detection window [10].

CLE-ASV has also been explored by others workers [11-13]. However, copper speciation determination by CLE-ASV with ethylenediamine [11] has not received much attention. The main reason for this shortage of much attention may be that (i) the sensitivity of ASV has no advantage over AdCSV, (ii) the detection window of CLE with ethylenediamine has no advantage over those of other popular competing ligands for copper by CLEAdCSV, such as 8-hydroxyquinoline, salicylaldoxime, benzoylacetone and tropolone [10]. 
The system containing $\mathrm{Cu}(\mathrm{II})$ and EDTA has been studied by other workers using ASV [14-18]. However, the deposition potential used in those studies varied significantly, resulting in difficulties to in defining the ASV-labile species. $\mathrm{Cu}(\mathrm{II})$-EDTA complex has been reported to be an inert species or partially labile species, or even an ASV-labile species in the ASV determination under different experimental conditions. This sums up briefly the current status of $\mathrm{Cu}$ (II) speciation using EDTA.

This work presents results of investigation of the use of EDTA to determine copper speciation by DPASV using a Hanging Mercury Drop Electrode (HMDE). The results show that under an appropriate deposition potential, $\mathrm{Cu}(\mathrm{II})$-EDTA complex is ASV-labile, which makes EDTA a suitable competing ligand for determination of copper speciation in natural waters. Finally, the copper speciation in freshwater water samples was determined by CLE-DPASV with EDTA as a competing ligand.

\subsection{Theory}

\subsubsection{ASV and DPASV}

The theory of ASV and DPASV has been discussed in Chapter 2.2.1.

\subsubsection{Competing Ligand Exchange (CLE) method}

The theory of ligand competition has been discussed in Chapter 3.2.2.

\subsection{Experimental}

\subsubsection{Sampling Location and Sampling Protocol}


The Rideau Canal, which spans 202 kilometers and links the lakes and rivers between Ottawa and Kingston, Ontario, Canada, is the oldest continuously operated canal in North America. Water samples were collected from a spot a short way upstream of the Hartwell locks beside Carleton University campus in Ottawa in September 2006 (see Figure 4.1).

Acid-cleaned Teflon bottles were used to collect samples. The bottled samples were immediately stored in the refrigerator and analyzed in the following days. The total trace metal concentrations were determined using a Perkin-Elmer Elan 6000 ICP-MS. The pH was measured by an Accumet $20 \mathrm{pH} /$ conductivity meter (Fisher Scientific). The Dissolved Organic Carbon (DOC) concentration of the sample was measured using a Shimadzu Total Organic Carbon Analyzer (TOC-VCPH). The major cations were determined by a Perkin-Elmer 603 Flame Atomic Absorption Spectrophotometer. The major anions were determined by Ion Chromatography with a Dionex anion exchange column.

\subsubsection{Reagents}

ICP-MS \& ICP-AES standard solution $(1000 \mu \mathrm{g} / \mathrm{ml})$ of $\mathrm{Cu}(\mathrm{II})$ was purchased from SCP Science, Montreal, Canada. Ultrapure water having resistivity of $18.2 \mathrm{M} \Omega . \mathrm{cm}$ was obtained direct from a Milli-Q-Plus water purification system (Millipore Corporation). A $2 \mathrm{M}$ stock solution of potassium nitrate, a $2 \mathrm{M}$ stock solution of 3-(N-Morpholino) propanesulfonic acid (MOPS) and a $2 \mathrm{M}$ stock solution of sodium hydroxide solution 


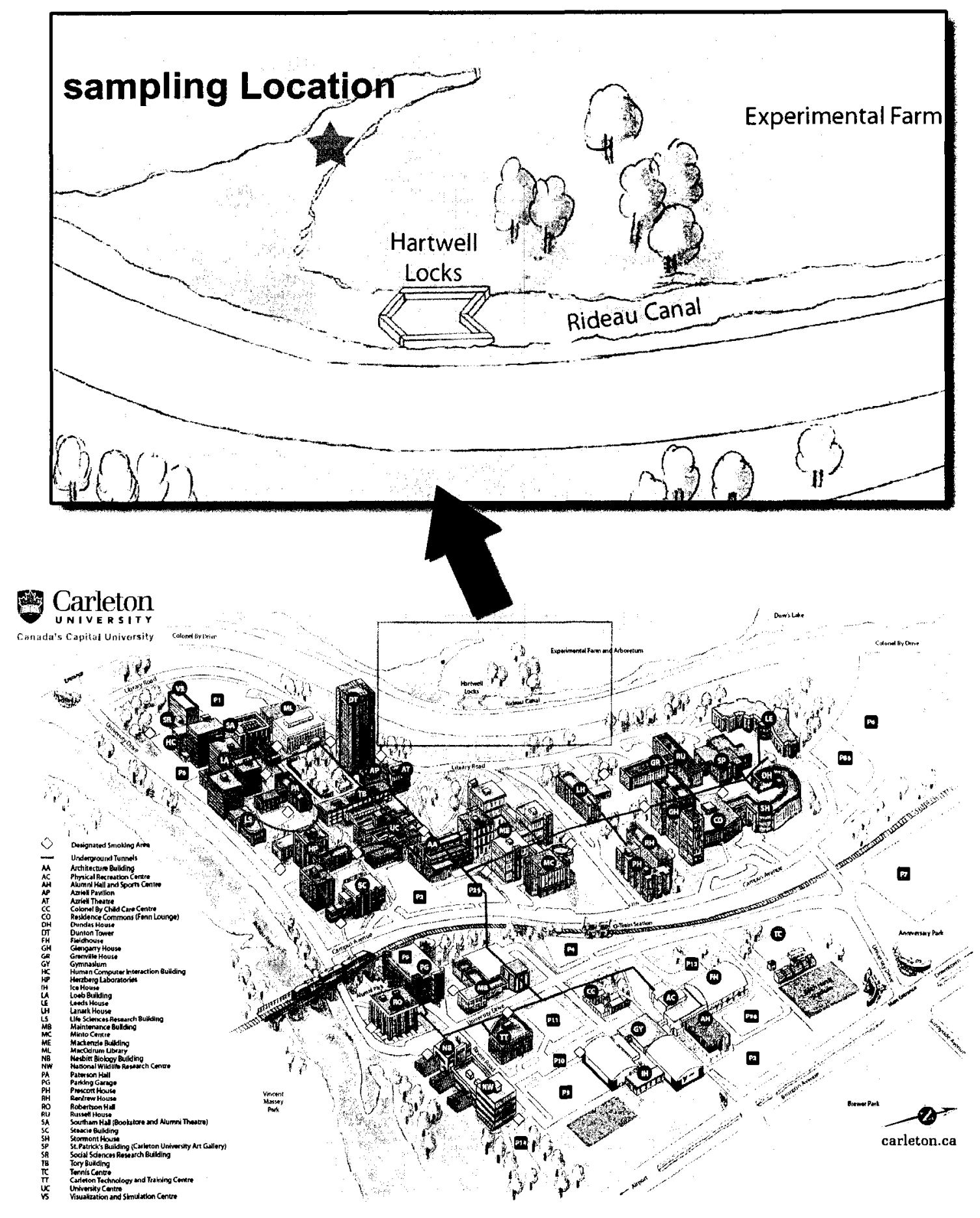

Figure 4.1 Map of Sampling site on Rideau Canal 
were prepared by dissolving an appropriate quantity of potassium nitrate (Aldrich) or MOPS (Sigma) or sodium hydroxide (Aldrich) in ultrapure water. The potassium nitrate, the MOPS and the sodium hydroxide solution were then purified separately by mercurycathode electrolysis at $-1.5 \mathrm{~V} v$ s. SCE for at least $48 \mathrm{~h}$ immediately prior to their use. To prevent the impurity metal from returning to the solution, the purified solution was removed while the electrolysis was going on. All the final test solutions contained $0.01 \mathrm{M}$ potassium nitrate, $6 \mathrm{mM}$ MOPS and appropriate amount of sodium hydroxide for adjusting the $\mathrm{pH}$. A $1 \times 10^{-2} \mathrm{M}$ stock solution of EDTA was prepared by dissolving an appropriate quantity of pure ethylenediaminetetraacetic acid (Aldrich) with an appropriate quantity of $2 \mathrm{M}$ sodium hydroxide solution in ultrapure water. A wellcharacterized standard: Suwannee River Fulvic Acid (SRFA Cat. No. 1S101F) was obtained from International Humic Substances Society (IHSS, USA). The concentrations of carboxylic and phenolic groups in the SRFA were 11.44 and $2.91 \mathrm{mmol} / \mathrm{g}$, respectively [19]. A $0.50 \mathrm{~g} / \mathrm{L}$ stock solution of SRFA was prepared by dissolving an appropriate quantity of the freeze-dried SRFA in ultrapure water. A soil Humic Acid (HA) was supplied by Dr. Les Evans [20] (University of Guelph, Guelph, Ontario), who characterized and purified the HA according to the procedure recommended by IHSS. Elemental analysis of the soil HA was as follows: $53.15 \% \mathrm{C}, 4.81 \% \mathrm{H}, 3.36 \% \mathrm{~N}, 0.46 \%$ $\mathrm{S}$, and $37.99 \%$ O. Solid state ${ }^{13} \mathrm{C}$ NMR was used to estimate the concentration of carboxylic and phenolic groups to be 6.21 and $3.55 \mathrm{mmol} / \mathrm{g}$, respectively. A $1.00 \mathrm{~g} / \mathrm{L}$ stock solution of HA was prepared by dissolving an appropriate quantity of the HA with an appropriate quantity of $2 \mathrm{M}$ sodium hydroxide solution in ultrapure water. 


\subsubsection{Apparatus}

Voltammetric measurements were made with a computer-controlled Autolab PGSTAT 30 potentiostat/galvanostat (Eco. Chemie BV, The Netherlands) in conjunction with a Metrohm 663 VA stand (Metrohm, Switzerland). The working electrode was a Hanging Mercury Drop Electrode (HMDE, Metrohm, Switzerland). The reference electrode was $\mathrm{Ag} / \mathrm{AgCl}$ electrode in a glass tube filled with $3 \mathrm{M} \mathrm{KCl}$ and fitted with a porous Vycor tip (Bioanalytical Systems, Inc., USA). The counter electrode was made of a platinum rod (Metrohm, Switzerland). Analysis of peaks was done using the General Purpose Electrochemical Software v4.9 (Eco Chemie BV, The Netherlands). The data were transferred to a Pentium computer and saved for processing. All the AdCSV analyses were performed in the same Teflon working cell to ensure reproducibility.

\subsubsection{Electrochemical parameters}

For all the ASV measurement, the following experimental conditions were used: purging with pure $\mathrm{N}_{2}$ gas for 5 minutes, deposition time 20-300 s (with stirring), and equilibration time 10-30 s. For the $\mathrm{Cu}$ (II) titration experiment with the model solutions, the deposition potentials were set at $-0.3 \mathrm{~V}$ and $-1.2 \mathrm{~V}$. All the voltages used in this study are reported with respect to the $\mathrm{Ag} / \mathrm{AgCl}$ reference electrode. For EDTA titrations, the deposition potential was set at $-1.2 \mathrm{~V}$. For the $\mathrm{Cu}$ (II) titration in the freshwater samples, the deposition potentials were set at $-0.7 \mathrm{~V}$ and $-1.2 \mathrm{~V}$. For all the stripping steps, the experimental conditions were: initial potential $-0.45 \mathrm{~V}$, end potential $0.1 \mathrm{~V}$, scan rate $0.0102 \mathrm{~V} \mathrm{~s}^{-1}$, and with a differential pulse mode. 


\subsubsection{Equilibration time for the EDTA spikes before DPASV determination}

The kinetics of complexation of copper with EDTA was studied. In copper model solution without SRFA or HA, the complexation reaction attained equilibrium rapidly (within 15 minutes), but with natural organic ligands in the sample solutions, the equilibration took about 24 hours. Therefore, $20 \mathrm{~mL}$ of each copper model solution without SRFA or HA were titrated with an appropriate amount of EDTA and then equilibrated for 15 minutes before the DPASV determination, but for the model solution with SRFA or HA, and for the freshwater samples, after the EDTA spikes, the equilibration time was 24 hours.

\subsubsection{Copper titration for the collected freshwater samples}

To obtain the copper titration curves, four series of Teflon cells, each containing $20 \mathrm{~mL}$ of the freshwater sample, were spiked with different concentrations of copper, with the highest concentration of copper spike being $1.57 \mu \mathrm{M}\left(100 \mathrm{ng} \mathrm{mL}^{-1}\right)$. Different series were then spiked with different concentrations of EDTA $\left(2 \times 10^{-5} \mathrm{M}, 4 \times 10^{-5} \mathrm{M}, 6 \times 10^{-5} \mathrm{M}\right.$, or $8 \times 10^{-5} \mathrm{M}$ ), followed with appropriate amounts of the electrolyte and the $\mathrm{pH}$ buffers, as described before. The $\mathrm{pH}$ was adjusted to 7.8 to simulate that of the original freshwater samples. After equilibration for 24 hours, the $\mathrm{pH}$ was rechecked and readjusted to $7.8 \mathrm{in}$ case of any $\mathrm{pH}$ shifts. This was immediately followed by DPASV determination.

\subsection{Results and discussions}

\subsubsection{Scan of deposition potential in model solutions}


Since the deposition potentials used in the ASV studies of copper-EDTA complex by other workers spanned the range from $-1.4 \mathrm{~V}$ to $0.0 \mathrm{~V}$ [14-18], for this study the deposition potential scan was set to start from $-1.6 \mathrm{~V}$ (initial) to $0.3 \mathrm{~V}$ (final). Figure 4.2 presents two pseudopolarograms for $\mathrm{Cu}$, with and without EDTA, in ultrapure water (model solution). Figure 4.3 presents two pseudopolarograms for $\mathrm{Cu}$ in the SRFA solution, with and without EDTA. Figure 4.4 presents two pseudopolarogram for $\mathrm{Cu}$ in the HA solution, with and without EDTA. In Figure 4.2, for the copper model solution without EDTA, the pseudopolarogram has a single inflection point at $\mathrm{ca} \sim 0.0 \mathrm{~V}$, whereas for the copper model solution with EDTA, the pseudopolarogram has two inflection points: one, at $\sim 0.0 \mathrm{~V}$ and the other, at $\sim-0.5 \mathrm{~V}$. When deposition potential was more positive than $-0.5 \mathrm{~V}$, the current signal was lower for the copper solution with EDTA than the one without EDTA, whereas at potential more negative than $-0.5 \mathrm{~V}$, the current signal was higher for the copper solution with EDTA than without EDTA. The systems containing SRFA and HA also showed this phenomenon. Since the copper model solutions without and with EDTA, contained only $\mathrm{Cu}(\mathrm{II})$ aqua complex, $\mathrm{Cu}(\mathrm{II})$ aqua plus $\mathrm{Cu}$ (II)-EDTA complex, respectively, it is reasonable to assume that $0.0 \mathrm{~V}$ and $-0.5 \mathrm{~V}$ are the half-wave potentials for the reduction of the $\mathrm{Cu}(\mathrm{II})$ aqua complex and the $\mathrm{Cu}(\mathrm{II})$ EDTA complex, respectively. This assumption is consistent with the fundamentals of electrochemistry: the free energy change of a chemical reaction is related to the electrical potential difference that can be generated by the reaction; since it is obviously easier to reduce the $\mathrm{Cu}(\mathrm{II})$ aqua complex than the $\mathrm{Cu}(\mathrm{II})$-EDTA complex. This is confirmed by Figures 4.3 and 4.4 which indicate that when the deposition potential was more negative than $-0.5 \mathrm{~V}$, the $\mathrm{Cu}(\mathrm{II})$-EDTA complex became ASV-labile, but when the deposition 
potential was more positive than $-0.5 \mathrm{~V}$, the ASV-lability of the $\mathrm{Cu}$ (II)-EDTA complexes decreased significantly. The significantly decreased current signal in the systems containing SRFA and HA in Figures 4.3 and 4.4 (compared with that in Figure 4.2) indicated that the $\mathrm{Cu}-\mathrm{SRFA}$ and $\mathrm{Cu}-\mathrm{HA}$ complexes did not contribute much to the peak current, and the range of deposition potential (from - $1.6 \mathrm{~V}$ to $0.3 \mathrm{~V}$ ) did not affect the lability of the Cu-SRFA and Cu-HA complexes significantly.

4.4.2 Copper titration of EDTA model solution and EDTA titration of copper model solutions

A model solution containing $0.3 \mu \mathrm{M}$ EDTA was titrated with copper. And, a model solution containing $0.1 \mu \mathrm{M}$ copper was titrated with EDTA. Copper species were measured by DPASV in both solutions. Figure 4.5 and 4.6 present the copper curves of the EDTA model solution and of the copper model solution, respectively, and show that $\mathrm{Cu}$ (II)-EDTA complex was fully ASV-labile at the deposition potential of $-1.2 \mathrm{~V}$, whereas the complex was not ASV-labile at the deposition potential of $-0.3 \mathrm{~V}$. In Figure 4.5, the slopes (of similar values) of the two copper titration curves (at the deposition potential of $-1.2 \mathrm{~V}$ and $-0.7 \mathrm{~V}$ ) after the $0.3 \mu \mathrm{M}$ copper spiking provide the analytical sensitivity of the $\mathrm{Cu}^{2+}$ free ion determination by DPASV. At the deposition potential of $1.2 \mathrm{~V}$, the difference between the two slopes before and after the addition of the $0.3 \mu \mathrm{M}$ copper spike, i.e. before and after all EDTA has formed Cu(II)-EDTA complex shows that the $\mathrm{Cu}(\mathrm{II})$-EDTA complex gave a higher analytical sensitivity than the $\mathrm{Cu}^{2+}$ free ion in the DPASV determination. 
In Figure 4.6, when EDTA was added to copper, the peak current increased because of the formation of $\mathrm{Cu}(\mathrm{II})$-EDTA complex till the point where all copper had been complexed by EDTA. After this point, formation of any more $\mathrm{Cu}$ (II)-EDTA complex ceased, and hence, the peak current leveled off, forming a plateau in the curve.

\subsubsection{Deposition potential scan of the freshwater samples}

Figure 4.7 presents two pseudopolarograms for copper in the freshwater samples, and shows clearly that at more negative deposition potentials, more copper-organic ligand complexes were reduced, i. e. became ASV-labile. For the freshwater sample alone, the deposition potential did not affect the peak current significantly. The reason was probably that there was only a small amount of copper, but a large amount natural organic ligand in the freshwater sample, resulting in the formation of only strong copper complexes, which were not ASV-labile even at very negative deposition potentials. For the copperspiked freshwater sample, the peak current increased dramatically when the deposition potential was more negative than $-0.7 \mathrm{~V}$, which might be due to the formation of new complexes between the spiked copper and the not-so-strong copper-binding organic ligands. For the subsequent copper titration, the deposition potentials were set at $-0.7 \mathrm{~V}$ and $-1.2 \mathrm{~V}$ to ensure good analytical sensitivity, and also to study the effect of deposition potential on the copper speciation. There were possibilities that both the deposition potentials might result in underestimation of the copper-binding organic ligands, since some copper complexes formed with strong copper-binding organic ligands were ASVlabile. But with the excess of EDTA, this underestimation should not be significant. 


\subsubsection{Titration of copper in the freshwater sample with EDTA as competing ligand}

Figure 4.8 presents the curves for copper titration in the freshwater sample with EDTA as competing ligand and shows that the analytical sensitivity at the deposition potential of $1.2 \mathrm{~V}$ is much higher than that at the lower deposition potential $-0.7 \mathrm{~V}$. The broken line and the solid line are the analytical sensitivities of the studied systems at different deposition potentials. The significant difference between two sensitivities is consistent with the observations in Figure 4.7. The increased ASV-lability of the complexes at the deposition potential of $-1.2 \mathrm{~V}$ provides a much higher analytical sensitivity. Theoretically, the deposition potential of $-0.7 \mathrm{~V}$ should give a more correct results of the copper speciation, since it minimizes the effects caused by ASV-lability of copper complexes formed between copper with strong copper-binding organic ligands, and between copper with not-so-strong copper-binding organic ligand.

Table 4.1 presents some general chemical information on the freshwater sample. Using the van den Berg-Ruzic plot, the titration data can be fitted very well with one-ligand model (see Figure 4.9 and Table 4.2). Since the detection windows used were in a very narrow high range, $10^{11.6}-10^{12.2}$, the weak and intermediate copper-binding natural organic ligands might not be detectable in these cases, which was confirmed by the van den Berg-Ruzic fits. It was assumed that the calculated very strong ligands obtained from the titrations within the different detection windows of the freshwater samples were the same ligands. The average conditional stability constants and the ligand concentrations determined with different detection windows using different deposition potentials for the different samples are present in Table 4.3. 
In the large number of reports on copper speciation in freshwater samples by CLE, to the best of our knowledge, there is no report on the existence of strong natural organic ligands that can form copper complexes with conditional stability constants above $10^{19}$ [21-25]. However, a number of studies have reported on the existence of a series of strong ligands that may have been freshly produced by organisms present in freshwaters $[21,26,27]$. The Rideau Canal freshwater samples were collected during late June and late September, when algae were blooming. It was also possible that some colloids existed in the freshwater samples representing kinetically inert copper complexes. Moreover, the detection window, $\alpha_{\mathrm{A}}$, of the current CLE methods used was not set above $10^{10}$, which allowed detection of only a limited range of natural organic ligands. When a high $\alpha_{A}$ was used, a very strong copper-binding natural organic ligand in freshwaters was detected by others [23].

The advantages of using EDTA as competing ligand are its high copper-binding stability constant, easiness of the study, easy handling and simple reaction mechanism. By changing the EDTA concentration from $10^{-3}$ to $10^{-6} \mathrm{M}$, the detection window, i.e. $\alpha_{\text {EDTA }}$, can be easily adjusted to span the range of approximately $10^{9}$ to $10^{12}$. For very strong copper-binding natural organic ligands, CLE-ASV with EDTA as competing ligand provides an indispensable tool for investigation of copper complexes in aqueous samples, comparable to the relatively mild competing ligands with the CSV method.

Use of different deposition potentials did not seem to be able to detect different organic ligands which formed copper complexes of different conditional stability constants since 
the conditional stability constants determined were not significantly different (Table 4.3). The reason was probably again the detection window. With the limited detection window and the heterogeneous nature of the organic ligands in natural waters, the overall detected organic ligands had to fit the applied detection windows, suggesting the importance of a wider range of detection windows in metal speciation research, as suggested also by others [28]. Nevertheless, the lower deposition potential did detect more organic ligands in the freshwater samples although it could not distinguish the ligands.

When the term "ASV-labile" is used to describe metal complex, it usually means that the metal complex can dissociate in the time scale of the ASV measurement. Under this concept, CuEDTA complex should be better described as electroactive, since it is reduced directly with dissociation. But when the "ASV-labile" is defined as ASV measurable in some other literature, CuEDTA complex can be described as ASV-labile. In this thesis, ASV-labile is defined as ASV measurable. 

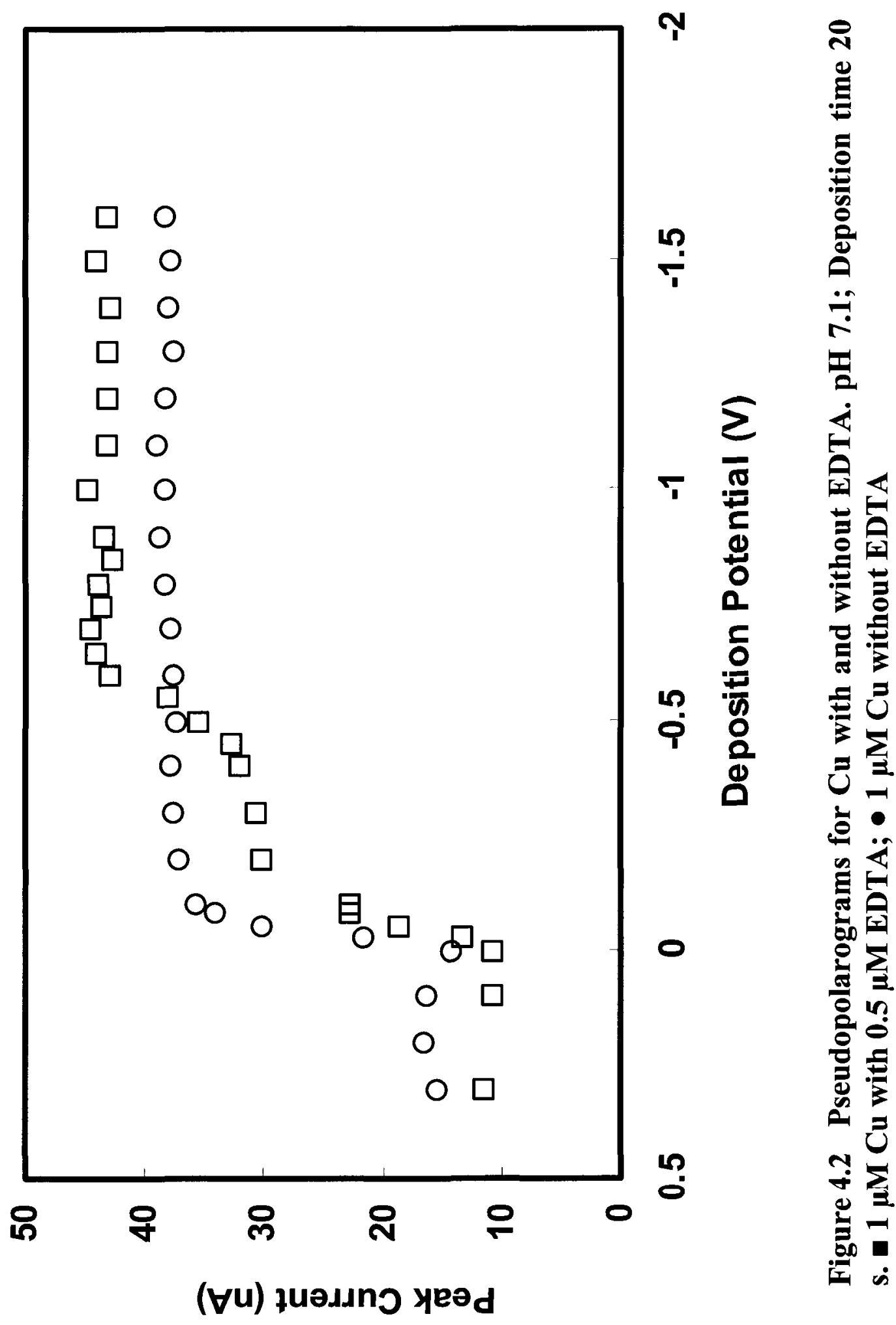


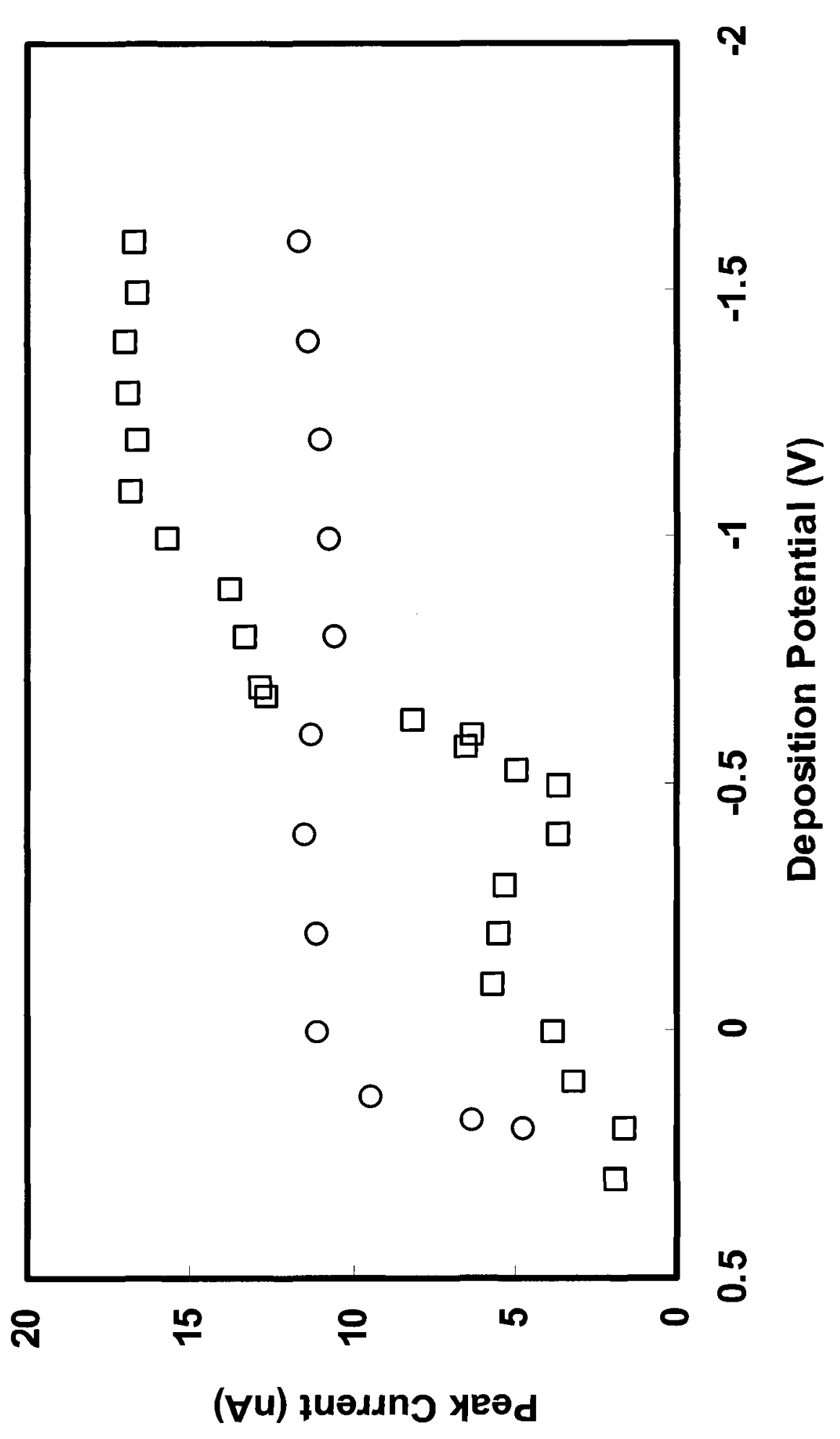

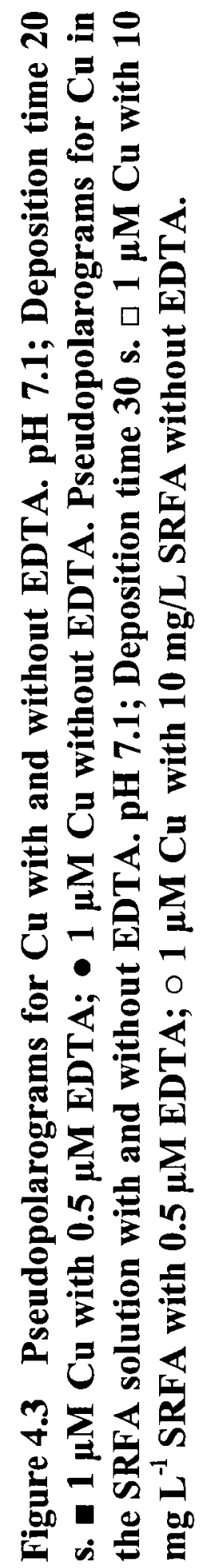




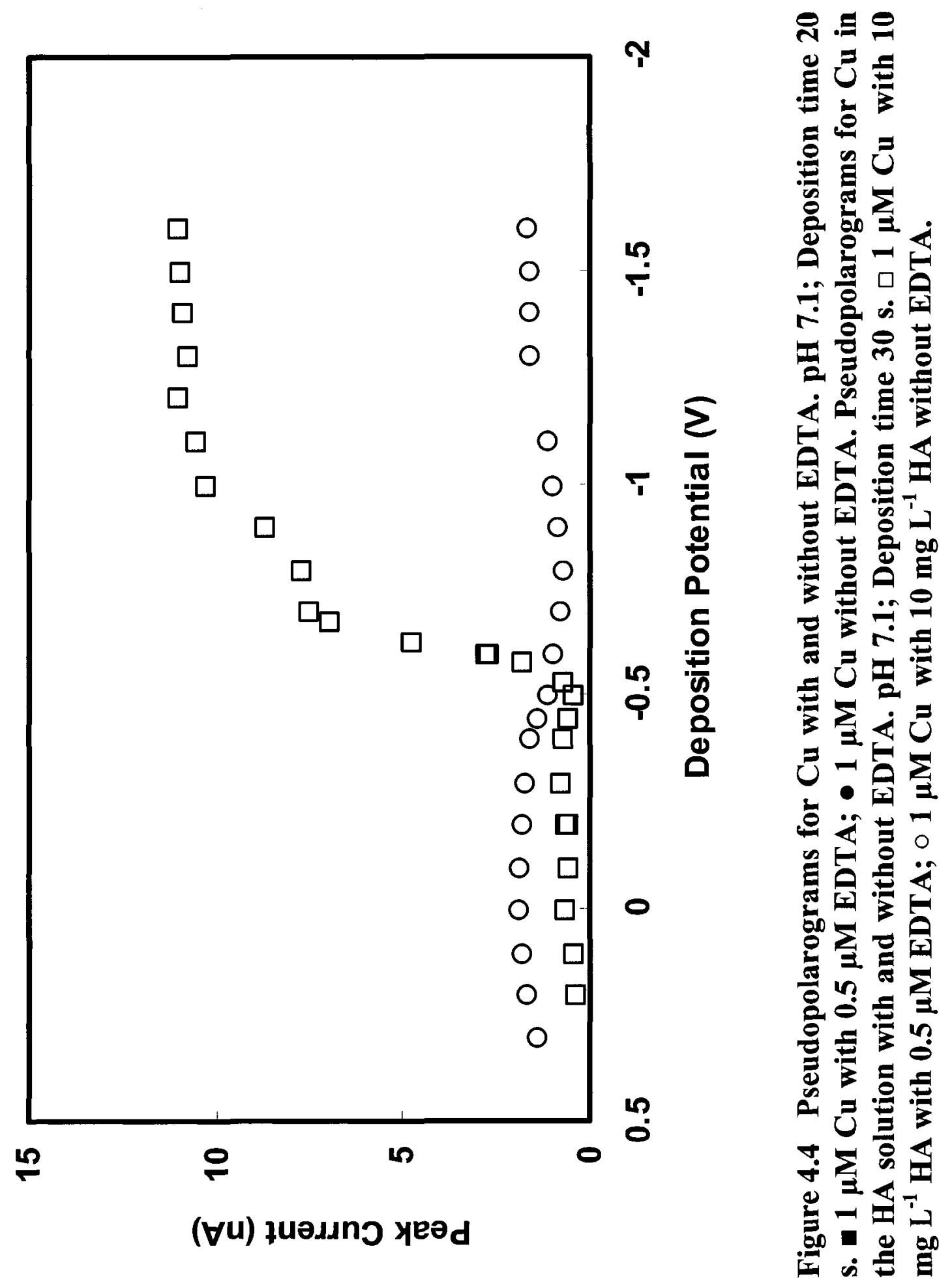




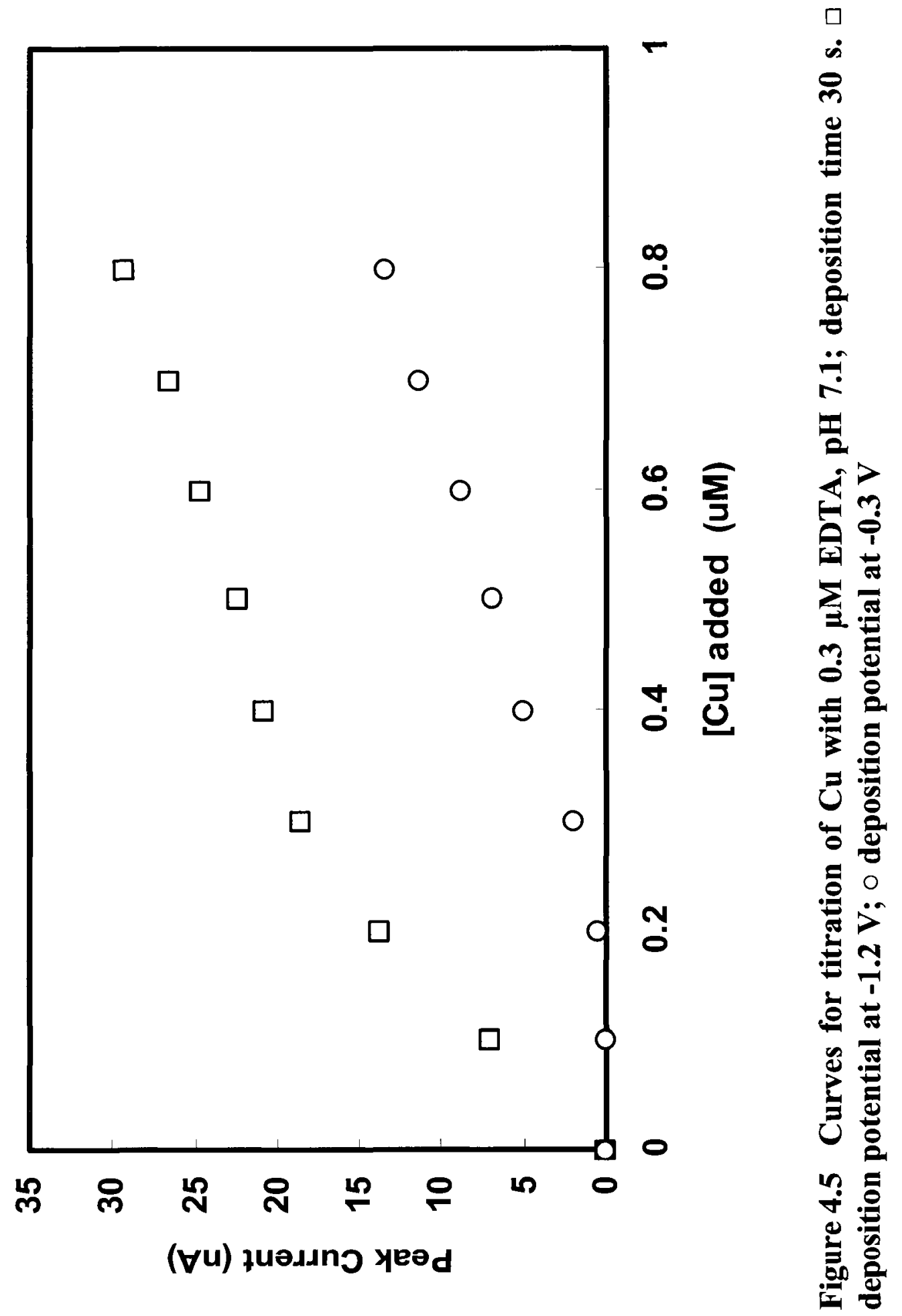




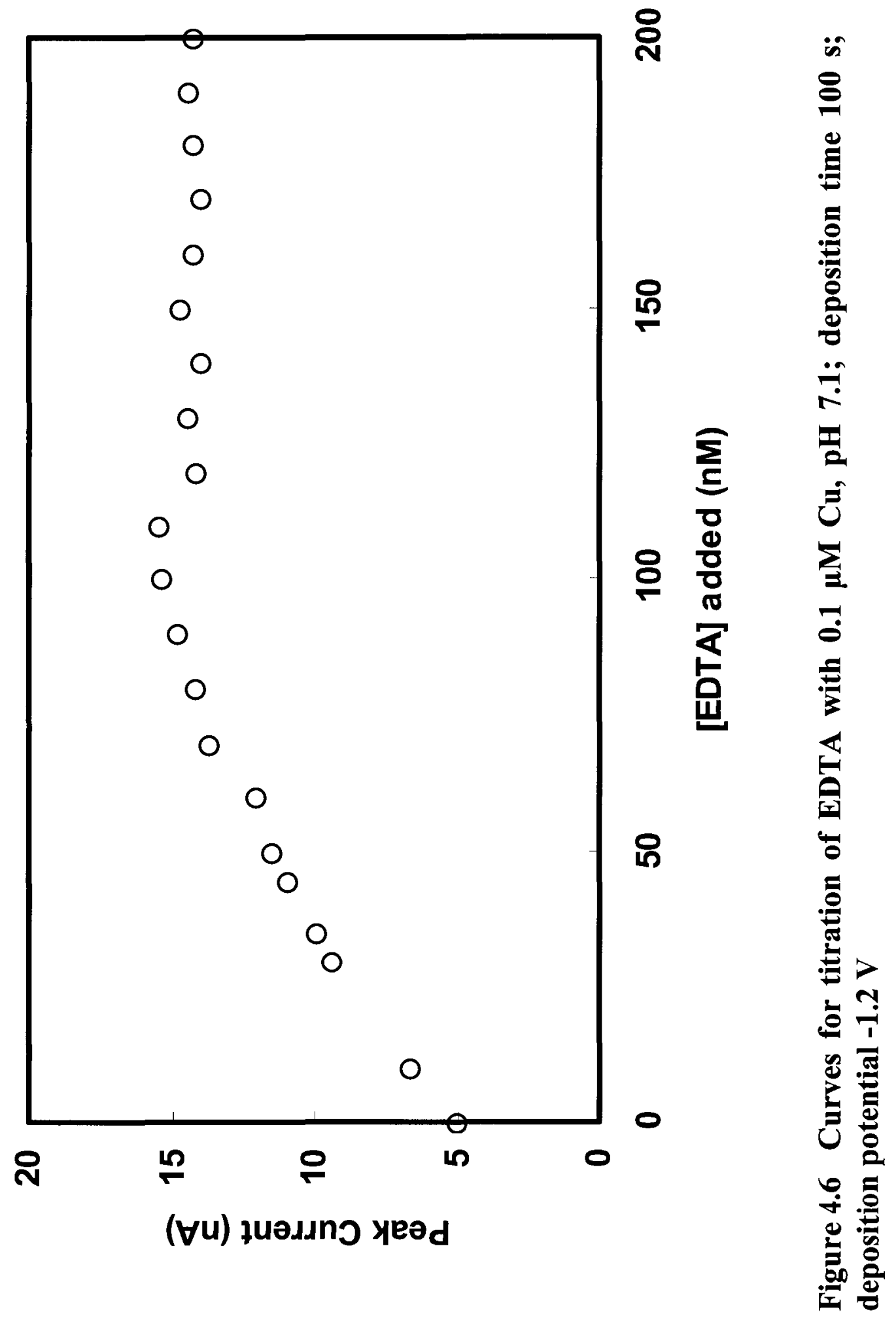

- 99 - 

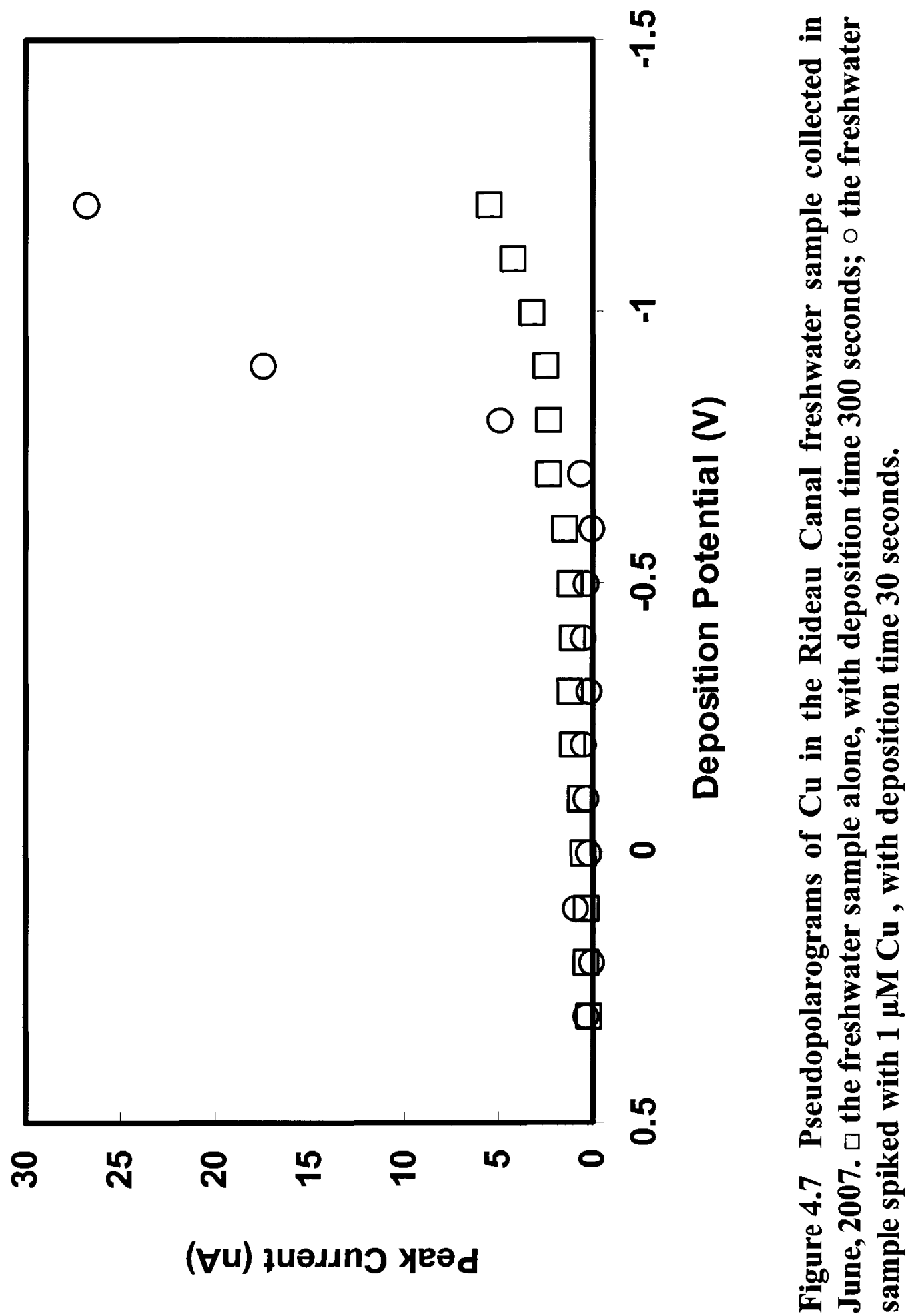


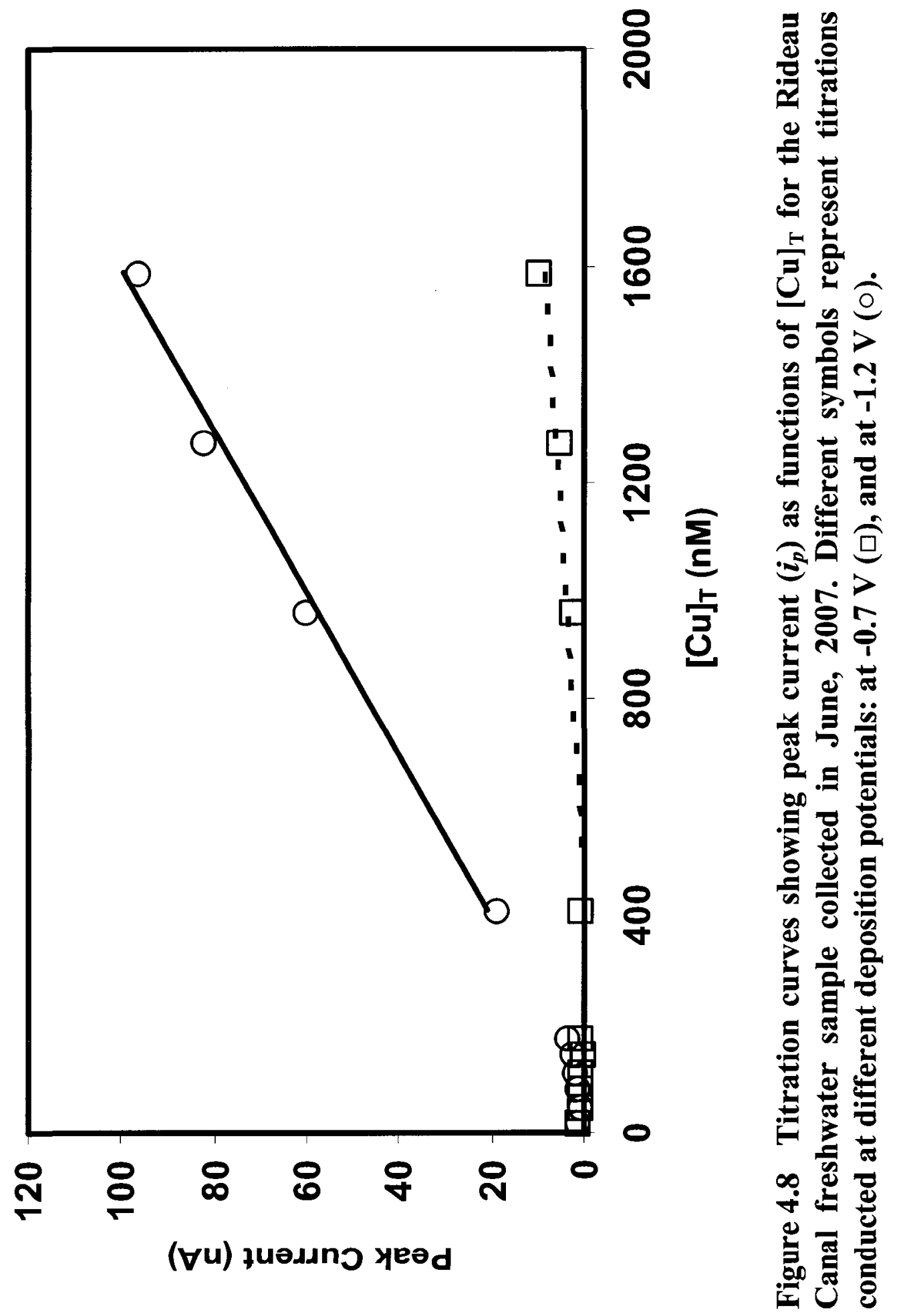




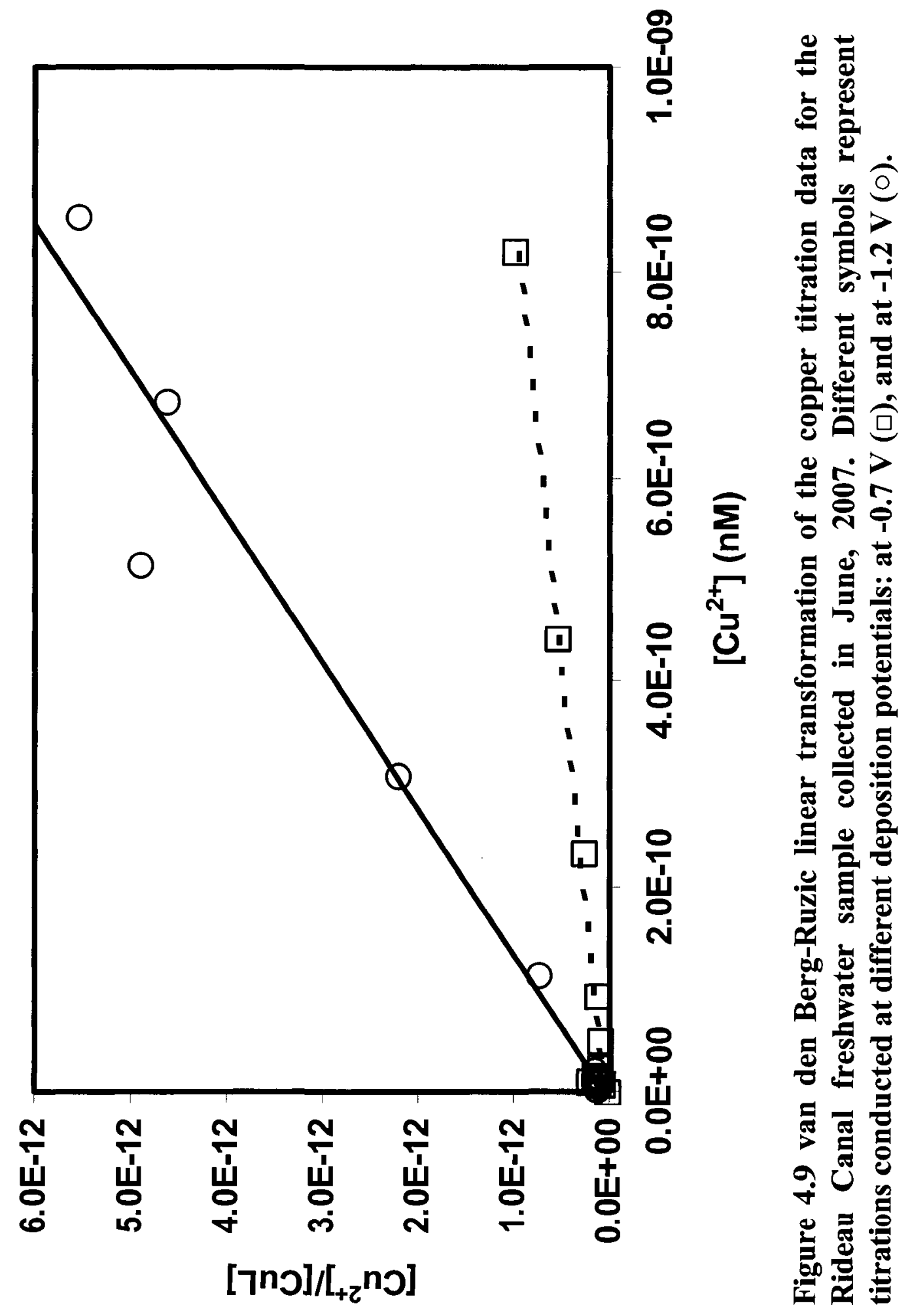




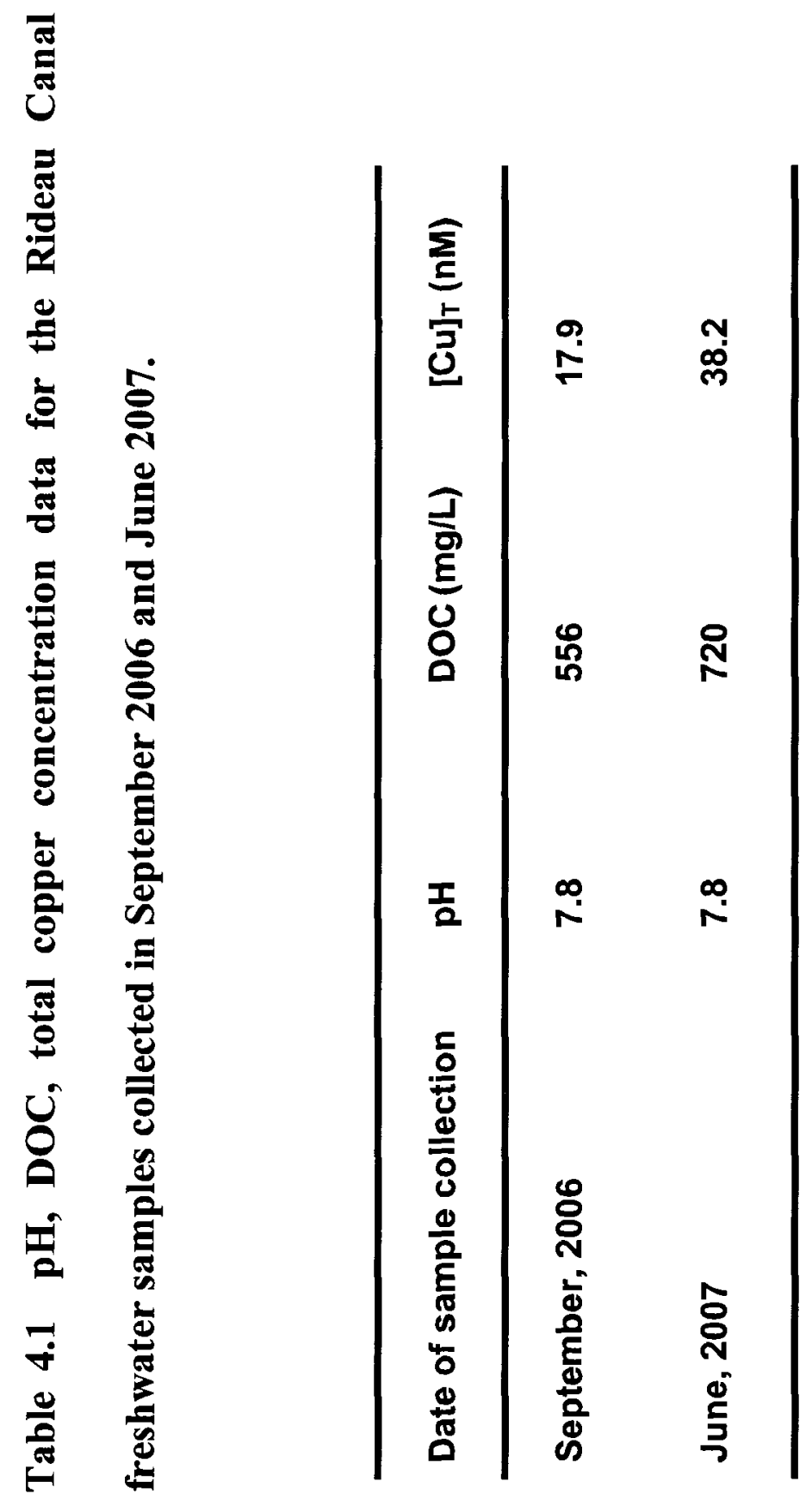




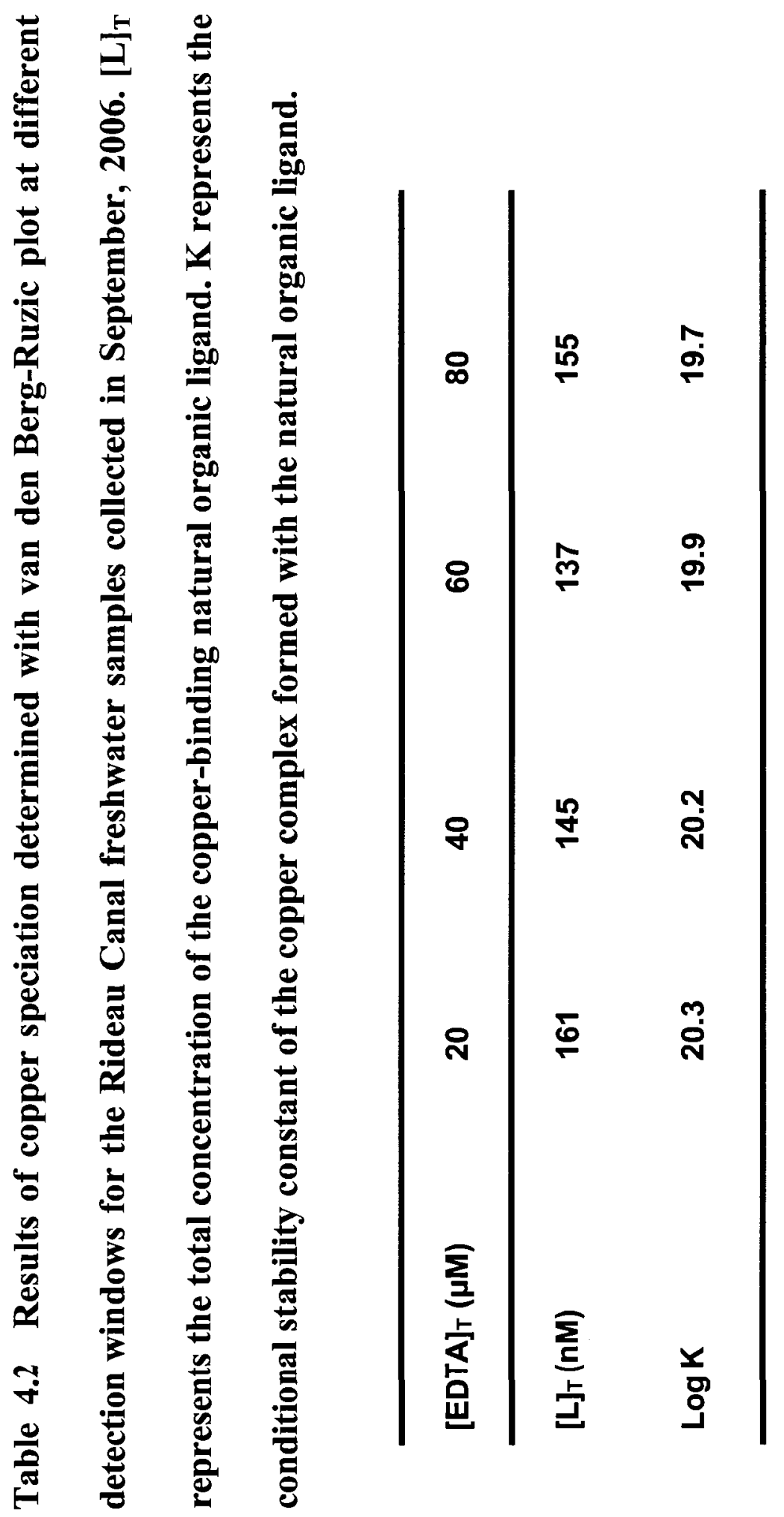



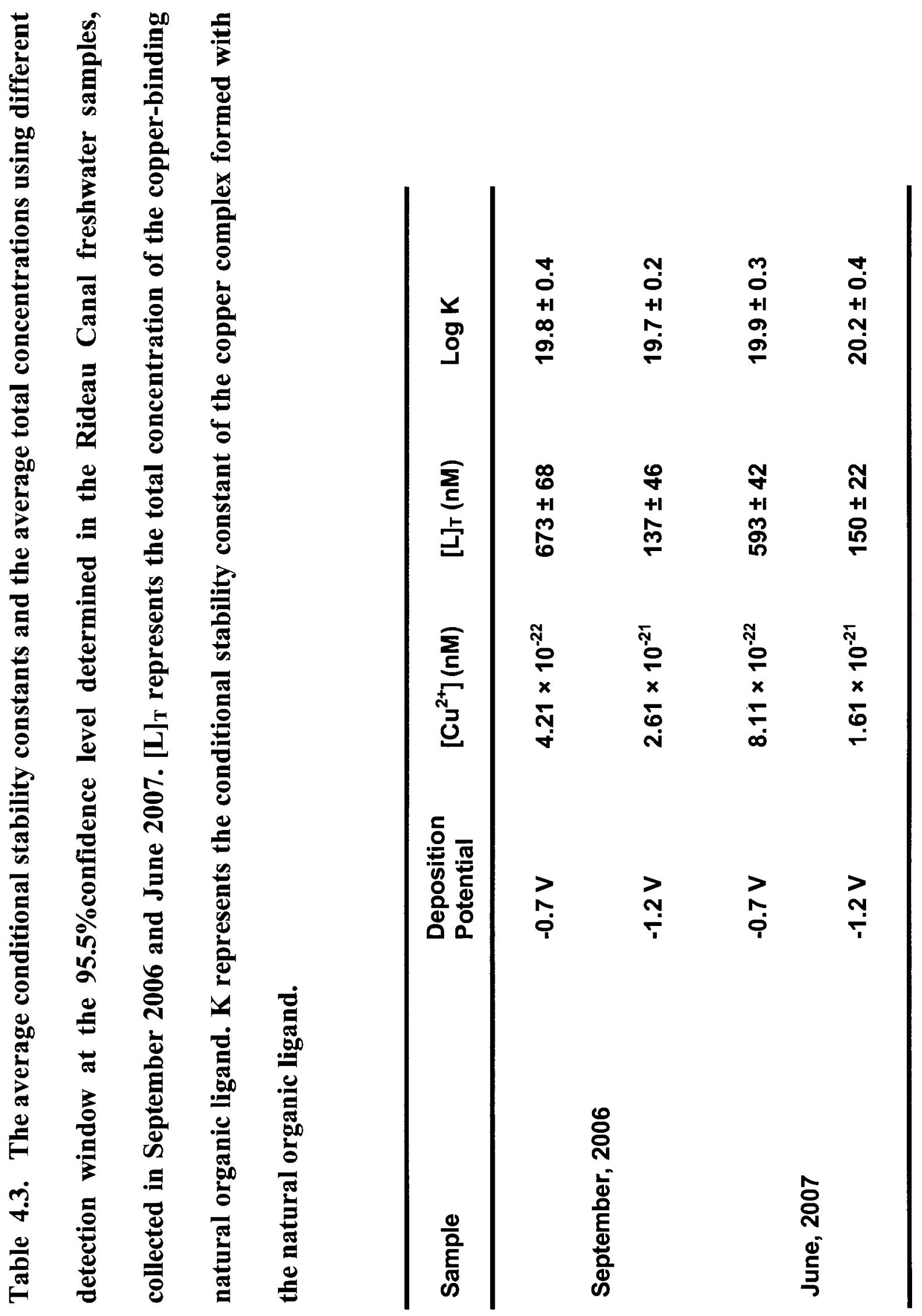


\subsection{References}

1. Gächter, R.; Davis, J.S.; Mares, A., Regulation of copper availability to phytoplankton by macromolecules in lake water Environmental Science and Technology (1978) 1416-1421

2. Swallow, K.C.; Westall, J.C.; McKnight, D.M.; Morel, N.M.L.; Morel, M.M., Potentiometric determination of copper complexation by phytoplankton exudates Limnology and Oceanography (1978) 538-542

3. Sunda, W.G.; Ferguson, R.L., Wong, C.S.; Boyle, E.; Bruland, K.W.; Burton, J.D.; Goldberg, E.O., Editors, Trace Metals in Seawater, Proc. NATO Adv. Res. Inst. Symp., Plenum Press, London, (1983)

4. Shuman, Mark S.; Woodward, George P., Jr. Stability constants of copperorganic chelates in aquatic samples. Environmental Science and Technology (1977), 11(8), 809-13

5. Shuman, M.S.; Cromer, J.L., Estimation of conditional formation constants with a titrimetric anodic stripping voltammetric procedure Environmental Science and Technology (1979), 13, 543-545

6. Ruzic, I.. Theoretical aspects of the direct titration of natural waters and its information yield for trace metal speciation. Analytica Chimica Acta (1982), 140(1), 99-113.

7. Coale, Kenneth H.; Bruland, Kenneth W. Copper complexation in the Northeast Pacific. Limnology and Oceanography (1988), 33(5), 1084-1101 
8. Donat, John R.; Lao, Kathy A.; Bruland, Kenneth W. Speciation of dissolved copper and nickel in South San Francisco Bay: a multi-method approach. Analytica Chimica Acta (1993), 284(3), 547-71.

9. Tuschall, John R., Jr.; Brezonik, Patrick L. Evaluation of the copper anodic stripping voltammetry complexometric titration for complexing capacities and conditional stability constants. Analytical Chemistry (1981), 53(13), 1986-9.

10. Turoczy, N. J.; Sherwood, J. E. Modification of the van den Berg/Ruzic method for the investigation of complexation parameters of natural waters. Analytica Chimica Acta (1997), 354, 15-21.

11. Kogut, M. B.; Voelker, B. M. Strong Copper-Binding Behavior of Terrestrial Humic Substances in Seawater. Environmental Science and Technology (2001), $35,1149-1156$

12. Voelker, B. M.; Kogut, M. B. Interpretation of metal speciation data in coastal waters: the effects of humic substances on copper binding as a test case. Marine Chemistry (2001), 74, 303-318

13. Croot, P. L.; Moffett, J. W.; Luther III, G. W. Polarographic determination of half-wave potentials for copper-organic complexes in seawater. Marine Chemistry (1999), 67, 219-232.

14. Van den Berg, C.M.G. Determination of the complexing capacity and conditional stability constants of complexes of copper(II) with natural organic ligands in seawater by cathodic stripping voltammetry of copper-catechol complex ions. Marine Chemistry (1984), 15, 1-18 
15. Van den Berg, Constant M. G. Determination of copper, cadmium and lead in seawater by cathodic stripping voltammetry of complexes with 8hydroxyquinoline. Journal of electroanalytical chemistry (1986), 215, 111-121

16. Lucia, M.; Campos, A.M.; van den Berg, Constant M.G. Determination of copper complexation in sea water by cathodic stripping voltammetry and ligand competition with salicylaldoxime. Analytica Chimica Acta (1994), 284, 481-496

17. Donat, John R.; Van den Berg, Constant M. G. A new cathodic stripping voltammetric method for determining organic copper complexation in seawater. Marine Chemistry (1992), 38(1-2), 69-90.

18. Moffett, James W. Temporal and spatial variability of copper complexation by strong chelators in the Sargasso Sea. Deep Sea Research (1995), 42, 1273-1295

19. Bruland, Kenneth W.; Rue, Eden L.; Donat, John R.; Skrabal, Stephen A.; Moffett, James W. Intercomparison of voltammetric techniques to determine the chemical speciation of dissolved copper in a coastal seawater sample. Analytica Chimica Acta (2000), 405, 99-113

20. Scarano, G.; Bramanti, E.; Zirino, A. Determinaation of copper complexation in sea water by a ligand competition technique with voltammetric measurement of the labile metal fraction. Analytica Chimica Acta (1992), 264, 153-162.

21. Xue, H. B.; Sigg, L. Zinc speciation in lake waters and its determination by ligand exchange with EDTA and differential pulse anodic stripping voltammetry. Analytica Chimica Acta (1994), 284, 505-515.

22. Xue, H. B.; Sigg, L. Cadmium speciation and complexation by natural organic ligands in fresh water. Analytica Chimica Acta (1998), 363, 249-259. 
23. Figura, Paul; McDuffie, Bruce. Use of Chelex resin for determination of labile trace metal fractions in aqueous ligand media and comparison of the method with anodic stripping voltammetry. Analytical Chemistry (1979), 51(1), 120-5

24. Schonberger, E. A.; Pickering, W. F. The influence of $\mathrm{pH}$ and complex formation on the ASV peaks of lead, copper, and cadmium. Talanta (1980), 27(1), 11-18.

25. Morrison, G. M. P.; Florence, T. M. Comparison of physicochemical speciation procedures with metal toxicity to Chlorella pyrenoidosa. Copper complexation capacity. Electroanalysis (1989), 1(2), 107-12.

26. Omanovic, D.; Pizeta, I.; Peharec, Z.; Branica, M. Voltammetric determination of the metal complexing capacity in model solutions. Marine Chemistry (1996), 53(1/2) 13th International Symposium "Chemistry of the Mediterranean", (1994), 121-129.

27. Croot, Peter L.; Moffett, James W.; Luther, George W., III. Polarographic determination of half-wave potentials for copper-organic complexes in seawater. Marine Chemistry (1999), 67(3-4), 219-232.

28. Ritchie, Jason D.; Perdue, E. Michael Proton-binding study of standard and reference fulvic acids, humic acids, and natural organic matter. Geochimica et cosmochimica acta (2003) 67, 85-96

29. Bolton, K. A.; Sjoeberg, S.; Evans, L. J. Proton binding and cadmium complexation constants for a soil humic acid using a quasi-particle model. Soil Science Society of America Journal (1996), 60(4), 1064-1072 
30. Xue, HanBin; Sigg, Laura. Free cupric ion concentration and copper(II) speciation in a eutrophic lake. Limnology and Oceanography (1993), 38(6), 12001213.

31. Gerringa, L. J. A.; Herman, P. M. J.; Poortvliet, T. C. W. Comparison of the linear Van den Berg/Ruzic transformation and a non-linear fit of the Langmuir isotherm applied to $\mathrm{Cu}$ speciation data in the estuarine environment. Marine Chemistry (1995), 48(2), 131-42.

32. Jin, L.; Gogan, N. J. Copper complexing capacities of freshwaters by adsorptive cathodic stripping voltammetry. Analytica Chimica Acta (2000), 412(1-2), 77-88.

33. Xue, HanBin; Sigg, Laura. A review of competitive ligand-exchangevoltammetric methods for speciation of trace metals in freshwater. $A C S$ Symposium Series (2002), 811(Environmental Electrochemistry), 336-370.

34. Ploeger, Anja; Fischer, Eric; Nirmaier, Hans-Peter; Laglera, Luis M.; Monticelli, Damiano; van den Berg, Constant M. G. Lead and copper speciation in remote mountain lakes. Limnology and Oceanography (2005), 50(3), 995-1010.

35. Achterberg, Eric P.; van den Berg, Constant M. G.; Boussemart, Marc; Davison, William. Speciation and cycling of trace metals in Esthwaite water: a productive English lake with seasonal deep-water anoxia. Geochimica et Cosmochimica Acta (1997), 61(24),

36. Xue, Hanbin; Sigg, Laura. Comparison of the complexation of $\mathrm{Cu}$ and $\mathrm{Cd}$ by humic or fulvic acids and by ligands observed in lake waters. Aquatic Geochemistry (1999), 5(4), 313-335. 
37. Town, R. M.; Filella, M. Crucial role of the detection window in metal ion speciation analysis in aquatic systems: the interplay of thermidynamci and kinetic factors as exemplified by nickel and cobalt. Analytica Chimica Acta (2002), 466(1-2), 285-293. 
-Chapter 5-

In situ determination of copper speciation using Diffusive Gradients in Thin Films (DGT) 


\subsection{Introduction}

Uncontaminated natural waters usually contain low concentrations of trace metals, requiring metal speciation techniques of high analytical sensitivity and selectivity for natural waters. Other requirements concern the sampling procedures including sample storage which can easily introduce systematic errors since degassing, coagulation, and oxidation due to $\mathrm{O}_{2}$ contamination, can happen anytime [1]. Therefore, a highly robotized in situ measurement with a high sensitivity should be adopted.

Diffusive Gradients in Thin Films (DGT) has been developed and used to measure metal labile species quantitatively in situ in natural water systems since 1994 [2]. When measuring labile species of trace metals, a layer of polyacrylamide hydrogel of certain thickness backed by a layer of ion-exchange resin (Figure 5.1), is required in the DGT.

For field deployment, a membrane filter is usually placed on top of the diffusive gel to minimize the adherence of fine particles on the gel. DGT is attached to a stable object: a cable, a rock, or a tree, during the deployment period. The metal diffusion in the hydrogel gel and the metal uptake in the resin layers are so arranged that transport of metal ions from the hydrogel to the resin is solely controlled by molecular diffusion (Figure 5.2). The advantages of DGT include simplicity, in situ preconcentration, by constraining the passage of the diffusive species results a better definition of the lability of the metal species, which are called "DGT-labile". All these attractive features of DGT have led to its rapid application. 


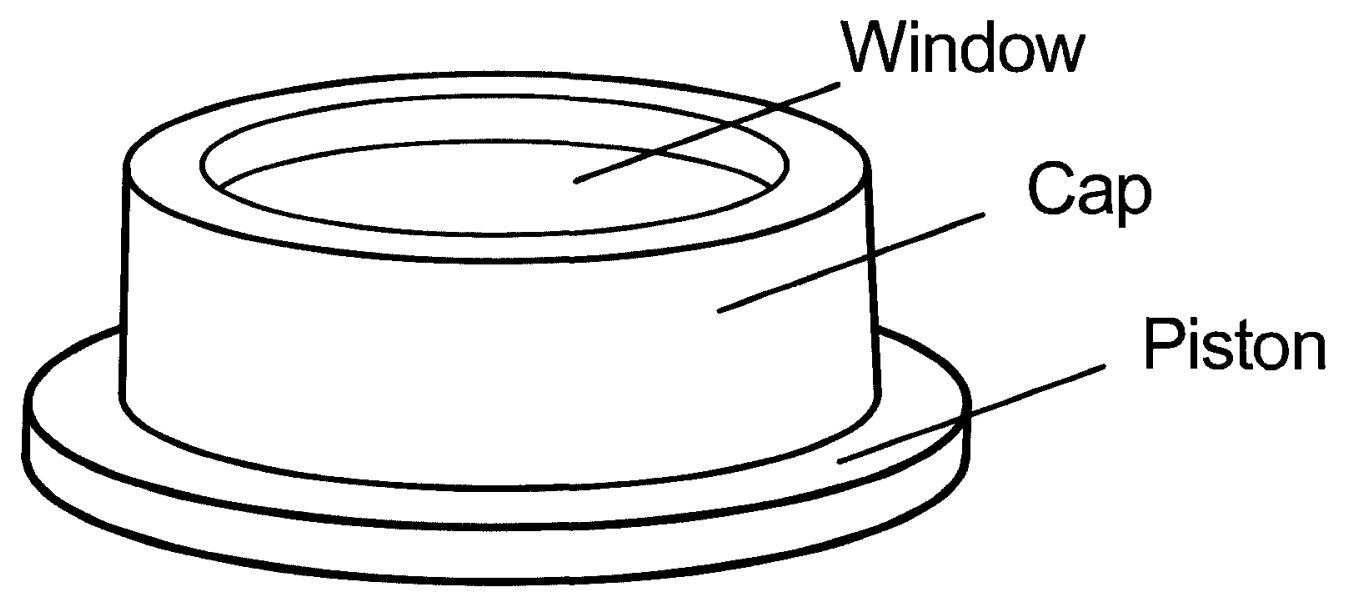

3D diagram

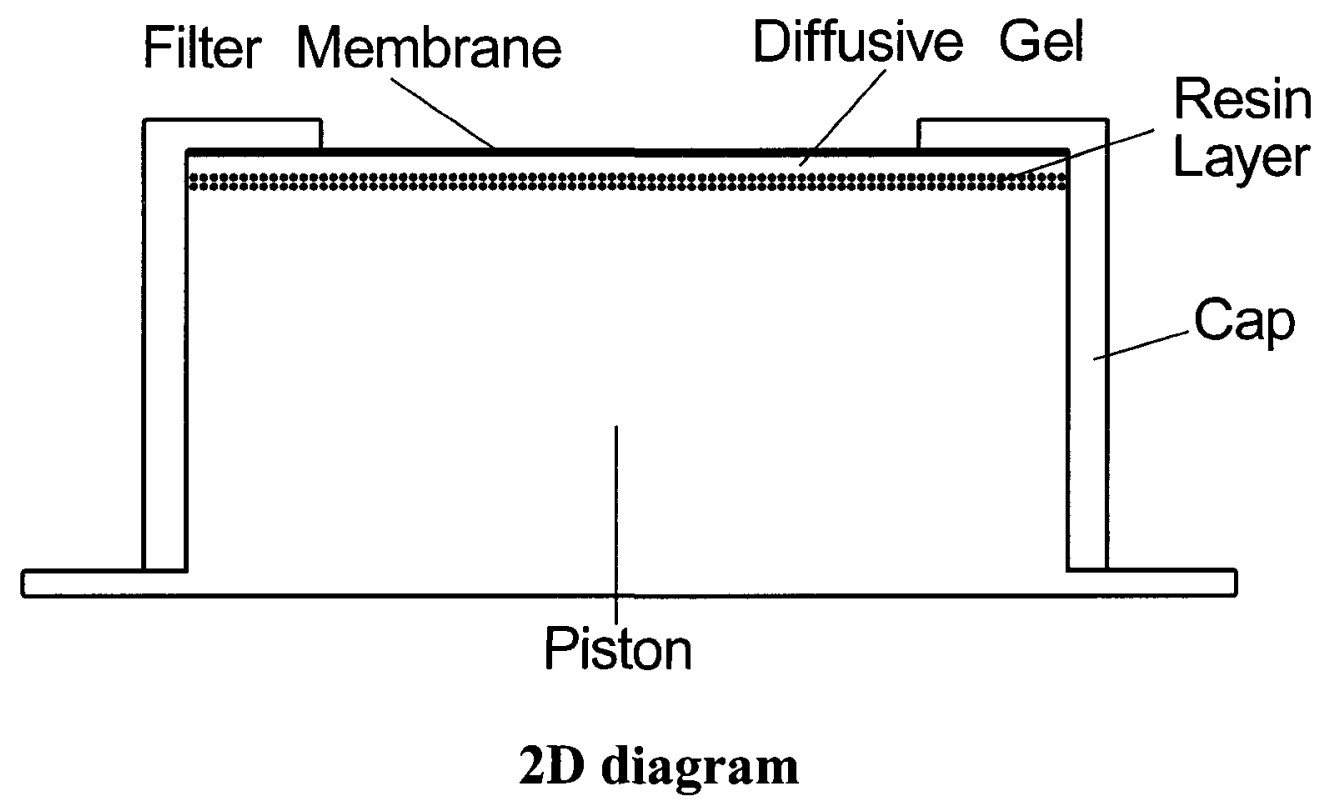

Figure 5.1 Diagram of DGT device 


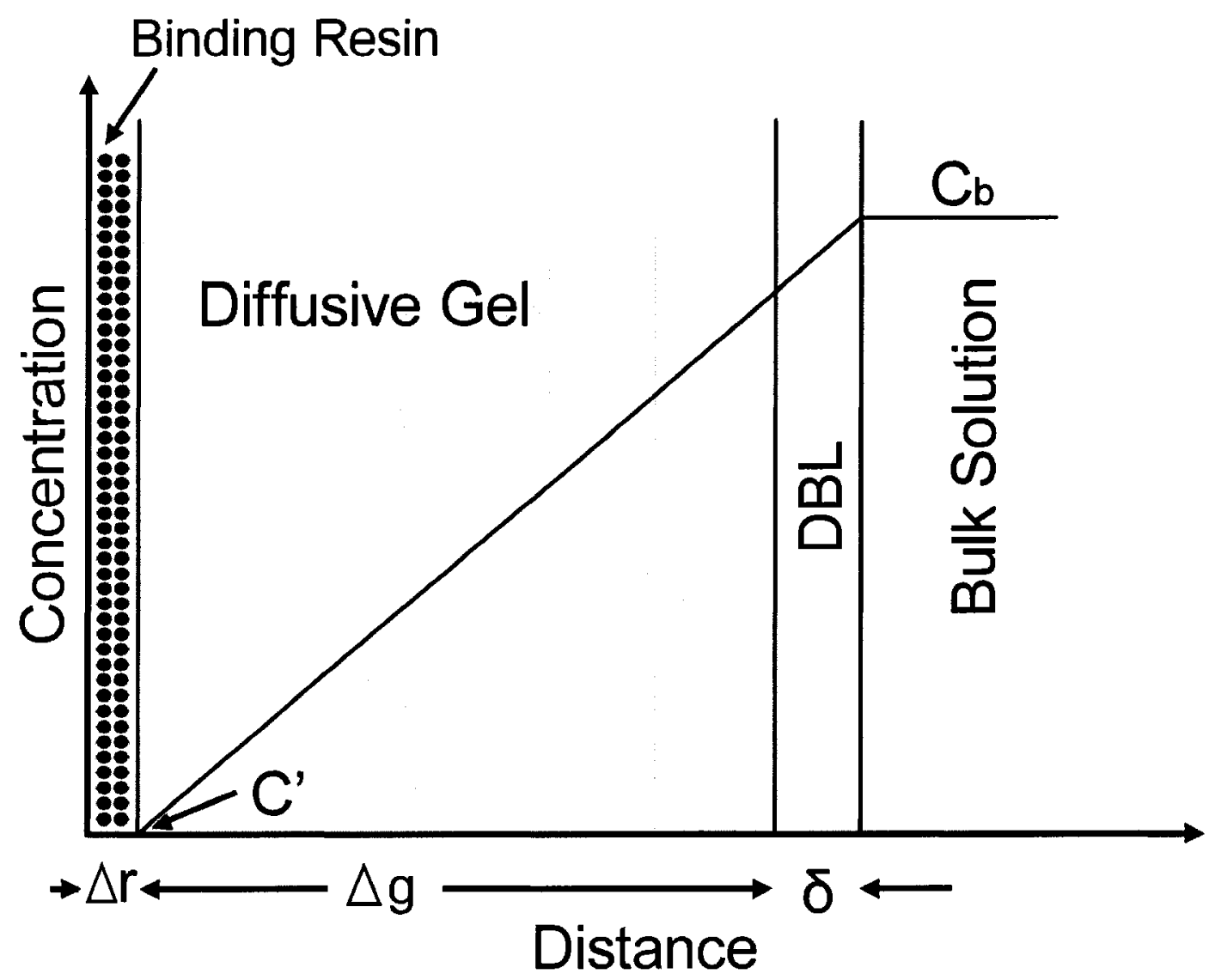

Figure 5.2 Schematic representation of the free concentration of ionic species in a hydrogel assembly in contact with aqueous solution, where the concentration is $C_{b}$. DBL is diffusive boundary layer. The rate of diffusion is assumed to be the same in the gel and solution. 


\subsection{Theory [3]}

The DGT has to have at least two layers: an ion-permeable diffusive gel layer with thickness $\Delta g$ and a metal-binding resin (such as ion-exchange resin Chelex-100) layer, with thickness $\Delta r$, as shown in Figure 5.2.

The diffusive layer is kept as the outside layer which contacts the bulk solution. Therefore, a diffusive boundary layer (DBL) with a thickness $\delta$ exists between the diffusive layer and the bulk solution. In both DBL and the diffusive gel, the transport of ions from the bulk solution to the metal-binding resin layer is solely controlled by molecular diffusion. If $\delta$ is negligibly small compared to $\Delta g$, the flux (F) of metal ions diffusing through the diffusive layer to the metal-binding resin layer can be expressed by

$$
F=D\left(C_{b}-C^{\prime}\right) / \Delta g
$$

where $D$ is the diffusion coefficient of the diffusing species in the gel; $C_{b}$ is the concentration of a free metal ion in bulk solution, and $C^{\prime}$ the concentration of the metal ion in the resin gel layer. If the free metal ions are in rapid equilibrium with the resin, with a large binding constant, in other words, if the free metal ions are rapidly taken up by the binding resin, $\mathrm{C}^{\prime}$ is effectively zero providing the binding resin is not saturated. Hence, equation 1 can be simplified to equation 2

$$
F=D C_{b} / \Delta g
$$

According to the definition of flux, $F(F=M / A t)$, the mass $(M)$ diffused through an area (A), after given time $(t)$ should be

$$
M=D C_{b} t A / \Delta g
$$


Before the saturation of the resin layer, all the diffused ions with the mass of $\mathrm{M}$ will be bound into the resin layer. As the mass of ions in the resin layer, M, can be analytically determined, the concentration in the bulk solution can be calculated by

$$
C_{b}=M \Delta g /(D t A)
$$

The mass of the diffused ion, $M$, can be obtained by two ways: one is direct measurement of the ion concentration, $\mathrm{C}_{\mathrm{r}}$, in the resin layer with total volume $V_{r}$. Hence,

$$
M=C_{r} V_{r}
$$

Another one is an indirect approach. First, the metal ions in the resin layer have to be eluted using a known volume of an eluent, usually $\mathrm{HNO}_{3}$ solution $\left(V_{e}\right)$. Then, the concentration of ions in the eluent, $C_{e}$, can be measured by Atomic Absorption Spectrometry (AAS) or Inductively Coupled Plasma-Mass Spectrometry (ICP-MS). In practice, only a fraction of the bound metal can be eluted. The ratio of the eluted to the bound metal is expressed as the elution factor, $\mathrm{f}_{\mathrm{e}}$, which is about $80 \%$ if $10 \% \mathrm{HNO}_{3}$ is used as the eluent. Taking the elution factor into account, the mass of diffused ions in the resin layer is

$$
M=C_{e}\left(V_{g}+V_{e}\right) / f_{e}
$$

where $V_{g}$ is the volume of resin gel layer. In practice $V_{g}$ is often negligible.

According to Zhang et al. [3], taking account of usual binding capacity of DGT and the usual trace metal concentrations in natural waters, the maximum deployment time of DGT can be from couple of months to 1 year. A practical consideration for the longduration deployment of DGT devices is biofouling, i.e. the progressive accumulation of 
organisms (mainly algal) growth on the DGT surface. Therefore, multiple configurations of DGT devices are usually deployed in order to correct for the deviation.

\subsection{Experimental}

\subsubsection{Gel preparation and mounting}

The diffusive gel and the chelex gel were prepared exactly according to the "Practical Guide for Making Diffusive Gel and Chelex Gel" provided by Hao Zhang for the DGT Resarch Ltd, UK.

\subsubsection{Reagents and materials}

Acrylamide solution, N,N,N'N'-Tetramethylethylenediamine (TEMED) catalyst, Chelex$100, \mathrm{Na}$ form, 200-400 wet mesh were purchased from Bio-Rad Laboratories. Ammonium persulfate (reagent ACS, 98+\%) was purchased from Acros Organic. Ammonium persulphate initiator $10 \%,(\mathrm{w} / \mathrm{v}) 0.1 \mathrm{~g}$ in $1 \mathrm{~g}$ of water was prepared daily. 0.45 $\mu \mathrm{m}$ pore size cellulose nitrate membranes were purchased from Fisher Scientific. A patented cross-linker derived from agarose, and the DGT units which include the front caps and pistons, were purchased from DGT Research Ltd, UK

\subsubsection{Pre-gel solution}

15 gram DGT gel cross-linker and $47.5 \mathrm{ml}$ ultrapure water with resistivity of $18.2 \mathrm{M} \Omega . \mathrm{cm}$ were mixed well together in a clean plastic bottle. Then $37.5 \mathrm{ml}$ acrylamide solution (40\%) were added to the mixture and mixed well by shaking. This gel solution can be stored in a refrigerator $\left(4^{\circ} \mathrm{C}\right)$ for at least three months. 


\subsubsection{Diffusive gel preparation}

$10 \mathrm{ml}$ prepared pre-gel solution, $70 \mu \mathrm{l}$ of ammonium persulphate solution and then $25 \mu \mathrm{l}$ of TEMED solution were added one after another into a $20 \mathrm{~mL}$ dilution vial and mixed well. The mixed solution was immediately cast between two glass plates separated by a plastic spacer of known thickness and incubated at $40^{\circ} \mathrm{C}$ for at least $1 \mathrm{~h}$. The diffusive gels were then hydrated in ultrapure water for at least $24 \mathrm{~h}$. Final thicknesses were in the range $0.4 \pm 0.1 \mathrm{~mm}$ (measured using a caliper vernier), depending on the chosen spacer. Gels were stored and conditioned in ultrapure water before use.

\subsubsection{Resin gel preparation}

$10 \mathrm{ml}$ prepared gel solution and $4 \mathrm{~g}$ of Chelex resin were added into a $20 \mathrm{~mL}$ dilution vial and mixed well. Then, $70 \mu \mathrm{l}$ of ammonium persulphate solution and $25 \mu \mathrm{l}$ of TEMED catalyst solution were added one after another into the vial and mixed vigorously. The mixed solution was immediately cast between two glass plates separated by a plastic spacer of known thickness, laid flat and incubated at $40^{\circ} \mathrm{C}$ for at least 1 hour. The resin

gels were then hydrated in ultrapure water for at least $24 \mathrm{~h}$. Gels were stored and conditioned in ultrapure water before use.

\subsubsection{DGT assembly}

A membrane, a diffusive gel and a resin gel were laid one above another onto the piston and then covered tightly with a front cap with a $2 \mathrm{~cm}$ diameter window (Figure 5.1).

\subsubsection{Sampling location and sampling protocol}


The sampling location was the same as the one in the CLE-ASV study reported in Chapter 3, which was a spot a short way upstream of the Hartwell locks beside Carleton University campus in Ottawa. A one-month study was undertaken in 2006 using DGT sampling periods ranging from 5 to 15 days, i.e., 5,11 and 15 -day periods. DGT devices were deployed in multiple arrays ( 4 in one set), all tied on a stable raft beside the canal bank with $40 \mathrm{~cm}$ fishing strings below the water surface. After retrieval, the DGT devices were lightly rinsed in the field with ultrapure water and then immediately taken back to the laboratory in a sealed plastic bag. During each field trip, the temperature was measured $\left(18.5 \pm 0.5^{\circ} \mathrm{C}\right)$. The water samples were collected using acid-cleaned Teflon bottles. The bottled samples were immediately stored in the refrigerator and analyzed in the following days.

\subsubsection{Binding gel and water samples treatment in the laboratory}

In a CLASS 100 clean room, the DGT devices were dissembled. Each of the binding gels was carefully collected in separate cells filled with $10 \mathrm{~mL} 10 \%$ ultrapure $\mathrm{HNO}_{3}$. The total trace metal concentrations in the acid were determined using a Perkin-Elmer Elan 6100 ICP-MS. The major chemical parameters in the water samples, such as $\mathrm{pH}, \mathrm{TOC}$, major cation and anion concentration were measured, as described in Experimental section 3.3.1 in Chapter 3.

\subsection{Results and discussions}


Figures 5.3-5.5 present the DGT uptake of copper, lead and nickel versus time of the deployment in Rideau Canal during the deployment period of 15 days. Table 5.1 presents some general chemical information on the collected samples (which remained unchanged during the sampling period of 15 days). Table 5.2 presents the concentration of labile metal species determined by DGT.

Figures 5.3-5.5 show that the concentrations of the accumulated metals increased linearly with the period of deployment of the DGT devices, in conformity with equation (3). These results reinforced the suitability of the DGT device for deployment in natural waters, long enough for useful measurement as long as the DGT device was not saturated with metals and biofouling of the DGT device did not occur. Table 5.2 shows that the average relative standard deviation of the three DGT sets (each with 4 replicates) for copper, lead and nickel were $37.7 \%, 36.7 \%$, and $20.9 \%$, respectively, which was mainly due to the low concentrations of the eluted metals (sub ppb level, near the ICP-MS detection limit). Although the reported measurement uncertainty of DGT multiple deployment is relative small in controlled laboratory conditions (e.g. $\leq 10 \%$ ), during in situ application the measurement uncertainty could be much larger [4]. Cleven reported that for $\mathrm{Cu}$ and $\mathrm{Ni}$, the average values for the reproducibility of the results for freshwater samples from river Meuse and Rhine were $28 \%$ and $17 \%$, respectively. The durations of the deployment (each set with replicates) in that case were bi-weekly or weekly for five months (the longest). For monitoring metal speciation in natural waters, DGT therefore appears to be a robust and easy-to-handle technique. The uncertainty could be easily decreased by extending the duration of the deployment within a reasonable range. 
As a sampler and metal speciation technique, what DGT determines not only depends on the conditions of the device and the sampling environment but also depends on the metal species distribution, i.e. more metal organic complex less DGT-labile metal species. Therefore, it is difficult to define the detection limit of DGT. However, with the increasing sensitivity of the metal analytical technique, e.g. ICP-MS in this study, and the increasing deployment time of DGT, the detectable concentration of DGT-labile species decreases. Theoretically, DGT should measure only labile species, similar to ASV [3]. The published literature contains a report showing consistent measurements between using DGT and ASV [5]. Based on the comparison between the copper DGT-labile species and the free copper ion concentration determined by CLE-ASV in the freshwater sample from Rideau Canal reported in Chapter 4, the conclusion that more than $99 \%$ copper was bound to NOM was valid, although the concentrations of the DGT-labile species was much larger than those of the free copper ion determined by CLE-ASV with EDTA. 


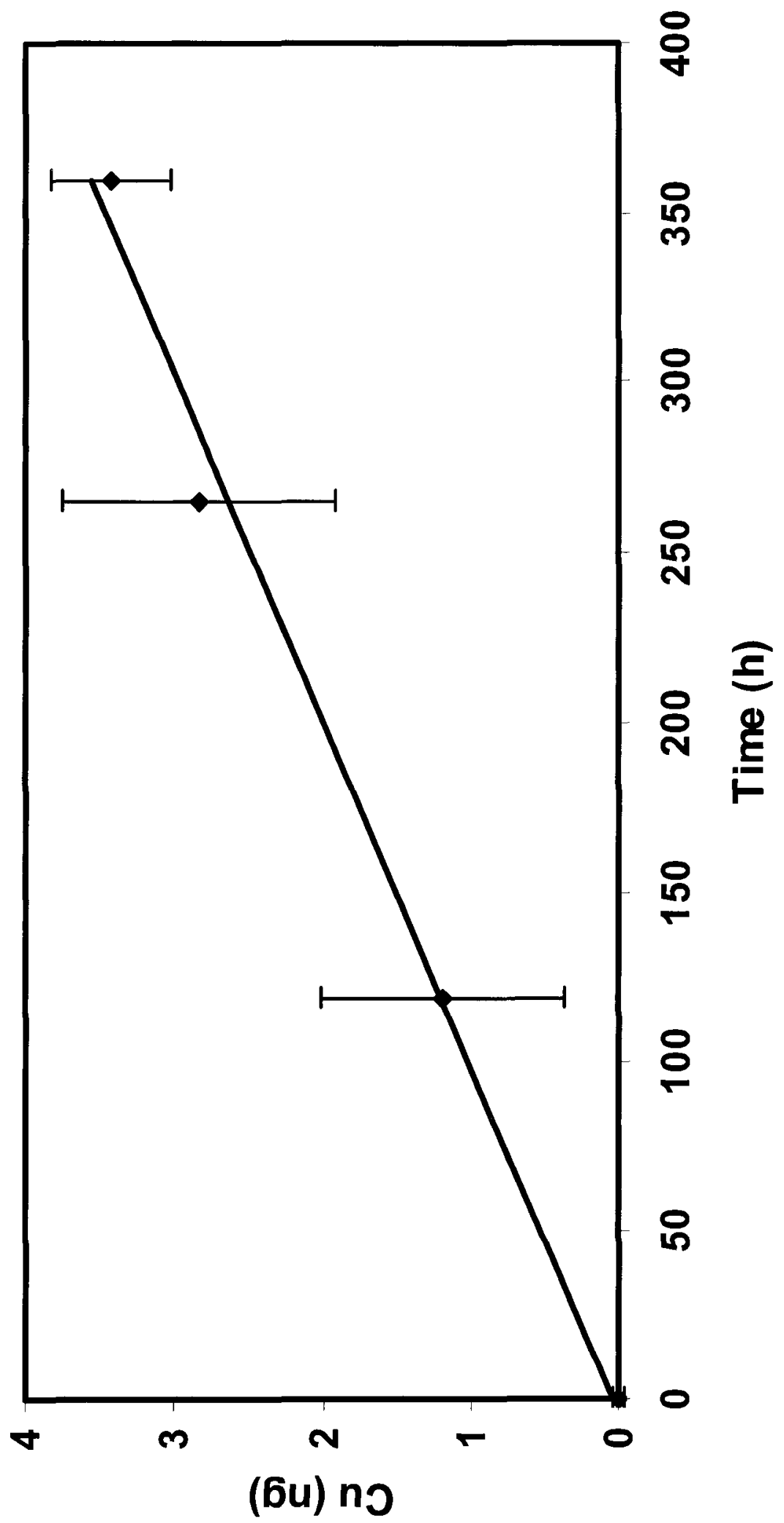

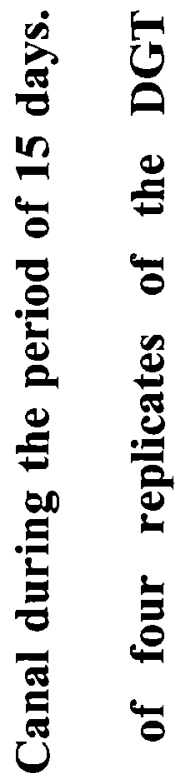

泀

葛

离

ย อ

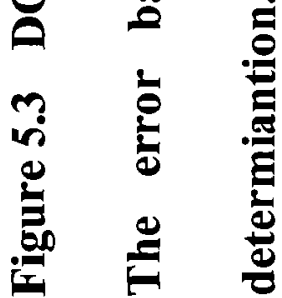




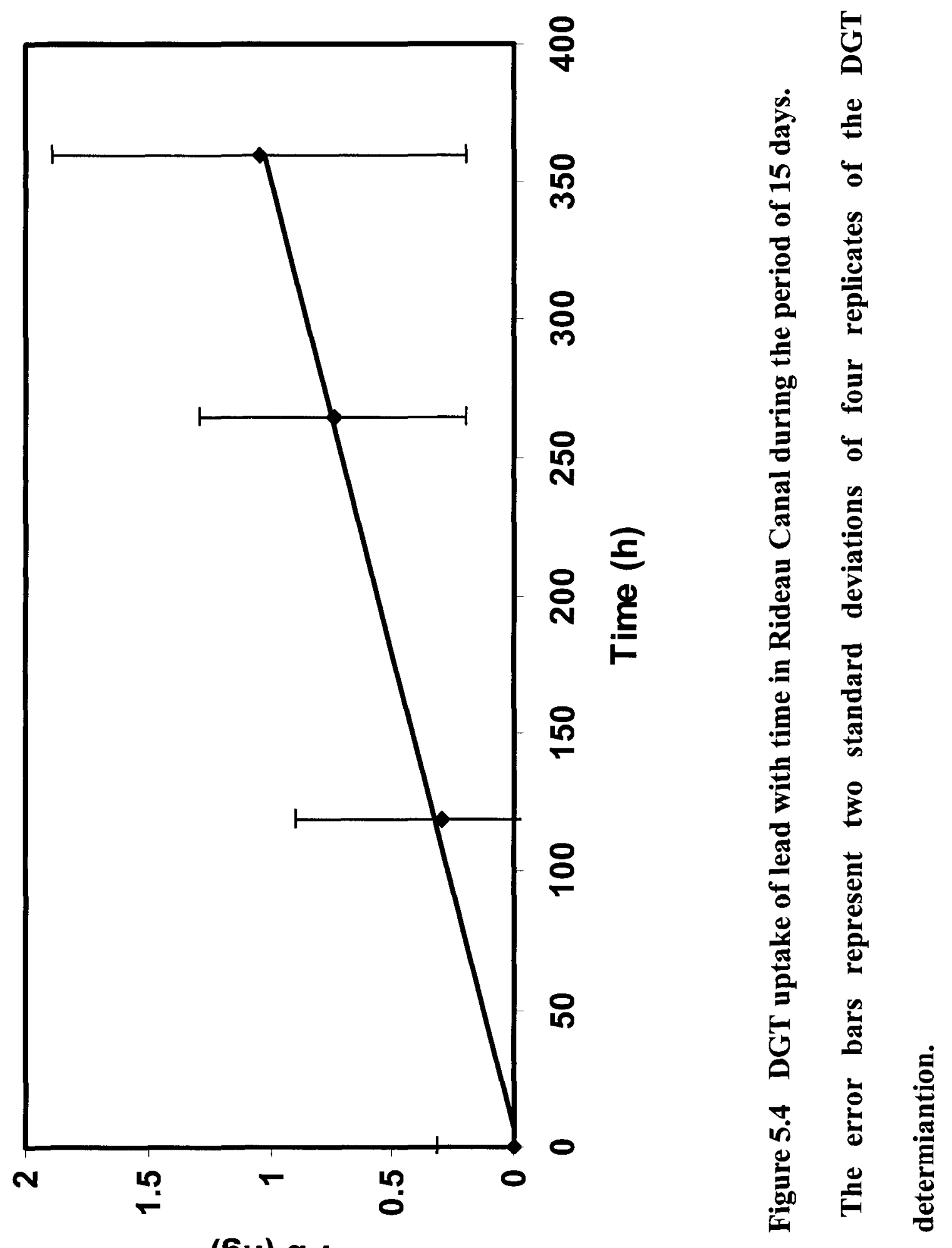

(6u) qd 


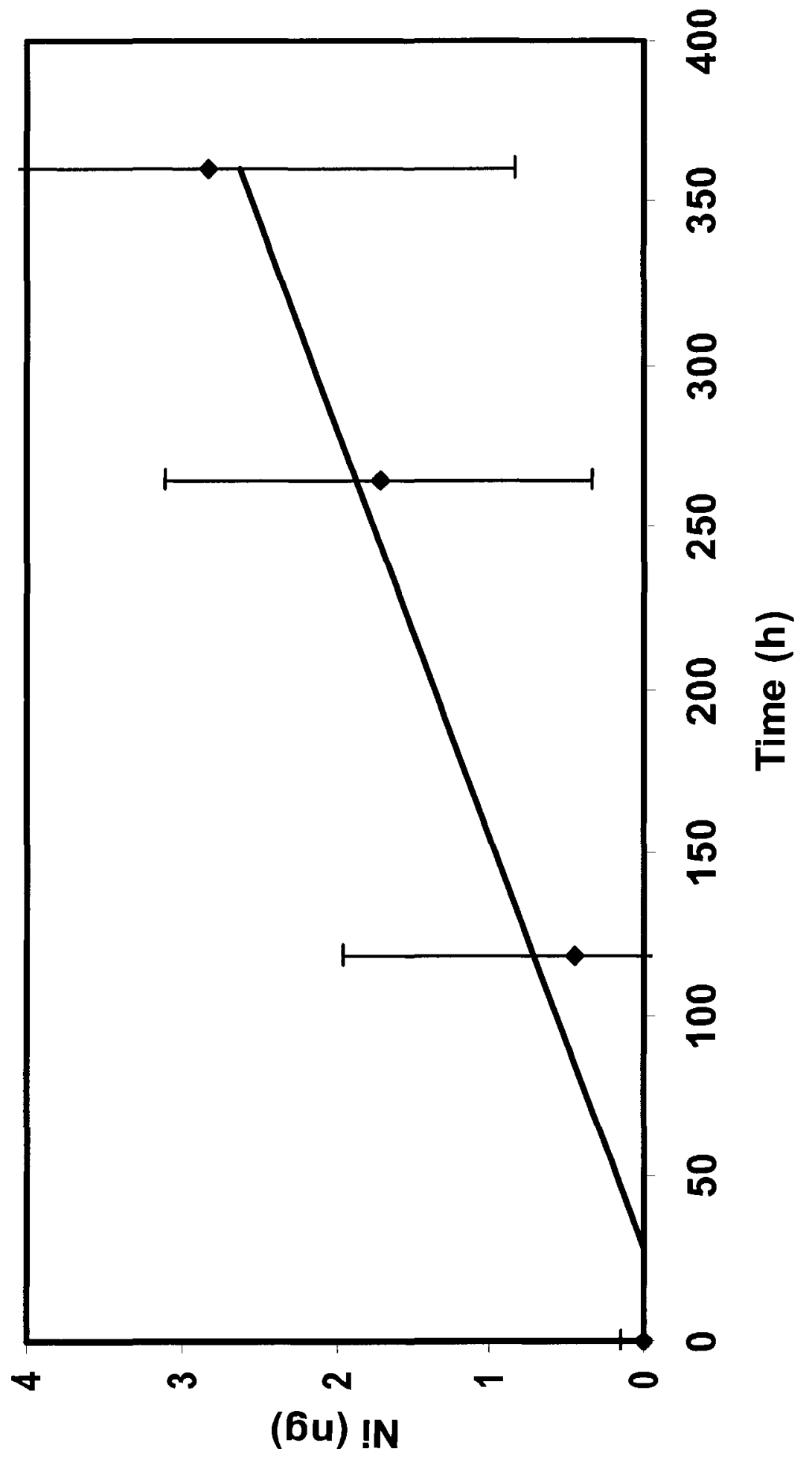

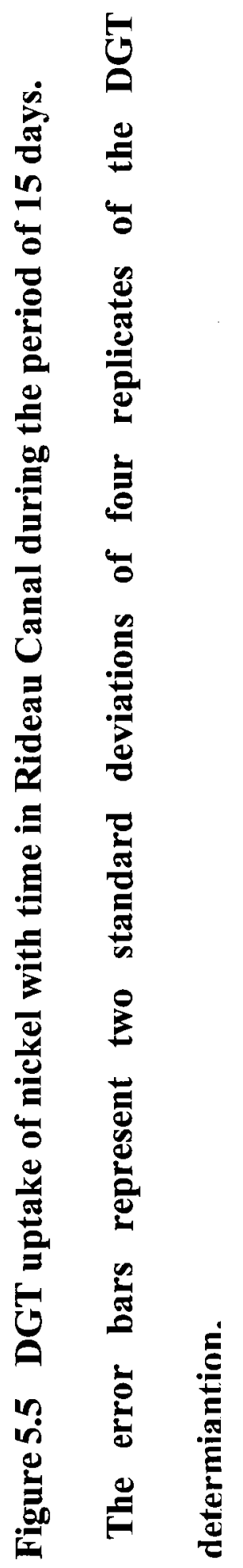



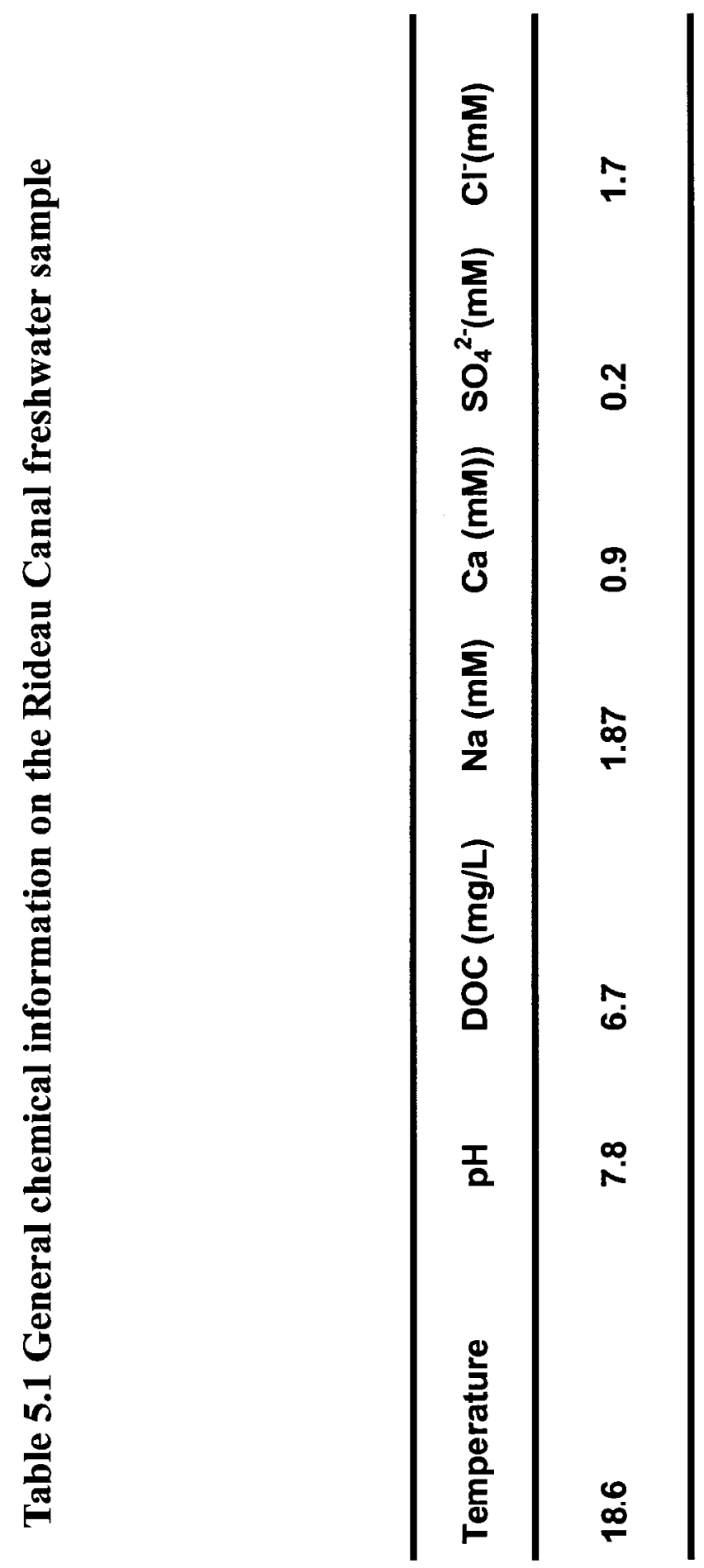


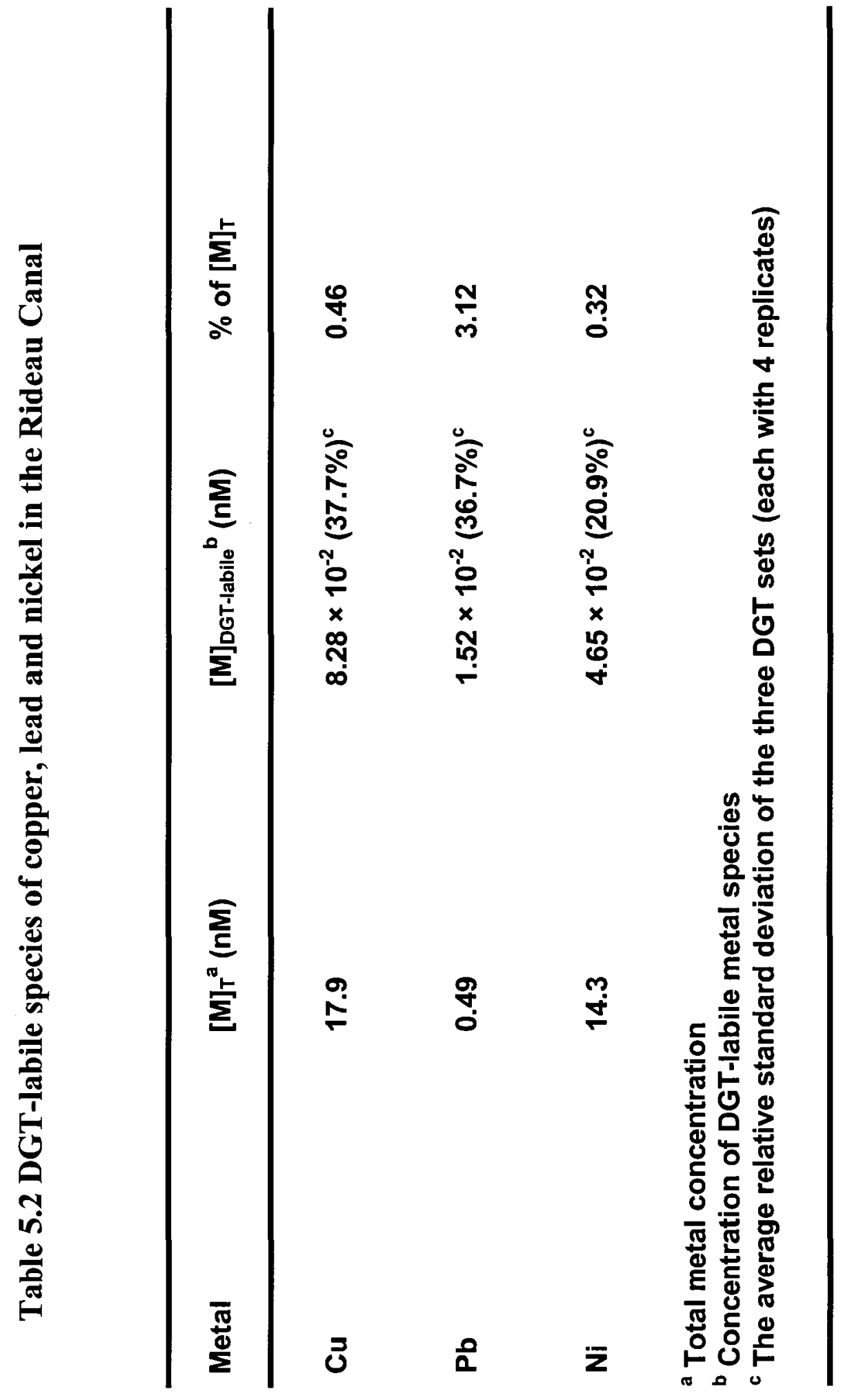




\subsection{References}

1. M -L. Tercier and J Buffle In Situ Voltammetric Measurements in Natural Waters:Future Prospects and Challenges Electroanalysis, (1993), (5), 187-200

2. W. Davison and H. Zhang In situ speciation measurements of trace components in natural waters using thin-film gels Nature (1994a), 367, 546

3. Zhang, Hao and Davison, William. Performance Characteristics of Diffusion Gradients in Thin Films for the in Situ Measurement of Trace Metals in Aqueous Solution. Analytical Chemistry (1995), 67(19), 3391-400.

4. Cleven, R.; Nur, Y.; Krystek, P.; and van den Berg, G. Monitoring metal speciation in the Rivers Meuse and Rhine using DGT. Water, Air, and Soil Pollution (2005) 165: 249--263

5. Zhang, Hao and Davison, William. Direct In Situ Measurements of Labile Inorganic and Organically Bound Metal Species in Synthetic Solutions and Natural Waters Using Diffusive Gradients in Thin Films. Analytical Chemistry (2000), 72, 4447-4457. 
-Chapter 6 -

Copper Toxicity Test using freshwater alga

Selenastrum capricornutum 


\subsection{Introduction}

The potential health and environmental effects of individual chemicals and their mixtures in the natural environment lead society to seek the basic information on toxicity. This leads to investigating any link between the speciation of a metal in natural waters and its bioavailability and toxicity to freshwater biota. The chemical speciation study is mainly to serve the bioavailability and the toxicity prediction purpose.

Although the current computer model Biotic Ligand Model (BLM) has proven to be a satisfactory model to predict acute ecological effects of metals to organisms in the aquatic systems in many cases, in some cases weaknesses still exist. First of all, in wastewaters, there are a wide variety of ligands that can bind to metals which are not currently accounted for the BLM. Secondly, metals can influence each other's toxicity in a variety of ways, which is also not accounted for in the BLM. For example, additive effects result when the toxicity of the mixture is equal to the sum of the toxicities of the

individual components. Synergistic or antagonistic interactions result when the toxicity of the mixture is greater or less than the sum of the toxicities of the individual components, respectively.

Biological tests using test organisms are the most direct approaches to get the toxicity information. However, it is impossible to use a single test with a single test organism to get a comprehensive understanding of the toxicity of even a single chemical. Still, because of the limitation of the time and the budget, a standard biological test by Environmental Canada was applied to promptly assess the chronic toxicity of a 
freshwater sample in order to improve the current computer-model BLM so as to predict reliably the chronic toxicity of metal mixtures. Growth Inhibition Test using $S$ capricornutum, was applied to the model solution and the collected freshwater sample [1].

\subsection{Theory [1]}

The test organism used in this work is Selenastrum capricornutum, a nonmotile, crescentshaped (40 to $60 \mu \mathrm{m}^{3}$ ), unicellular green alga which is ubiquitous in most freshwaters in North America.

The test consists of the exponentially growing $S$ capricornutum being exposed in a static, microtitre system to various concentrations of a test substance over several generations, under well-defined conditions. The growth of the algae exposed to the test substances is compared with the growth of the algae in an appropriate control over a fixed period. A test substance is considered toxic when a statistically significant, dose-dependent inhibition of algal growth occurs.

\subsection{Experimental}

\subsubsection{Sampling Location and Sampling Protocol}

Freshwater sample was collected from Lake Dufault in June 2003, in Rouyn-Noranda area, northwestern Quebec, Canada (see Chapter 2.3.1).

\subsubsection{Reagents}


One of the stock solution of copper, which was used to spike the growth inhibition test solutions, was an ICP-MS \& ICP-AES standard solution (1000 $\mu \mathrm{g} / \mathrm{ml})$ of copper prepared from copper nitrate purchased from SCP Science, Montreal, Canada. Another such stock solution $(100 \mu \mathrm{g} / \mathrm{ml})$ of copper was prepared by dissolving an appropriate quantity of copper sulfate pentahydrate (Aldrich) in ultrapure water. Ultrapure water having resistivity of $18.2 \mathrm{M} \Omega . \mathrm{cm}$ was obtained direct from a Milli-Q-Plus water purification system (Millipore Corporation). A 2 M stock solution of sodium hydroxide solution was prepared by dissolving an appropriate quantity of sodium hydroxide (Aldrich) in ultrapure water. All the chemicals for the growth medium of the algal culture were of reagent grade purity. The prepared growth medium was filter-sterilized in a vacuum (not exceeding $50.7 \mathrm{kPa}$ ), using a sterile apparatus and a prewashed $0.2 \mu \mathrm{m}$ membrane.

\subsubsection{Algal culturing}

The "starter" culture of $S$. capricornutum was purchased from University of Toronto Culture Collection (UTCC 37). The composition of the sterilized growth medium is listed in Table 6.1. The algal stock cultures were aseptically incubated in the growth medium at $24 \pm 2^{\circ} \mathrm{C}$ under continuous "cool white" fluorescent light with an intensity of 4.0 klux at the surface of the flask. The flask with the algae was placed on a continuous shaker at $100 \mathrm{rpm}$. The algal culture took 7 to 14 days to reach the exponential growth phase. When this occurred, the culture was very green in color and the cell concentration was approximately $2 \times 10^{6}$ to $3 \times 10^{6}$ cells $/ \mathrm{mL}$. The maintenance of the algal culture was exactly according to the Environmental Canada Report [1]. 
Table 6.1 Final concentrations of nutrients in the liquid growth medium of the stock algal culture.

\begin{tabular}{|c|c|c|c|}
\hline Macronutrient & Concentration (mg/L) & Element & Concentration (mg/L) \\
\hline $\mathrm{NaNO}_{3}$ & 25.2 & $\mathbf{N}$ & 4.20 \\
\hline $\mathrm{MgCl}_{2} \cdot 6 \mathrm{H}_{2} \mathrm{O}$ & 10.0 & $\mathbf{M g}$ & 2.65 \\
\hline $\mathrm{CaCl}_{2} \cdot 2 \mathrm{H}_{2} \mathrm{O}$ & 4.42 & $\mathrm{Ca}$ & 1.20 \\
\hline $\mathrm{MgSO}_{4} \cdot 7 \mathrm{H} 2 \mathrm{O}$ & 14.7 & $\mathbf{s}$ & 1.91 \\
\hline \multirow[t]{2}{*}{$\mathrm{K}_{2} \mathrm{HPO}_{4}$} & 1.04 & $\mathbf{P}$ & 0.186 \\
\hline & & $\mathbf{K}$ & 0.469 \\
\hline \multirow[t]{2}{*}{$\mathrm{NaHCO}_{3}$} & 15.0 & $\mathrm{Na}$ & 11.0 \\
\hline & & C & 2.14 \\
\hline Micronutrient & Concentration ( $\mu \mathrm{g} / \mathrm{L})$ & Element & Concentration $(\mu \mathrm{g} / \mathrm{L})$ \\
\hline $\mathrm{H}_{3} \mathrm{BO}_{3}$ & 185.52 & $\mathbf{B}$ & 32.44 \\
\hline $\mathrm{MnCl}_{2} \cdot 4 \mathrm{H}_{2} \mathrm{O}$ & 415.62 & Mn & 115.38 \\
\hline $\mathrm{ZnCl}_{2}$ & 3.28 & $\mathrm{Zn}$ & 1.57 \\
\hline $\mathrm{CoCl}_{2} \cdot 6 \mathrm{H}_{2} \mathrm{O}$ & 1.43 & Co & 0.35 \\
\hline $\mathrm{CuCl}_{2} \cdot 2 \mathrm{H}_{2} \mathrm{O}$ & 0.012 & $\mathrm{Cu}$ & 0.004 \\
\hline $\mathrm{Na}_{2} \mathrm{MoO}_{4} \cdot 2 \mathrm{H}_{2} \mathrm{O}$ & 7.26 & Mo & 2.88 \\
\hline $\mathrm{FeCl}_{3} \cdot 6 \mathrm{H}_{2} \mathrm{O}$ & 160 & $\mathbf{F e}$ & 33.1 \\
\hline $\mathrm{Na}_{2}$ EDTA $\cdot 2 \mathrm{H}_{2} \mathrm{O}$ & 300 & & \\
\hline
\end{tabular}




\subsubsection{Growth inhibition test using S. capricornutum}

The test solutions including the control waters and freshwater samples from Lake Dufault were prepared one day before the growth inhibition test. A series of $5 \mathrm{~mL}$ ultrapure waters were spiked with different volumes of the copper standard solution to prepare

copper concentrations of $0,5,10,15,20,25,30,35,40,50,100 \mathrm{mg} \mathrm{L}^{-1}$, respectively. A series of $5 \mathrm{~mL}$ freshwater samples from Lake Dufault were spiked with different volumes of the copper standard solution to prepare copper concentrations of $0,25,50,75,100$, $125,150,175,200,250,500 \mathrm{mg} \mathrm{L}^{-1}$, respectively. The $\mathrm{pH}$ of the two series of copper solutions was adjusted to 7.0 using appropriate amounts of sodium hydroxide solution.

Two microplates with lids were sterilized using ultraviolet light for 15 to 20 minutes prior to use. A multichannel pipette was used to dispense $220 \mu \mathrm{L}$ of ultrapure water from a plastic reagent reservoir to each of the 36 peripheral wells of a microplate. $200 \mu \mathrm{L}$ of ultrapure water was pipetted into each of the 10 wells (from D2 to D11) that would serve as the standard reagent controls (see Figure 6.1). With the multichannel pipette dispenser, starting with the lowest concentration of test solution and ending with the highest concentration of test solution, the control waters and freshwater samples from Lake Dufault with different copper concentrations were added to the appropriate microplate wells in two different microplates. With the multichannel pipette dispenser, $20 \mu \mathrm{L}$ of algal inoculum and enrichment medium mixture was added to each well of the microplate, except the peripheral wells. The cell concentration in each microplate well was $10000 \pm$ 1000 cells $/ \mathrm{mL}$. The final concentrations of nutrients in the microplate well from the enrichment medium are listed in Table 6.2. 


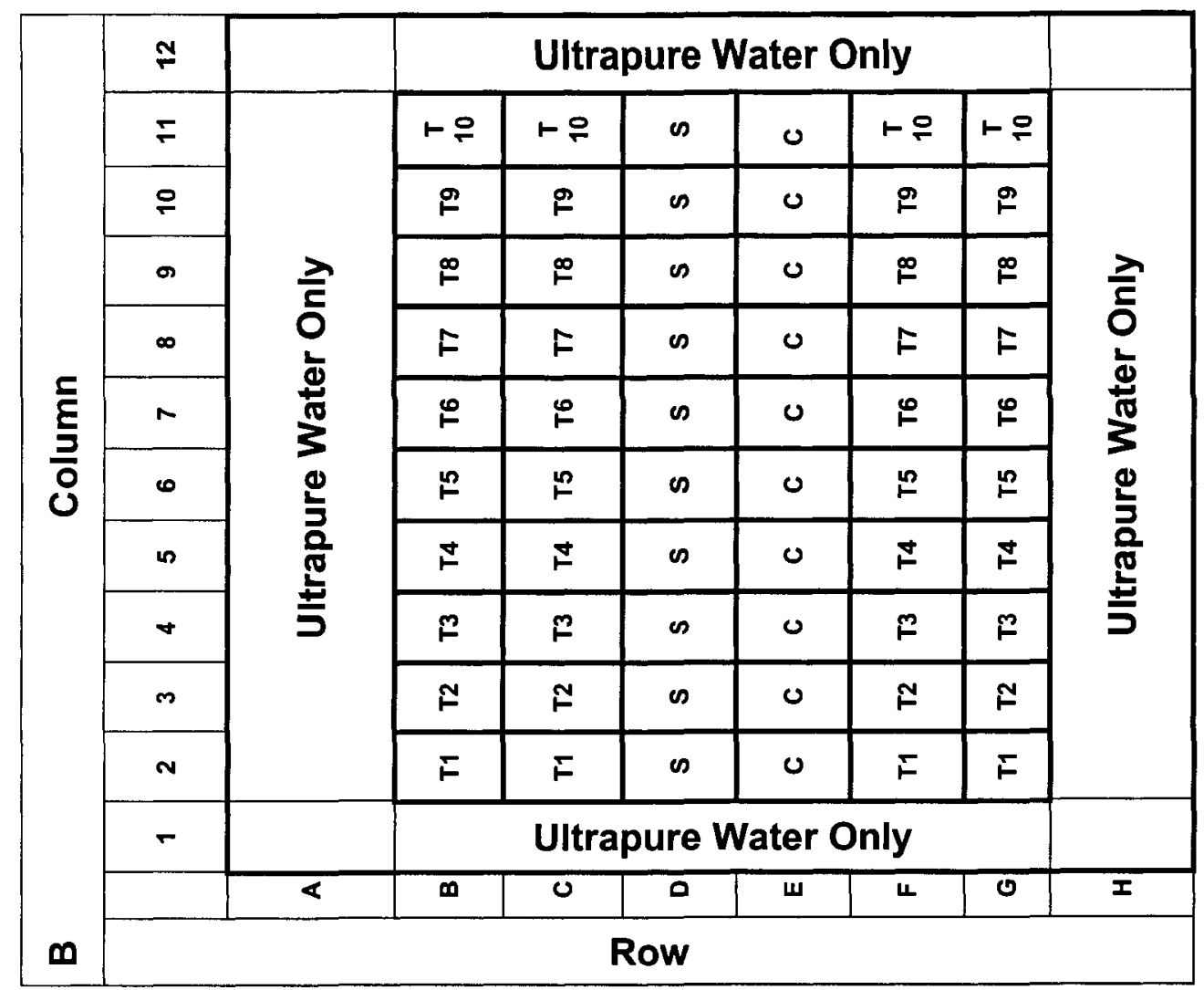

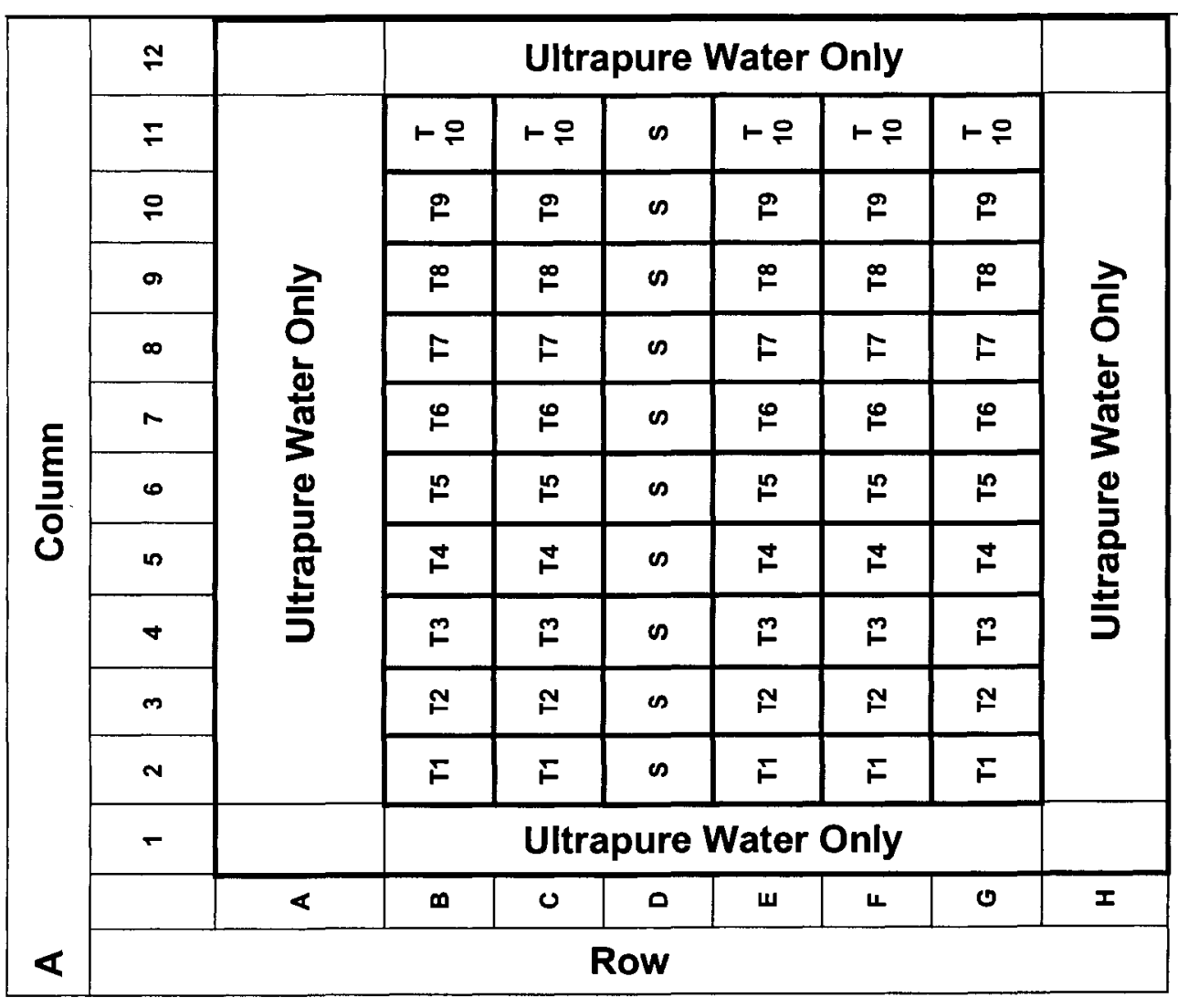

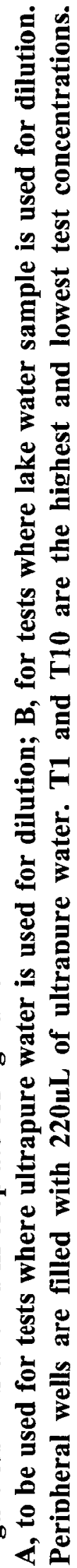


Table 6.2 Final concentrations of nutrients in the microtest medium.

\begin{tabular}{|c|c|c|c|}
\hline Macronutrient & Concentration (mg/L) & Element & Concentration (mg/L) \\
\hline $\mathrm{NaNO}_{3}$ & 15.94 & $\mathbf{N}$ & 2.63 \\
\hline $\mathrm{MgCl}_{2} \cdot 6 \mathrm{H}_{2} \mathrm{O}$ & 6.25 & $\mathbf{M g}$ & 1.65 \\
\hline $\mathrm{CaCl}_{2} \cdot 2 \mathrm{H}_{2} \mathrm{O}$ & 2.76 & $\mathbf{C a}$ & 0.75 \\
\hline $\mathrm{MgSO}_{4} \cdot 7 \mathrm{H} 2 \mathrm{O}$ & 9.19 & $\mathbf{S}$ & 1.20 \\
\hline \multirow[t]{2}{*}{$\mathrm{K}_{2} \mathrm{HPO}_{4}$} & 0.65 & $\mathbf{P}$ & 0.12 \\
\hline & & $\mathbf{K}$ & 0.293 \\
\hline \multirow[t]{2}{*}{$\mathrm{NaHCO}_{3}$} & 9.38 & $\mathrm{Na}$ & 6.88 \\
\hline & & C & 1.34 \\
\hline Micronutrient & Concentration ( $\mu \mathrm{g} / \mathrm{L}$ ) & Element & Concentration ( $\mu \mathrm{g} / \mathrm{L})$ \\
\hline $\mathrm{H}_{3} \mathrm{BO}_{3}$ & 115.95 & B & 20.27 \\
\hline $\mathrm{MnCl}_{2} \cdot 4 \mathrm{H}_{2} \mathrm{O}$ & 259.76 & Mn & 72.11 \\
\hline $\mathrm{ZnCl}_{2}$ & 2.05 & $\mathbf{Z n}$ & 0.98 \\
\hline $\mathrm{CoCl}_{2} \cdot 6 \mathrm{H}_{2} \mathrm{O}$ & 0.89 & Co & 0.22 \\
\hline $\mathrm{CuCl}_{2} \cdot 2 \mathrm{H}_{2} \mathrm{O}$ & 0.008 & $\mathrm{Cu}$ & 0.003 \\
\hline $\mathrm{Na}_{2} \mathrm{MoO}_{4} \cdot 2 \mathrm{H}_{2} \mathrm{O}$ & 4.54 & Mo & 1.8 \\
\hline $\mathrm{FeCl}_{3} \cdot 6 \mathrm{H}_{2} \mathrm{O}$ & 100 & $\mathrm{Fe}$ & 20.7 \\
\hline $\mathrm{Na}_{2}$ EDTA $\cdot 2 \mathrm{H}_{2} \mathrm{O}$ & 187.5 & & \\
\hline
\end{tabular}


The lids were added to cover each microplate. The microplates were sealed separately in plastic bags. The test began as soon as the microplates were ready. The sealed microplates were then placed in a incubator at $24 \pm 2^{\circ} \mathrm{C}$ under continuous "cool white" fluorescent light with an intensity of $4.0 \mathrm{klux}$ at the surface of the microplate for 72 hours.

The growth inhibition tests were done twice: once, using copper nitrate solution for the copper spiking, the other time, using copper sulfate solution for the copper spiking.

\subsection{Results and discussions}

Table 6.3 shows the copper toxicity results in freshwater sample from Lake Dufault using Selenastrum capricorntum. The EC50 values for controls determined in this study are not very different from those reported by other researchers, for example, $6 \mathrm{ppb}$ and $17 \mathrm{ppb}$ by Franklin [2, 3], 47 ppb by Nyholm [4], although using different growth inhibition test protocols.

The results show that the lake water containing DOC was even less tolerant of copper than the de-ionized water, which seems unreasonable, since DOC should bind copper to reduce the copper toxicity. This anomaly may be the result of the very high zinc concentration in the lake waters, while the concentrations of the other trace metals were low (see Table 6.4). There are number of studies showing that copper and zinc interact with each other on the metal toxicity to different organisms [5]. BLM certainly could not provide accurate prediction on copper toxicity for this freshwater sample, which proves 
the importance of the study on how metal-metal interaction affects the metal bioavailability and metal toxicity.

Although the concentrations of free copper ion and labile copper, which provide valuable information to predict copper toxicity to biota, can be determined using several copper speciation techniques, such as ASV, CLE-AdCSV, DGT, and other techniques, they cannot provide direct quantitative information on copper toxicity. Bioassay, such as the growth inhibition test using $S$. capricornutum, is the most straightforward method to assess copper toxicity. Microorganisms are becoming more and more important test organisms for bioassay because of their sensitivity, reproducibility, robustness, and other properties, especially, the short lifecycle of microorganism is a significant advantage over higher organism for chronic test. However, when trying to link metal speciation with metal bioavailability and toxicity, simple metal speciation and toxicity information become insufficient, since simple correlation cannot provide cause. Metals interact with each other, affecting their toxicities, by non-additive, additive, synergistic or antagonistic effects. The next chapter will provide valuable information on this subject. 

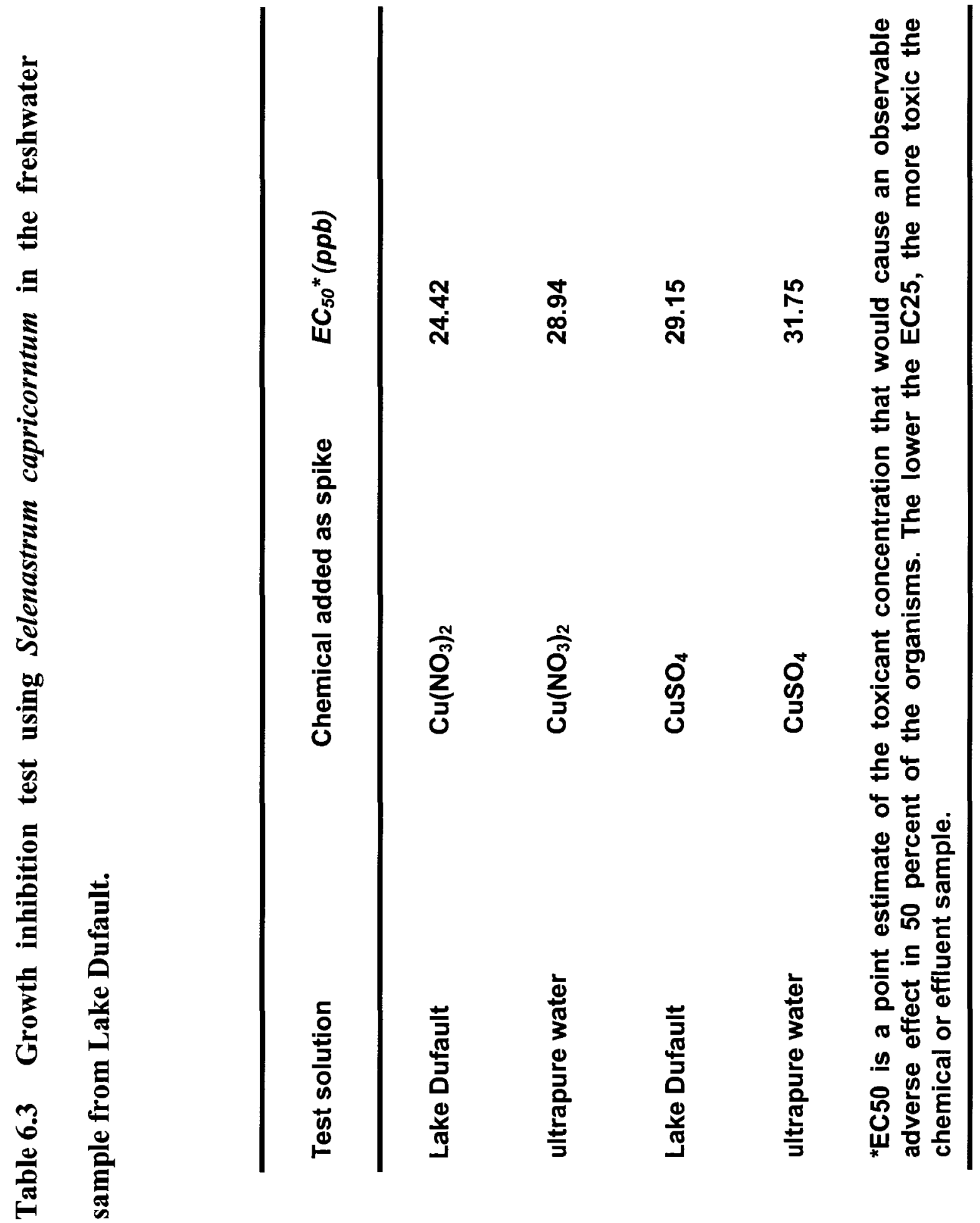

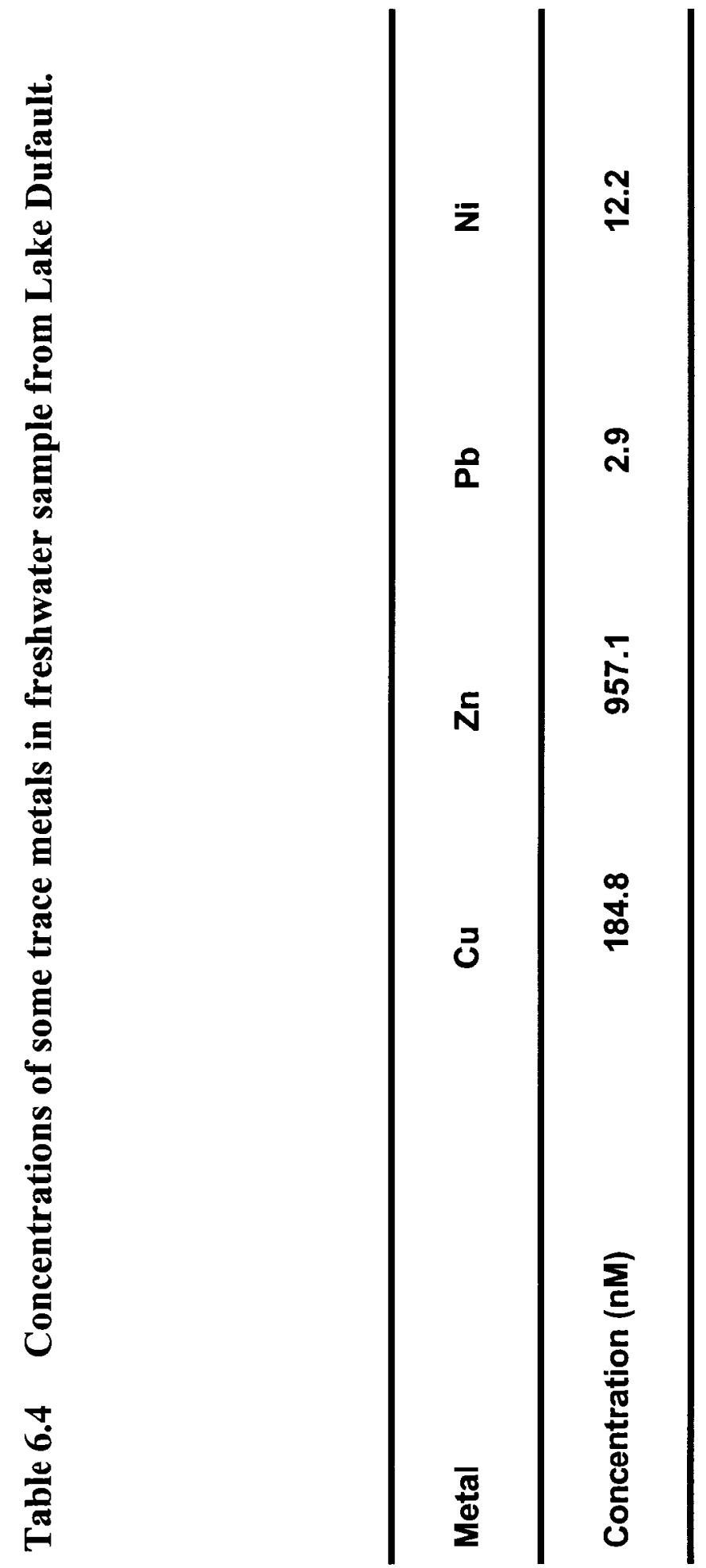


\subsection{References}

1. Biological test method: Growth Inhibition Test Using the Freshwater Alga Selenastrum capricornutum / Environmental Protection Service report series. EPS 1/RM/25, Environment Canada. 1992

2. Franklin, N.M., Stauber, J.L., and Lim, R.P. 2000b. Development of flow cytometry-based algal bioassays for assessing the toxicity of metals in natural waters. Environmental Toxicology and Chemistry (2001) 20(1), 160-70

3. Franklin, N.M., Stauber, J.L., Apte S.C., and Lim, R.P. Effect of initial cell density on the bioavailability and toxicity of copper in microalgal bioassays. Environmental Toxicology and Chemistry (2002) 21(4),742-51

4. Nyholm, N. Expression of results from growth inhibition toxicity tests with algae. Archive Environment Contamination and Toxicology (1990) 19, 518-522.

5. Preston, S., N. Coad, J. Townend, K. Killham, and G.I. Paton. Biosensing the acute toxicity of metal interactions: Are they additive, synergistic, or antagonistic? Environmental Toxicology and Chemistry, (2000), 19, 775-780. 
-Chapter 7-

Investigation of copper uptake kinetics by freshwater alga Selenastrum capricornutum using Competing Ligand Exchange Method (CLEM)

with Inductively Coupled Plasma-Mass Spectrometry (ICP-MS) 


\subsection{Introduction}

After many years of testing, BLM has been accepted as the best available model to account for a wide body of experimental and field data on metal bioavailability and toxicity in the aquatic environment. The main assumptions underlying BLM are 1) the complexation of the free metal ion, $M$, and ligand, $L$, in the bulk solution is at chemical equilibrium, 2) the binding reaction of $\mathrm{M}$ and biotic ligand, $\mathrm{B}$, is close to chemical equilibrium and 3) the trans-membrane transportation occurs at a rate slower than the complexation reaction and the binding reaction, stay commonly true under most experimental conditions (high metal ion concentrations, constant inorganic ion composition, synthetic organic chelators and acute toxicity effect). [1]

However, there are some areas where BLM has not been applied. First, under the natural freshwater condition, where humic (or fulvic) acid concentration is high and metal concentration is low, assumptions 1) and 3) are questionable; especially, for the chronic toxicity effect, the strong binding sites of humic (or fulvic) acid may become important, whereas they have been regarded as inert when only rapid complextion reaction between free metal ions and weak binding sites and acute toxicity effect are studied. The kinetics of metal complexation in the bulk solution, of metal binding with the biotic ligand and of trans-membrane transport may have to be taken into account. [2]

There is another problem with the BLM, which is that metal-contaminated freshwaters, especially municipal or industrial effluents, contain large amounts of complex mixtures of multi-metals and anthropogenic ligands. Different metals may enter the biological 
membrane through different biotic ligand or sharing the same biotic ligand. When the latter happens, the multi-metal effect must be taken into account in BLM. BLM has not been applied to multi-metal estimation. Also, the simple additive or non-additive theory often cannot account for the metal toxicity under such conditions. [3, 4]

The kinetic distinction between metal-binding and inside-the-biota trans-membrane processes is currently often neglected partly because it can be difficult to measure experimentally. First, if one tries to separate the above two processes, the multi-operation steps involved may introduce large experimental errors. Secondly, the kinetics of diffusion is also often neglected because of experimental difficulties. Moreover, studies to date have often relied on the calculated rather than the experimental measured speciation in the medium. The current speciation measurements are usually timeconsuming and painstaking, and involve large experimental errors. Furthermore, the experimental conditions in which high metal concentrations and synthetic organic ligands have been used are far removed from those in natural waters.

The ICP-MS should provide an ideal tool for fast-sequential, almost instantaneous monitoring of the metal concentrations in test solutions, allowing a continuous recording of the kinetic event. Freshwater alga Selenastrum capricorntum has the right size (> $0.45 \mu \mathrm{m}$ ) and relatively short life cycle (in the scale of an hour, perfect for chronic toxicity effect). The combination of CLEM and algae can bypass the difficulty of separate kinetics measurement and directly compare these metal-algae uptake processes with one another. Also, the method may prove to be a powerful tool for investigating the 
multi-metal influence on metal uptake kinetics by biota.

The algae-CLEM research has been undertaken to study the above situations in order to get a better understanding of the application conditions of BLM.

\subsection{Theory}

The reaction kinetics can be studied efficiently by Competing Ligand Exchange Method (CLEM), which was proposed by Olson and Shuman in 1980s [5, 6], and explored by others since then. Using this concept, the modified device (Figure 7.1) has been applied to several kinetics studies in this lab [7-10]. Using CLE-ICP-MS (Figure 7.1), the distribution and the binding kinetics (dissociation rate coefficient) of binding site (strong and weak) can be derived.

Consider an aqueous mixture of $\mathrm{n}$ components in which each component, designated $\mathrm{ML}_{\mathrm{i}}$, undergoes a first-order or pseudo-first-order reaction simultaneously with all other components

$$
\mathrm{ML}_{\mathrm{i}} \underset{\mathrm{k}_{-1}}{\stackrel{\mathrm{k}_{1}}{\longrightarrow}} \mathrm{M}+\mathrm{L}_{\mathrm{i}} \quad \text { (slow) }
$$

where $\mathrm{k}_{1}$ and $\mathrm{k}_{-1}$ are the rate coefficients for the forward and the backward reaction, respectively. The charges on $\mathrm{M}$ and $\mathrm{L}$ have been neglected in this general statement of the reaction. In CLEM with solid Chelex-100 cation-exchange resin", the latter reacts with $\mathrm{M}$ as follows: 


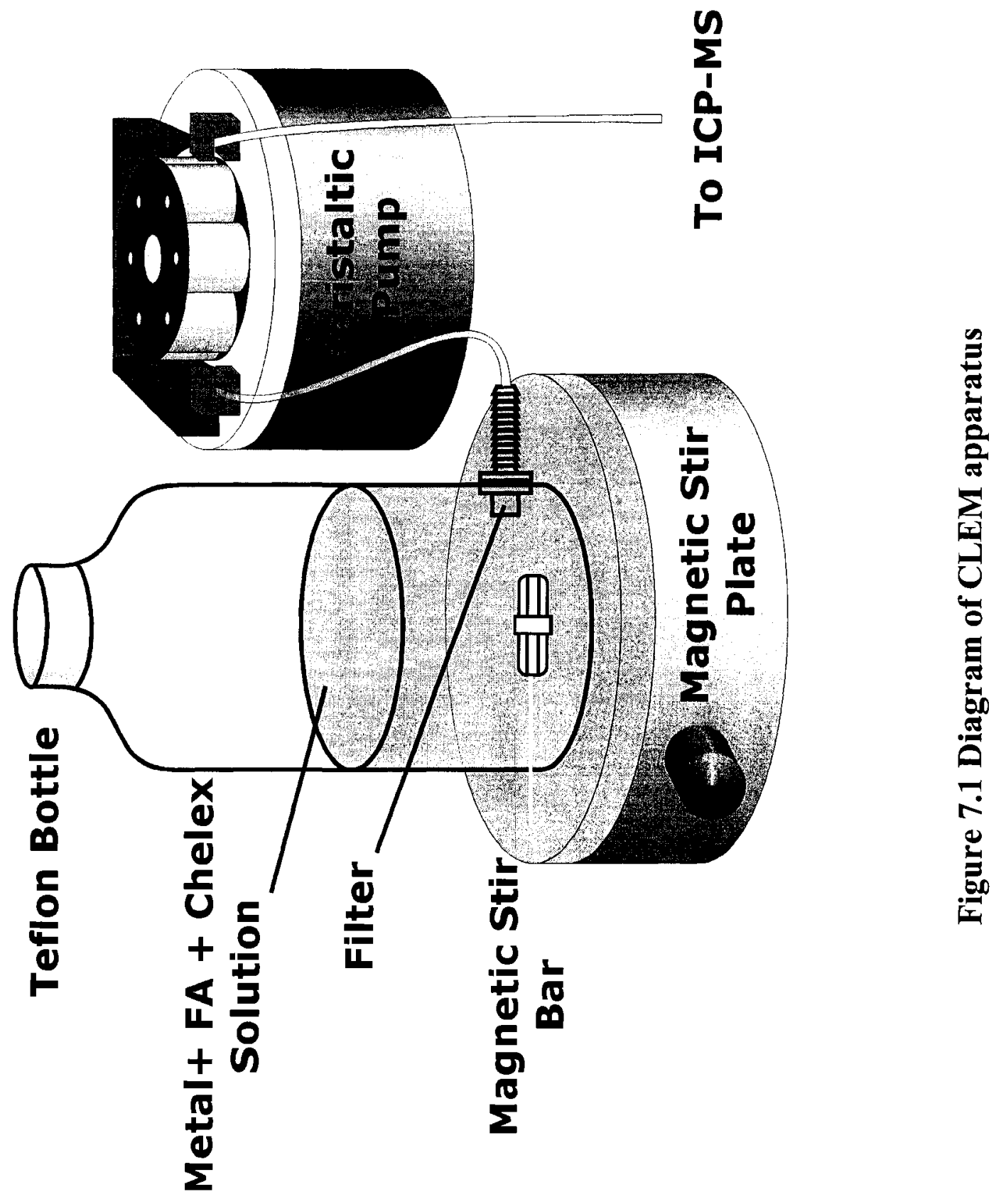




$$
\text { Chelex }+\mathrm{M} \underset{\mathrm{k}_{-2}}{\stackrel{\mathrm{k}_{2}}{\rightleftarrows}} \text { Chelex }-\mathrm{M} \quad \text { (fast) }
$$

The model assumes that:

(a) reaction (2) is much faster than reaction (1), which is slow,

(b) M-Chelex complex is thermodynamically much stronger than ML complex,

(c) $\mathrm{C}_{\text {Chelex }} \gg \mathrm{C}_{\mathrm{M}}$, and

(d) Chelex does not bind with the ML.

Because $[$ Chelex $] \gg>[M]$, reaction (2) is pseudo-first-order. Since $k_{2}$ is large, as has been determined by inductively-coupled plasma mass spectrometry, and Chelex-100 is in sufficiently large excess, the condition $\mathrm{k}_{2}[$ Chelex $] \gg \mathrm{k}_{-1}[\mathrm{~L}]$ is valid.

$$
\text { Chelex }+\mathrm{ML}_{\mathrm{i}} \rightarrow \text { Chelex }-\mathrm{M}+\mathrm{L}_{\mathrm{i}}
$$

The rate of formation of the M-Chelex complex is hence determined by the rate of dissociation of $\mathrm{ML}_{\mathrm{i}}$ in reaction (1), and the rate expression is simply as follows:

$$
\frac{\mathrm{d}[\mathrm{M}-\mathrm{Chelex}]}{\mathrm{dt}}=-\frac{\mathrm{d}\left[\mathrm{ML}_{\mathrm{i}}\right]}{\mathrm{dt}}=\mathrm{k}_{1}\left[\mathrm{ML}_{\mathrm{i}}\right]
$$

If each complex, $\mathrm{ML}_{\mathrm{i}}$, undergoes, independently and simultaneously, a first-order or pseudo-first-order dissociation reaction, the sum of the concentrations of all components remaining in the solution at time $t, \mathrm{C}_{\mathrm{ML}}(\mathrm{t})$, decreases exponentially as:

$$
C_{M L}(t)=\sum_{i=1}^{n} C_{i}^{0} \exp \left(-k_{i} t\right)
$$


where $\mathrm{C}_{\mathrm{i}}^{0}$ is the initial concentration of $\mathrm{ML}_{\mathrm{i}}$, the ith component. The concentration of the metal complexes remaining in the test solution, $\mathrm{C}_{\mathrm{ML}}(\mathrm{t})$, is measured as a function of time. The time taken for completion of reaction (2), which will provide its rate, will establish the theoretical upper limit of the kinetics of dissociation reaction that can be studied with this technique.

Freshwater algae Selenastrum capricorntum, humic (or fuvic) acid and metal to be studied will be spiked into a Teflon Reactor. The Reactor will yield a filtered solution $(<0.45 \mu \mathrm{m})$, provided Selenastrum capricorntum has the right size $(>0.45 \mu \mathrm{m})$. The metal concentrations will be quantified by using ICP-MS.

Using this method, the following information may be obtained:

- By changing the stirring rate of the stirrer in the Reactor, or the metal concentration in the bulk solution, the diffusion rate relative to other processes may be investigated.

- From the comparison of the results from algae and Chelex 100 (or other competing ligand), the binding by the biotic surface membrane, and inside-thebiota trans-membrane rate related to metal complex dissociation and diffusion may be investigated, and the validity of BLM can be examined.

- The metal binding rate may be investigated using competitive binding by a strong anthropogenic ligand, such as EDTA.

- The dissociation rate of metal-DOC complex related to the metal's transmembrane transport inside the biota may be investigated. 
- The influence of metal mixtures to metal uptake by biota may be investigated.

\subsection{Experimental}

\subsubsection{Preliminary experiment}

$250 \mathrm{ml}$ of $5 \times 10^{-4} \mathrm{M} \mathrm{NaCl}$ solution was added to a Reactor, and then injected into the ICP-MS, and the concentrations of $\mathrm{Cu}$ and $\mathrm{Zn}$ were monitored. When $2 \times 10^{-8} \mathrm{M}$ copper was added to the Reactor, a continuously decreasing emission reading of ICP-MS was expected if there were adsorption in the system. But the copper and zinc reading turned out to be still increasing even after 3600 seconds (about 50 minutes, see Figure 7.2). 250 $\mathrm{ml} 5 \times 10^{-4} \mathrm{M} \mathrm{NaCl}$ solution was added to the second Reactor with the same sampling tube and then injected into the ICP-MS. $2 \times 10^{-8} \mathrm{M}$ copper was added to the Reactor seven times at intervals of 420 seconds (about 7 minutes), and the concentrations of copper and zinc were monitored. The emission readings of ICP-MS still continued to increase. The reading at the start was significantly higher than that for the first Reactor (see Figure 7.3). $250 \mathrm{ml} 5 \times 10^{-4} \mathrm{M} \mathrm{NaCl}$ solution was added to the third Reactor with the same sampling tube and then injected to ICP-MS, and the concentrations of copper and zinc were monitored. The blank reading remained high after more than 10 minutes. 1\% (v/v) $\mathrm{HNO}_{3}$ was therefore injected into the ICP-MS from a different container with the same sampling tube; the emission readings of ICP-MS for copper and zinc now jumped to more than 1 million counts. Then, ultrapure water containing $1 \% \mathrm{HNO}_{3}$, and ultrapure water alone were injected into the ICP-MS successively using the same sampling tube. Finally, $2 \times 10^{-8} \mathrm{M}$ copper was added to the third Reactor twice. The readings were finally consistent with those of the first Reactor (see Figure 7.4). The above preliminary 
experiments showed that the sampling tube had an unexpectedly significant adsorption for metals under the experimental condition used.

In order to eliminate the metal adsorption, a new Reactor with an extra sampling tube for injecting $2 \%(\mathrm{v} / \mathrm{v})$ nitric acid (ultrapure) was assembled (see Figure 7.5 ), and used.

Using the uptake information from literature [11], in $2 \times 10^{-8} \mathrm{M}$ copper solution, to have a significant change in the ICP-MS reading, the algae concentration must be at least $10^{6}$ cell/ml. The algal inoculums were prepared by centrifuging the algae from the growth medium followed by three times rinsing using $5 \times 10^{-4} \mathrm{M} \mathrm{NaCl}$ solution. With the new Reactor, $6 \times 10^{6} \mathrm{cell} / \mathrm{ml}$ algae were added to $5 \times 10^{-4} \mathrm{M} \mathrm{NaCl}$ and $4 \times 10^{-9} \mathrm{Cu}\left(\mathrm{NO}_{3}\right)_{2}$ solution. No expected copper concentration decrease was observed in the ICP-MS reading, which meant no significant adsorption or uptake occurred. Moreover, the ICPMS readings of $\mathrm{Cu}$ and $\mathrm{Zn}$ increased after algae addition (Figure 7.6).

In order to intensify the adsorption/uptake effect by algae, the algal inoculum was prepared by centrifuging the algae from the growth medium, washed with $10^{-4} \mathrm{M}$ EDTA, followed by rinsing in the macronutrient medium (see Table 6.1 in Chapter 6) and filtration through a $0.45 \mu \mathrm{m}$ Nuclepore polycarbonate membrane three times. $2 \times 10^{6}$ cell $/ \mathrm{mL}$ algae were added to macronutrient medium and $4 \times 10^{-8} \mathrm{M} \mathrm{Cu}\left(\mathrm{NO}_{3}\right)_{2}$ solution in the Reactor. A significantly decreasing ICP-MS reading was observed (Figure 7.7). The experiment was repeated again and provided the similar (consistent) results. 


\subsection{Discussions}

Because the copper uptake study needs very sensitive measurement, the old Reactor was re-examined. A significant metal adsorption effect was found on the wall of the ICP-MS sampling tube. Therefore, an extra tube was added to the Reactor, which introduced $2 \%$ (v/v) $\mathrm{HNO}_{3}$. When the peristaltic pump connected with ICP-MS applied more power, the solution passing through filter membrane was acidified so that the metal adsorption was eliminated. Replicates of the preliminary experiments showed good agreement.

Because of its large size ( $>0.45 \mu \mathrm{m}$ three-dimensionally), freshwater algae Selenastrum capricorntum could not pass through filter membrane, which made it suitable for the metal uptake kinetics study using the modified experimental set-up (the new Reactor). With metal, natural organic ligands, algae, and competing ligands in the system, the metal adsorption by algae, metal uptake by algae, dissociation of metal complexes, and the influence on metal uptake by multi-metals can be investigated simultaneously.

The preliminary experiment attempted to use algae in the Reactor. When the algae had not been washed with EDTA, the concentrations of copper and zinc in the Reactor increased after the algae addition (Figure 7.6), which indicated that there were copper and zinc released from the algae into the solution. Many algae had long been known to be able to concentrate metals from dilute solution $[12,13]$. Since there are trace amounts of copper and zinc in the algal growth medium (see Table 6.1 in Chapter 6), it is understandable that the algal cell membrane adsorbs considerable amounts of copper and zinc. Nevertheless, after algae had been washed with EDTA, the expected copper 
adsorption and uptake (by algae) curve was observed by ICP-MS (Figure 7.7). Moreover, with the tough nature of the algae, they were still alive after the experiment. Figure 7.7 shows that after algae were added to the Reactor, the copper concentration decreased quickly for the first several minutes, then continued to decrease slowly for the next 50 minutes. This concentration change was consistent with the general understanding of the copper adsorption and uptake kinetics by algae: a fast adsorption on the algal cell membrane which reaches equilibrium within several minutes, followed by a slow active uptake into the cytoplasm [12-15]. The rate of copper adsorption plus uptake by algae can be roughly estimated from the curve with an average cell volume, $50 \mu \mathrm{m}^{3}$ [16]. The rate was in the order of $10^{-4} \mathrm{~mol} / \mathrm{L}-$ cell $/ \mathrm{hr}$, the same order of magnitude as reported by Mylon et al. [11], which confirms the utility of this method.

The advantage of this method comes from the advantage of ICP-MS and the advantage of the Reactor over the traditional techniques (voltammetry, atomic absorption spectrometry, radioisotope, and others), including high sensitivity, fast-sequential, almost instantaneous analysis, and multi-element determination.

When alga is regarded as a competing ligand, comparing the metal uptake kinetics results by algae and Chelex 100 (or other competing ligand), the membrane adsorption rate, and trans-membrane/uptake rate by the algae related to the rate of dissociation of metal natural organic complexes may be investigated. Furthermore, the validity of BLM can be examined. The kinetically-controlled situation can be easily detected, i.e. the situation 
when metal adsorption and uptake rate by algae is higher than the rate of metal complex dissociation can be easily detected.

This method would also provide a powerful tool to study multi-metal effect on metal uptake by algae because of the multi-element determination capability of ICP-MS. For example, when concentrations of copper and zinc are changed in the solution, the kinetics of copper and zinc adsorption and uptake by algae should also change, which can be easily detected by this method.

As a result of this work, some progress has been made in the preliminary experiments on the algae-CLEM research. Carefully designed, additional experiments will be able to provide valuable information on the linkages between metal speciation and metal bioavailability and toxicity in natural waters. 


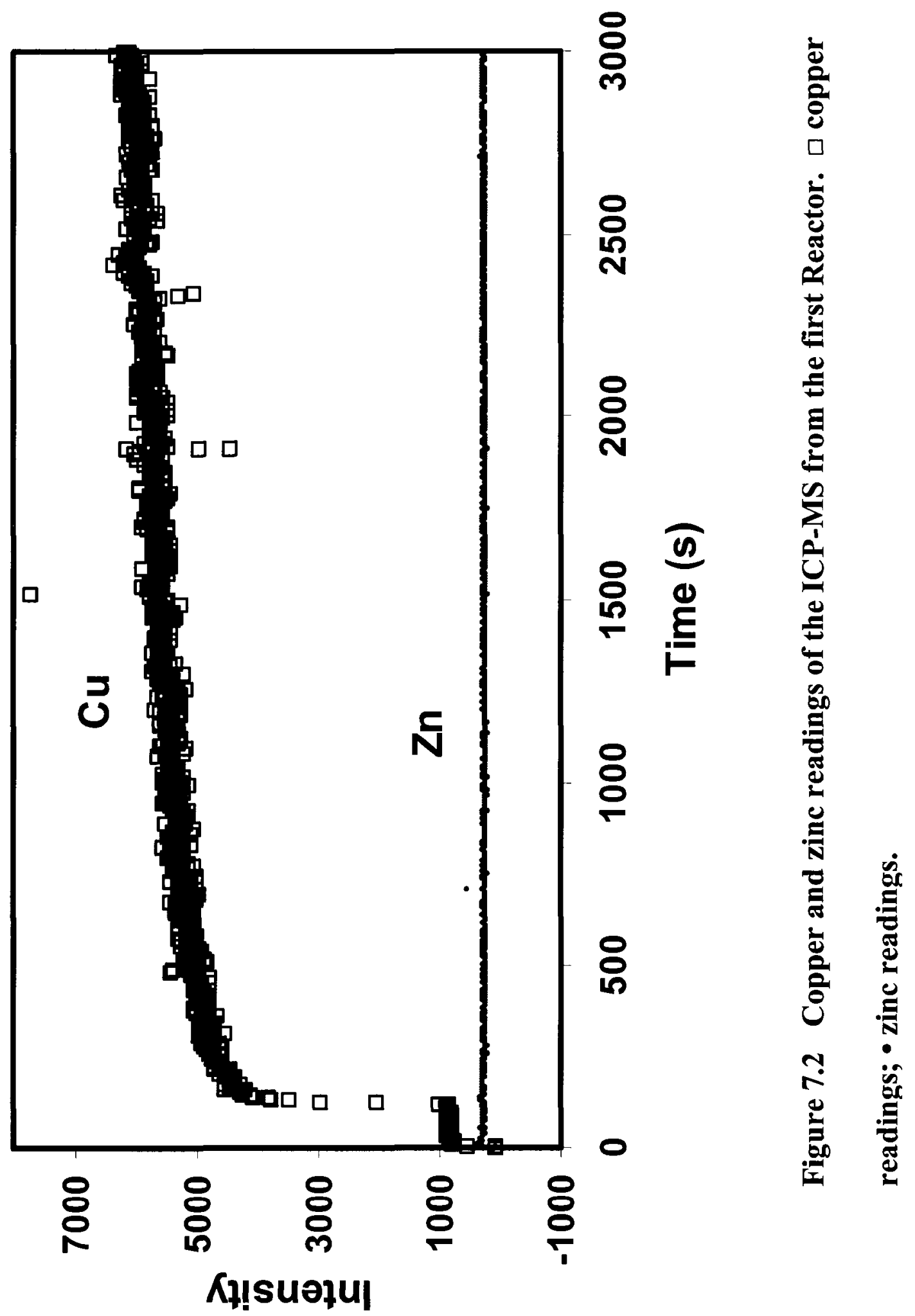




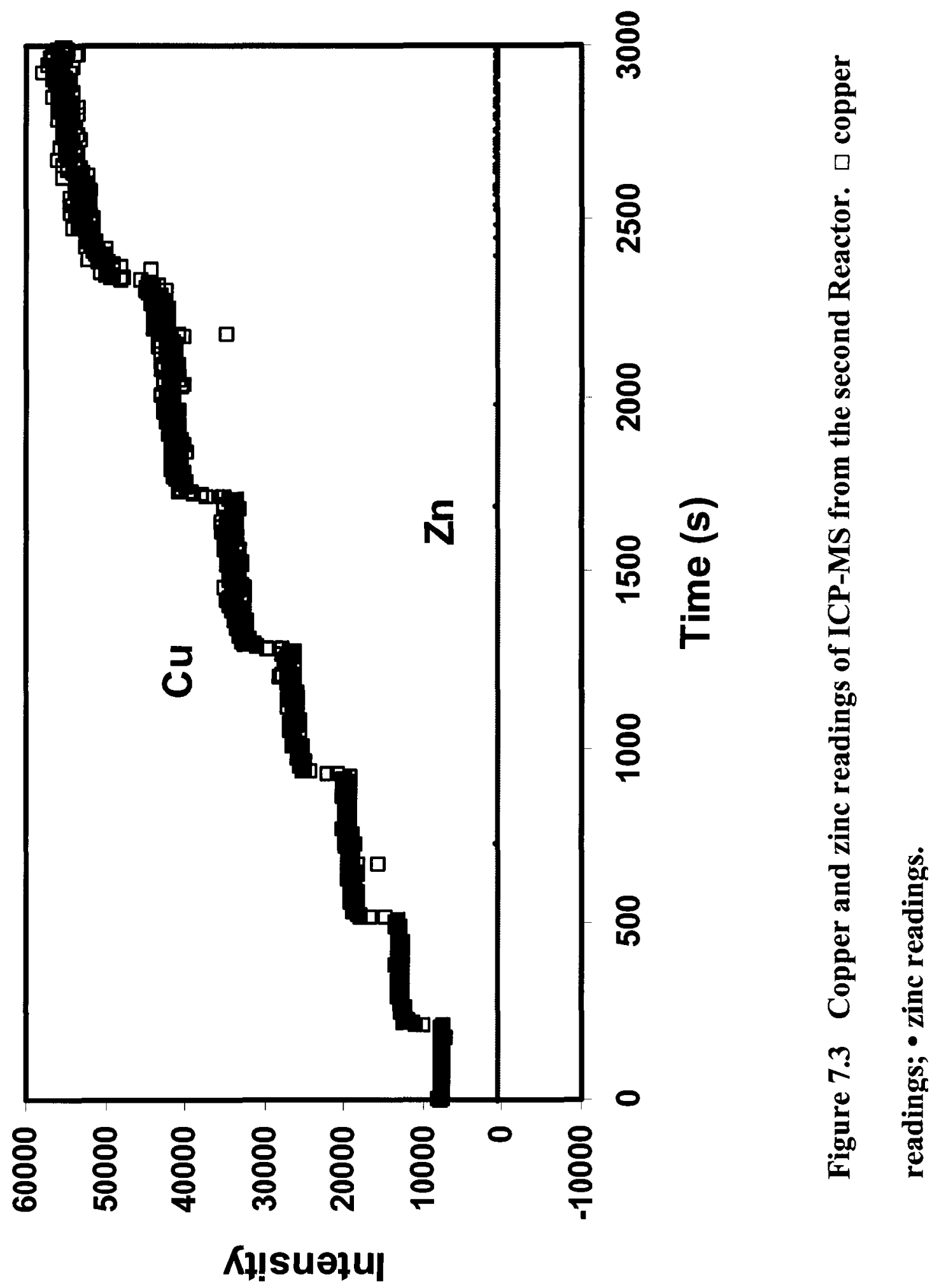




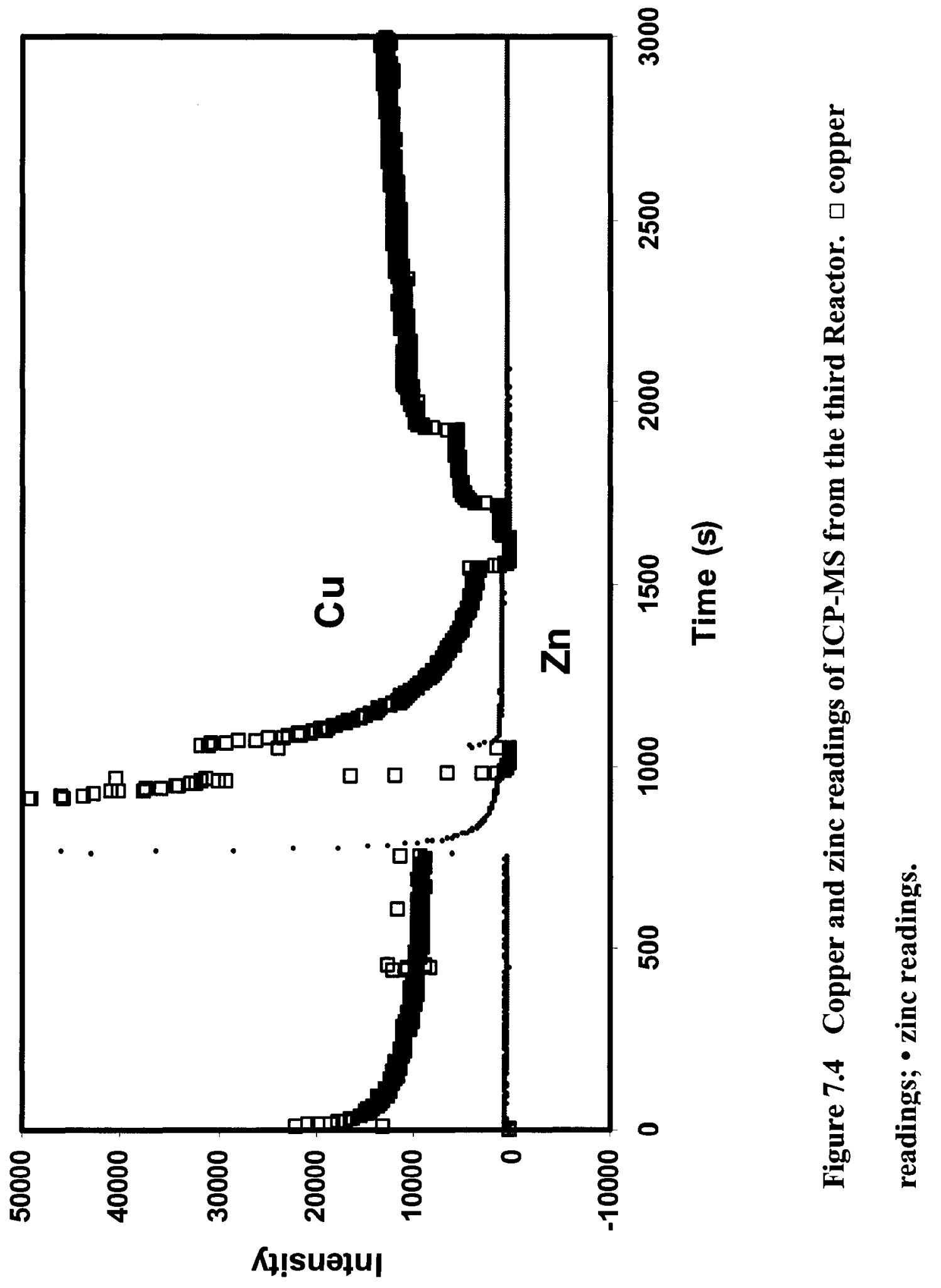




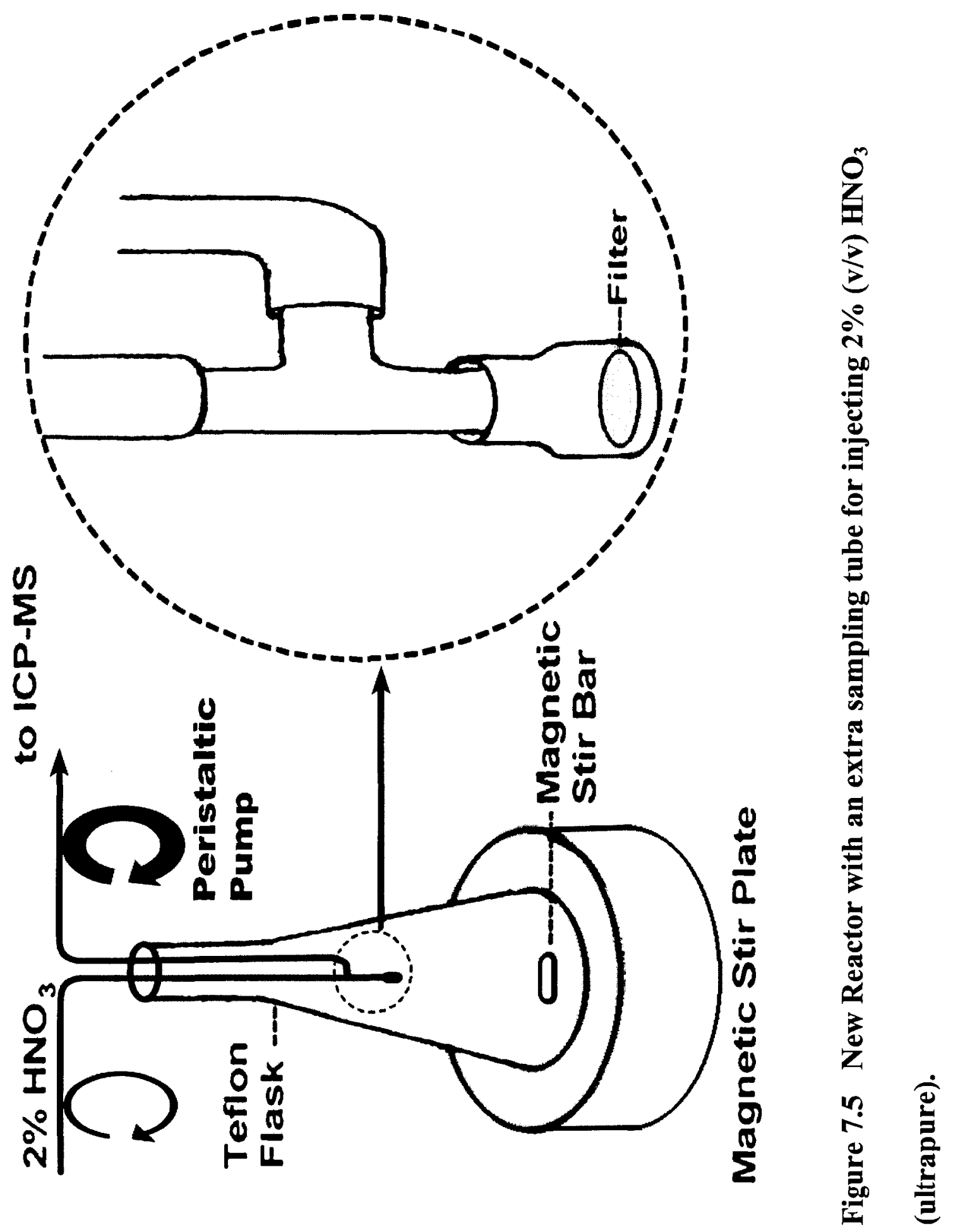




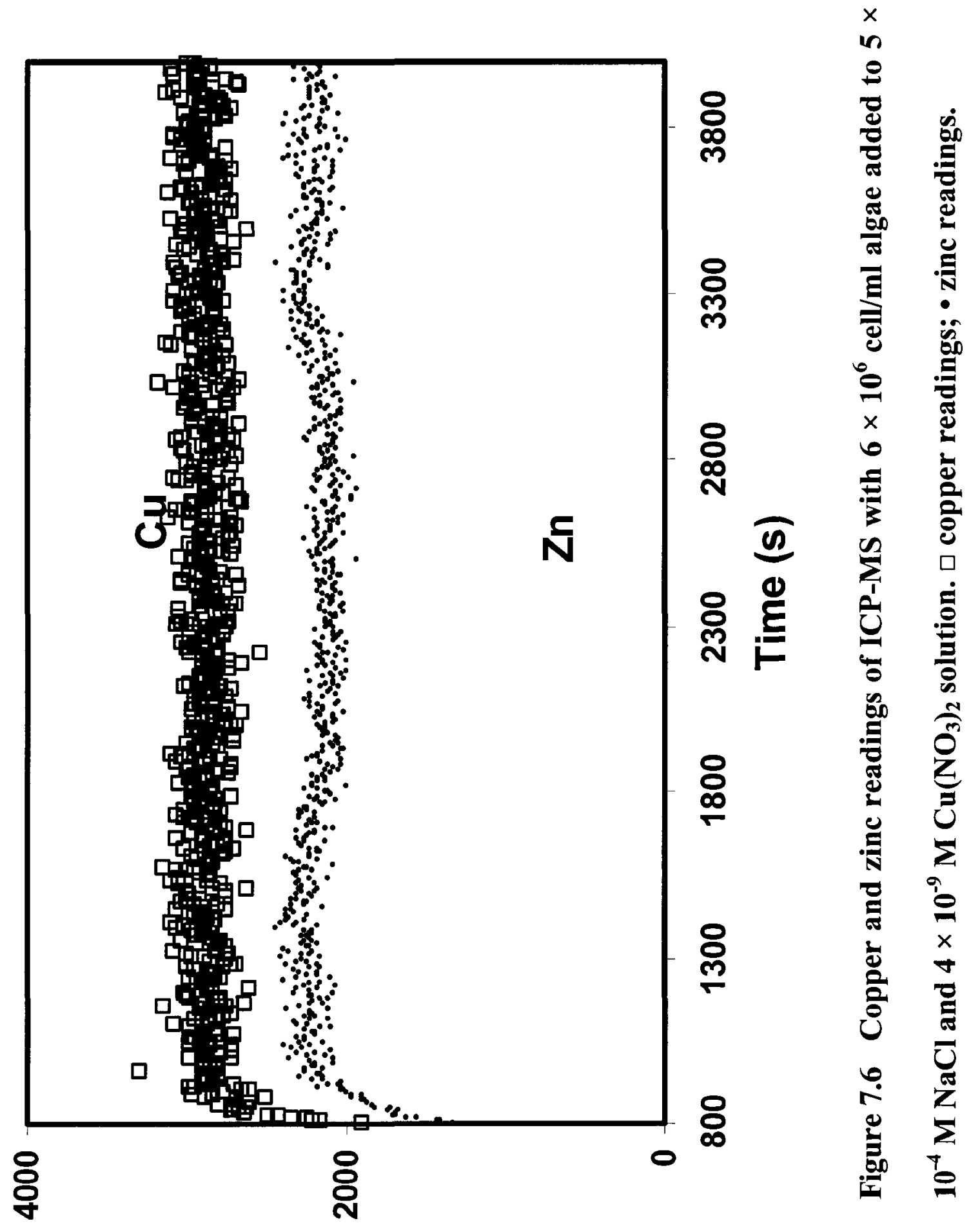

אᄊ!suəૃய 


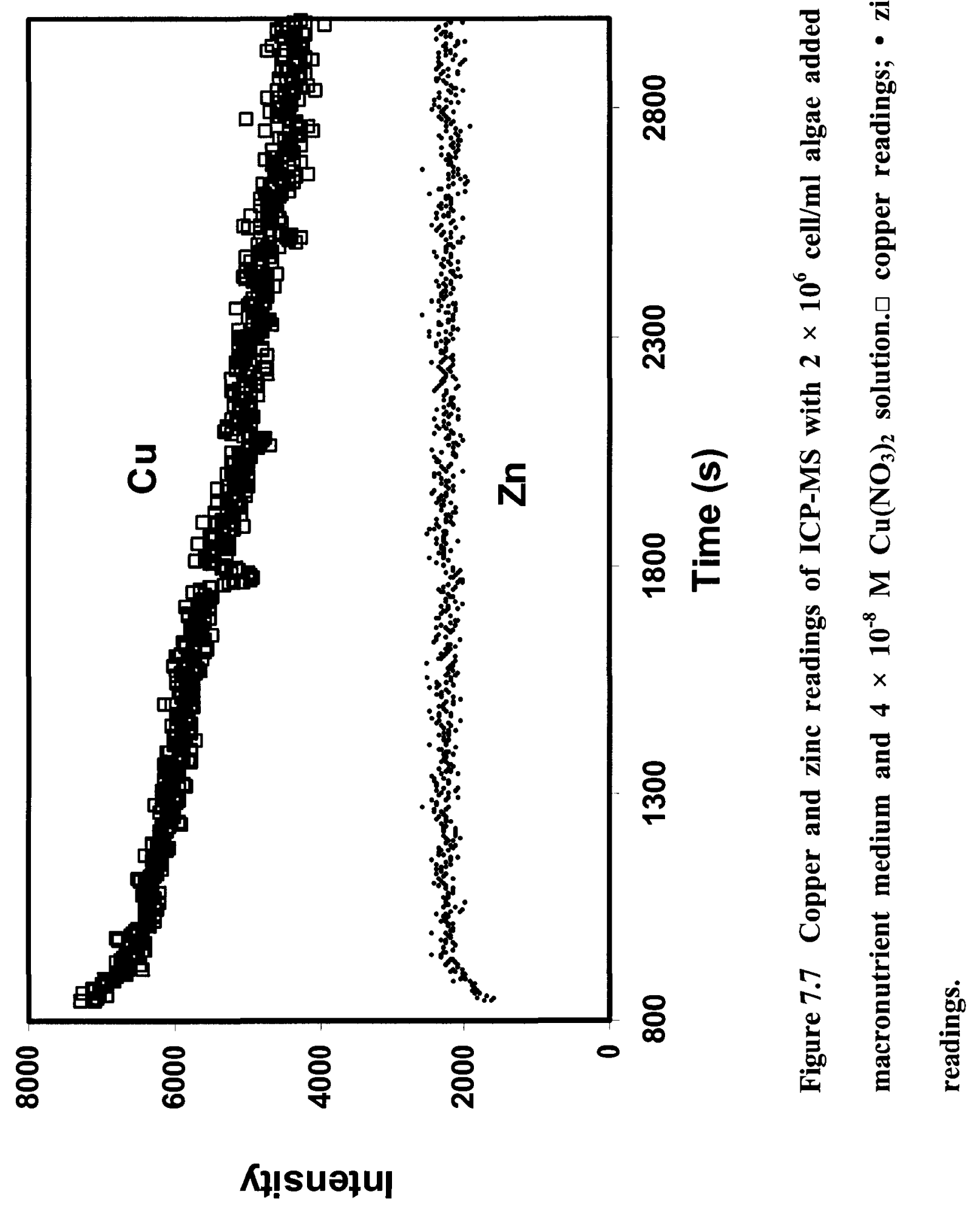


7.5 References

1. Hudson, R.J.M., Which aqueous species control the rates of trace metal uptake by aquatic biota? Observations and predictions of non-equilibrium effects, The Science of the Total Environment (1998), 219, 95-115

2. Paquin, Paul R.; Gorsuch, Joseph W.; Apte, Simon; Batley, Graeme E.; Bowles, Karl C.; Campbell, Peter G.C.; Delos, Charles G.; Di Toro, Dominic M.; Dwyer, Robert L.; Galvez, Fernando; Gensemer, Robert W.; Goss, Gregory G.; Hogstrand, Christer; Janssen, Colin R.; McGeer, James C.; Naddy, Rami B.; Playle, Richard C.; Santore, Robert C.; Schneider, Uwe; Stubblefield, William A.; Wood, Chris M.; Wu, Kuen Benjamin, The biotic ligand model: a historical overview, Comparative Biochemistry and Physiology Part C (2002), 133, 3-35

3. Franklin, Natasha M., Stauber, Jennifer L., Lim, Richard P.; Petocz, P., Toxicity of metal mixtures to a tropical freshwater alga (Chlorella SP.): The effect of interactions between copper, cadmium, and zinc on metal cell binding and uptake. Environmental Toxicology and Chemistry (2002), 21, 2412-2422

4. Mowat, F.S., Bundy, K.J., Experimental and mathematical / computational assessment of the acute toxicity of chemical mixtures from the Microtox ${ }^{\circledR}$ assay, Advances in Environmental Research (2002), 6, 547-558

5. Olson, Dean L.; Shuman, Mark S. Kinetic spectrum method for analysis of simultaneous, first-order reactions and application to copper(II) dissociation from aquatic macromolecules. Analytical Chemistry (1983), 55(7), 1103-7. 
6. Olson, Dean L.; Shuman, Mark S. Copper dissociation from estuarine humic materials. Geochimica et Cosmochimica Acta (1985), 49(6), 1371-5.

7. Chakraborty, Parthasarathi; Gopalapillai, Yamini; Murimboh, John; Fasfous, Ismail I.; Chakrabarti, Chuni L.. Kinetic speciation of nickel in mining and municipal effluents. Analytical and Bioanalytical Chemistry (2006), 386(6), 1803-1813.

8. Fasfous, Ismail I.; Yapici, Tahir; Murimboh, John; Hassan, Nouri M.; Chakrabarti, Chuni L.; Back, Margaret H.; Lean, David R. S.; Gregoire, D. Conrad. Kinetics of Trace Metal Competition in the Freshwater Environment: Some Fundamental Characteristics. Environmental Science and Technology (2004), 38(19), 4979-4986.

9. Guthrie, J. W.; Mandal, R.; Salam, M. S. A.; Hassan, N. M.; Murimboh, J.; Chakrabarti, C. L.; Back, M. H.; Gregoire, D. C. Kinetic studies of nickel speciation in model solutions of a well-characterized humic acid using the competing ligand exchange method. Analytica Chimica Acta (2003), 480(1), 157-169.

10. Sekaly, Amina L. R.; Murimboh, John; Hassan, Nouri M.; Mandal, Rupasri; Ben Younes, Mufida E.; Chakrabarti, Chuni L.; Back, Margaret H.; Gregoire, D. Conrad. Kinetic Speciation of $\mathrm{Co}(\mathrm{II}), \mathrm{Ni}(\mathrm{II}), \mathrm{Cu}(\mathrm{II})$, and $\mathrm{Zn}(\mathrm{II})$ in Model Solutions and Freshwaters: Lability and the d Electron Configuration. Environmental Science and Technology (2003), 37(1), 68-74.

11. Mylon, S.E.; Twining, B.S.; Fisher, N.S.; and Benoit, G. Relating the Speciation of $\mathrm{Cd}, \mathrm{Cu}$, and $\mathrm{Pb}$ in Two Connecticut Rivers with Their Uptake in Algae. Environmental Science and Technology 2003, 37(7), 1261-1267 
12. Ting, Y.P.; Lawson, F.; and Prince, I.G. Uptake of Cadmium and Zinc by the Alga Chlorella vulagaris: II. Multi-ion Situation. Biotechnology and Bioengineering (1991), 37(5), 445-455

13. Xue, H.B.; Stumm, W.; and Sigg L. The Binding of Heavy Metals to Algal Surfaces. Water Research (1988), 22(7), 917-926

14. Gonzalez-Davila, M. The role of phytoplankton cells on the control of heavy metal concentration in seawater. Marine Chemistry (1995) 48, 215-236

15. Gonzalez-Davila, M.; Santana-Casiano, J. M.; Perez-Pena, J.; Millero, F.J. The binding of $\mathrm{Cu}(\mathrm{II})$ to the surface and exudates of the Alga Dunaliella Tertiolecta in seawater, Environmental Science and Technology (1995), 29, 289-301.

16. Biological test method: Growth Inhibition Test Using the Freshwater Alga Selenastrum capricornutum / Environmental Protection Service report series. EPS 1/RM/25, Environment Canada. 1992 
-Chapter 8-

Conclusions

- 163 - 
The objective of this thesis was to test the following hypotheses: (1) that the extended detection window would provide better knowledge of copper - NOM interactions, and would thereby lead to a greater understanding of the heterogeneity of NOM and more reliable prediction of copper speciation in natural waters; (2) that the study of kinetics of copper uptake by organisms would provide greater knowledge of the relationship between metal speciation, bioavailability and toxicity, enhancing our ability to predict copper toxicity in natural waters. Test results of the above hypotheses are presented below.

The ASV techniques (the ASV technique alone and the ASV technique, coupled with copper titration) significantly underestimate the complexation capacity of NOM because of the operationally-defined nature of the measurement, and the ASV techniques are only capable of measuring weak copper natural organic complex. The experimental conditions, i.e. the deposition potential and the rotation rate, require careful manipulation to get meaningful results. CLE-AdCSV has obvious advantages over the ASV techniques, including higher analytical sensitivity and large, flexible detection windows. More than $95 \%$ of the total dissolved copper in all of the lake freshwater samples studied by CLEAdCSV was found to be complexed with NOM.

In order to further extend the detection window, EDTA was tested as a competing ligand for CLE-ASV. This new method was found to be a significant improvement over CLEAdCSV. Its detection window $\left(10^{9}-10^{12}\right)$ extends the detection window of CLE-AdCSV $\left(10^{2}-10^{9}\right)$ by several orders of magnitude. CLE-ASV with EDTA was applied to the study 
of copper speciation in freshwater samples from Rideau Canal, Ottawa, ON, Canada, and was found to be able to determine very strong natural organic ligands for binding copper. The results show presence of a very strong copper-binding organic ligand with a conditional stability constant above $10^{19}$, with a very high concentration of above $100 \mathrm{nM}$ in the Rideau Canal freshwater samples. To the best of our knowledge, the conditional stability constants of copper complexes by natural organic ligands in natural waters reported previously in the literature were not higher than $10^{19}$, as determined by CLE technique. The modeling of copper speciation in natural waters can be improved by this advance in determining high stability constant values.

The disadvantages of the voltammetry techniques (ASV and AdCSV) include the problem of contamination and the necessity for adopting rigorous experimental conditions, such as control of $\mathrm{pH}$, ionic strength, and freedom from dissolved oxygen. These problems were tackled by applying an in situ technique, Diffusive Gradients in Thin Films (DGT). The DGT device was deployed in situ in freshwaters to determine the metal speciation in the Rideau Canal, and was found to be highly robust, efficient, and sensitive. Even with very low concentrations of trace metals in the sampled freshwaters, DGT could easily determine DGT-labile species of copper, lead, and nickel simultaneously. It was found that more than $95 \%$ of copper, lead and nickel were complexed with NOM. However, it was also found that the deployment time of the DGT had to be carefully chosen to maintain satisfactory reproducibility. 
The copper toxicity in a contaminated freshwater sample, determined using growth inhibition test with freshwater alga Selenastrum capricornutum, showed that the lake freshwater sample was less tolerant of copper than de-ionized water, i.e. copper was more toxic to Selenastrum capricornutum in de-ionized water than in the freshwater sample, regardless of the NOM in the sample. The copper toxicity result may be affected because of the very high concentration of zinc. The unexpected high toxicity of copper to the alga in the freshwater sample confirms that the response of the organism is the result of the combined effects of all the chemicals in the sample. A single metal toxicity test is therefore insufficient to account for the toxicity of any freshwater sample.

Finally, CLEM-ICP-MS was found to be useful for linking metal speciation with bioavailability and toxicity. This technique, which was used exclusively for kinetic study of metal speciation in natural waters, was found to be suitable for simultaneous study of the copper uptake kinetics by Selenastrum capricornutum. The above method and the modified Reactor proved to be successful in the preliminary experiments. By changing the competing ligand and the rotation rate of the stirring bar in the Reactor, the relationship between the metal adsorption and the uptake rate by algae and the metal complex dissociation rate could be studied. The kinetics- controlled situation, i.e. the situation when the metal adsorption and the uptake rate by algae are higher than the metal complex dissociation rate, can be detected. Therefore, this method offers a promising potential to study the linkage between metal speciation, bioavailability, and toxicity in natural waters. The effect of mixtures of multi-metals to the metal adsorption and uptake 
by algae can also be investigated because ICP-MS can monitor multi-element simultaneously.

From all the findings and results of this Thesis, the over-all conclusion can be drawn that from the chemical equilibrium point of the view there is still a great deal of advance to be made in the study of metal speciation in natural waters. The heterogeneity of natural organic ligands in freshwater systems requires re-examination in the very strong metalbinding range. While chemical equilibrium is a useful paradigm in the study of metal speciation and metal toxicity, kinetics can dominate the metal bioavailability and toxicity under certain circumstances, e.g. when the metal adsorption and the uptake rate by algae are greater than the metal complex dissociation rate. A method, CLEM-ICP-MS, has been proposed in the Thesis to study the above circumstances. 